\begin{abstract}
UNIVERSIDADE DE SÃO PAULO
FACULDADE DE CIÊNCIAS FARMACÊUTICAS

Programa de Pós-Graduação em Fármaco e Medicamentos

Área de Produção e Controle Farmacêuticos

Desenvolvimento de comprimidos de liberação prolongada de furosemida: influência das ciclodextrinas
\end{abstract}

Rodrigo Spricigo

Dissertação para obtenção do grau de MESTRE

Orientadora:

Profa. Dra. Cristina Helena dos Reis Serra

São Paulo

2006 


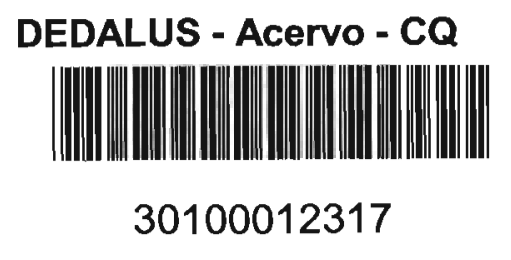

Ficha Catalográfica

Elaborada pela Divisão de Biblioteca e

Documentaçåo do Conjunto das Quimicas da USP

\section{Spricigo, Rodrigo}

S769d Desenvolvimento de comprimidos de liberaçăo prolongada de furosemida : influência das ciclodextrinas / Rodrigo Spricigo. -. São Paulo, 2006.

$138 \mathrm{p}$.

Disser taçào (mestrado) - Faculdade de Ciências Farmacèuticas da Universidade de Sào Paulo. Departamento de Farmácia.

Orientador: Serra, Cristina Helena dos Reis

1. Formulaçōes farmacêuticas 2. Comprimido: Farmacotécnica 3 Fármaco: Cinética de dissolução: Química farmacêutica 4. Biofarmacotécnica I. T. ll. Serra, Cristina Helena dos Reis, orientador.

$$
615.4 \quad C D D
$$




\title{
Rodrigo Spricigo
}

Desenvolvimento de comprimidos de liberação prolongada de furosemida: influência das ciclodextrinas

\author{
Comissão Julgadora \\ da \\ Dissertação para obtenção do grau de Mestre
}

Profa. Dra. Cristina Helena dos Reis Serra orientador/presidente

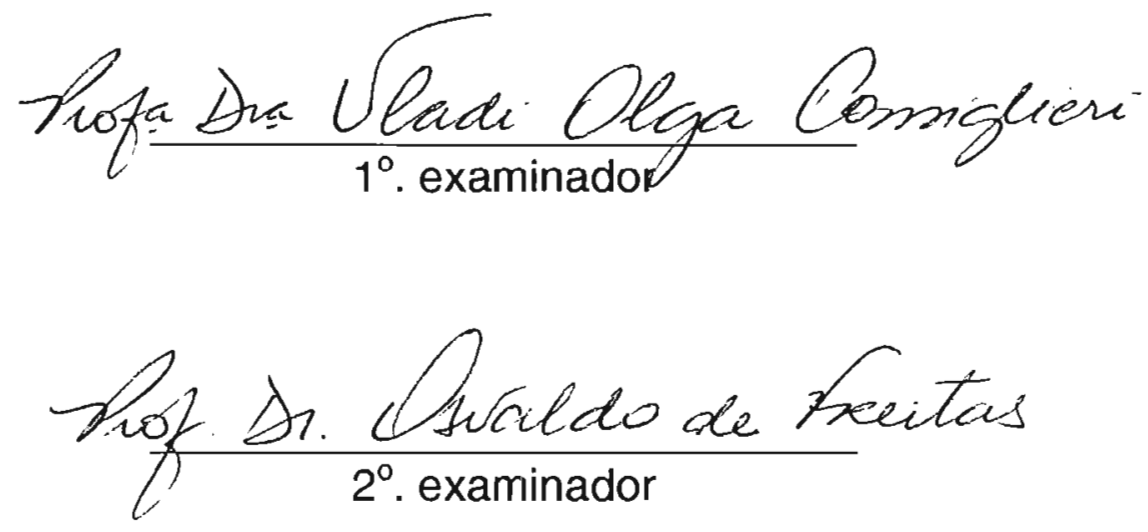

São Paulo, 27 de Dútubs de 2006. 


\section{ÍNDICE}

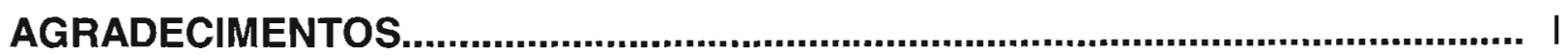

LISTA DE ABREVIATURAS.................................................................................... II

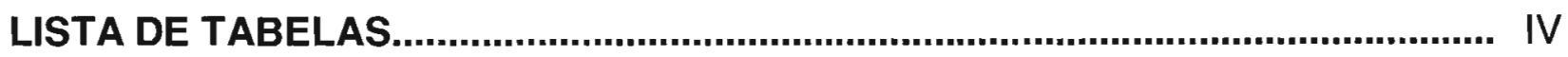

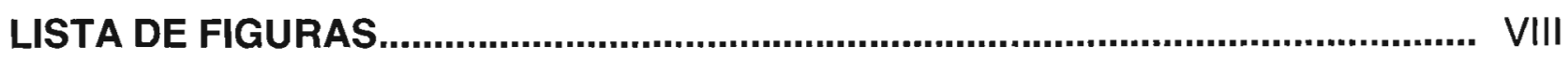

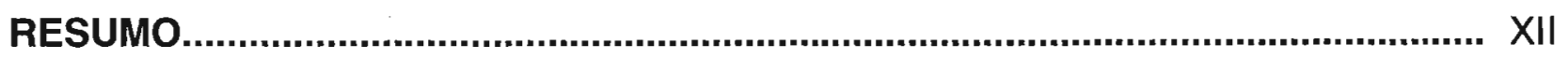

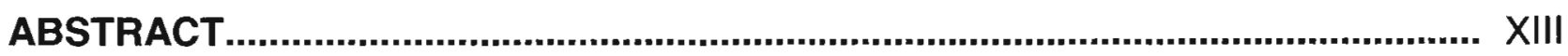

1. INTRODUÇÃO

2. REVISÃO DA LITERATURA...................................................................... 4

2.1. Etiologia da hipertensão......................................................................... 5

2.2. Furosemida

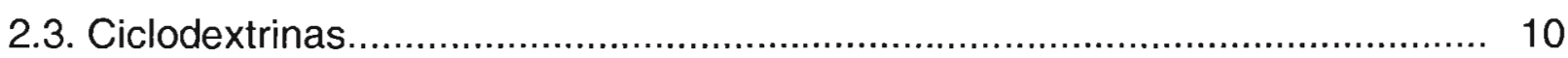

2.4. Sistemas de liberação de fármacos................................................................ 17

2.4.1. Considerações gerais..................................................................... 17

2.4.2. Fármacos candidatos à incorporação em formas de liberação modificada. 20

2.4.3. Vantagens e desvantagens das formas de liberação modificada................ 22

2.4.4. Formas farmacêuticas perorais de liberação prolongada............................ 23

2.4.4.1. Sistema reservatório................................................................... 24

2.4.4.3. Sistemas matriciais...................................................................... 25

2.4.4.3.1. Matrizes inertes............................................................. 27

2.4.4.3.2. Matrizes hidrofóbicas....................................................... 29

2.1.4.3.3. Matrizes hidrofílicas........................................................... 30

3. OBJETIVOS

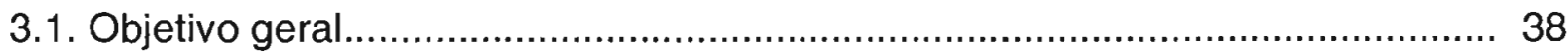

3.2. Objetivos especificos............................................................................. 38

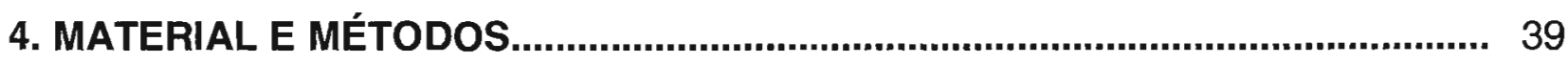

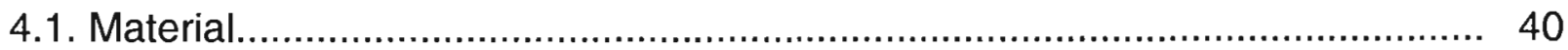

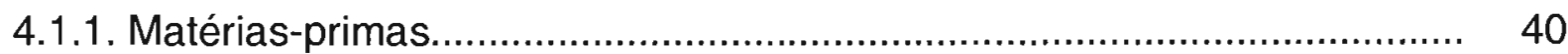

4.1.2. Substância de referência...................................................................... 40

4.1.3. Reagentes................................................................................. 40 
4.1.4. Equipamentos.................................................................... 41

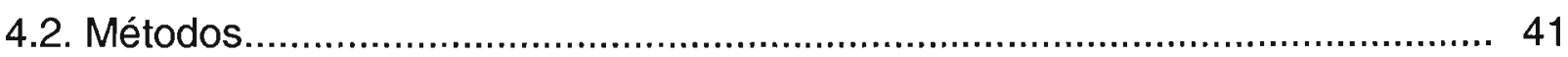

4.2.1. Obtenção de complexos de inclusão de inclusão de furosemida............. 4.1

4.2.1.1. Malaxagem...................................................................... 41

4.2.1.2. Liofilização...................................................................... 42

4.2.1.3. Mistura física.................................................................. 43

4.2.2. Caracterização dos complexos de inclusão de furosemida.................... 43

4.2.2.1. Teor de furosemida ......................................................... 43

4.2.2.2. Ensaios termoanalíticos........................................................ 44

4.2.2.3. Espectrofotometria na região do infravermelho............................. 44

4.2.2.4. Ensaios de dissolução......................................................... 44

4.2.3. Obtenção dos comprimidos matriciais......................................... 45

4.2.3.1. Formulações................................................................... 46

4.2.4. Ensaios de dissolução dos comprimidos........................................ 47

4.2.4.1. Determinação dos perfis de dissolução da furosemida em meio

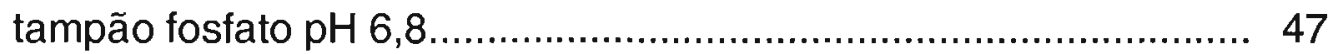

4.2.4.2. Determinação da eficiência de dissolução da furosemida............... 49

4.2.4.3. Determinação da cinética de dissolução da furosemida................. 49

4.2.4.3.1. Determinação das constantes cinéticas............................ 51

4.2.4.4. Determinação dos perfis de dissolução da furosemida em meio

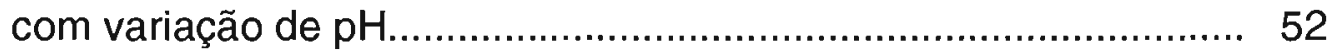

4.2.5. Avaliação física dos commprimidos.............................................. 52

4.2.5.1. Peso médio....................................................................... 52

4.2.5.2. Friabilidade........................................................................ 52

4.2.5.3. Dureza..................................................................... 53

4.2.6. Validação dos ensaios de quantificação da furosemida por espectrofotometria no UV ......................................................... 53

4.2.6.1. Espectro de absorção do fármaco na região do ultravioleta........... 53

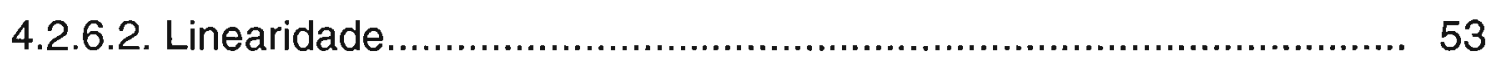

4.2.6.2.1. Preparo da solução-padrão e soluções de trabalho............. 54

4.2.6.3. Precisão intra e inter-ensaio................................................ 54

4.2.6.4. Limite de quantificação.................................................... 55 


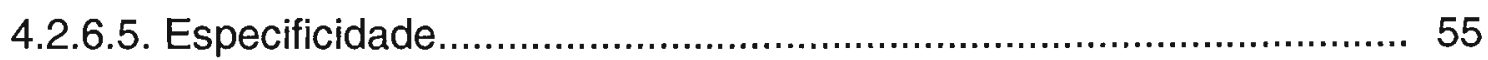

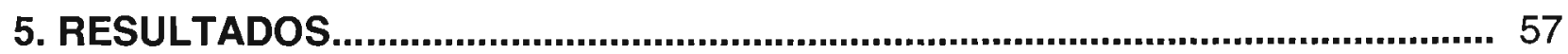

5.1. Caracterização dos complexos de inclusão de furosemida............................ 58

5.1.1. Teor de furosemida........................................................................ 58

5.1.2. Ensaios termoanalítico...................................................................... 58

5.1.3. Espectrofotometria na região do infravermelho.................................... 60

5.1.4. Ensaios de dissolução dos complexos de inclusão.................................. 61

5.2. Ensaios de dissolução dos comprimidos..................................................... 68

5.2.1. Determinação dos perfis de dissolução da furosemida em meio tampão

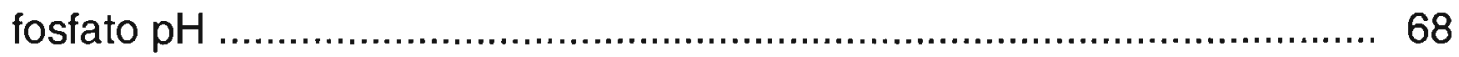

5.2.2. Determinação da eficiência de dissolução da furosemida........................... 75

5.2.3. Determinação da cinética de dissolução da furosemida.......................... 84

5.2.3.1. Determinação das constantes 90

5.2.4. Determinação dos perfis de dissolução da furosemida com variação de $\mathrm{pH}$

5.3. Ensaios físicos dos comprimidos.......................................................... 97

5.4. Validação dos ensaios de quantificação da furosemida.................................... 98

5.4.1. Espectro de absorção da furosemida................................................... 98

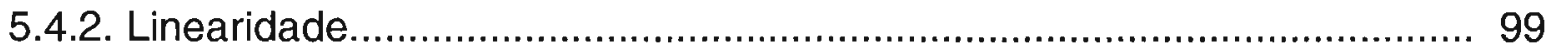

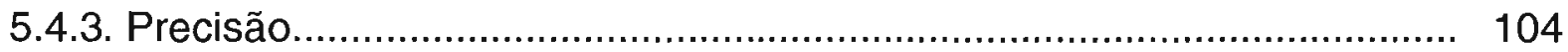

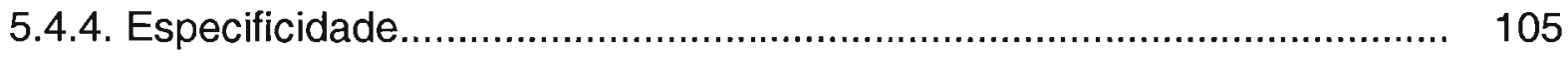

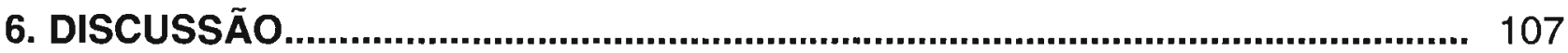

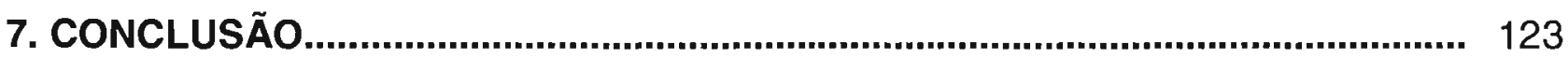

8. REFERÊNCIAS BIBLIOGRÁFICAS............................................................. 125

9. ANEXOS 
À Deus, pela vida maravilhosa que tenho.

Aos meus pais, Laurindo e Rosanna, pelo amor e carinho que sempre me deram, pela dedicação em tempo integral e por me nortearem para os caminhos da dignidade.

À minha tia Silvana, minha segunda mãe, a quem muito devo pelo que sou hoje.

A meu irmão Fábio, pela presença constante em todos os momentos. 


\section{AGRADECIMENTOS}

À minha orientadora, Profa. Dra Cristina Helena dos Reis Serra, pela oportunidade, amizade, incentivo e compreensão em todas as horas

À Profa. Vladi Olga Consiglieri, pela atenção, carinho e nobres conselhos despendidos nesta minha etapa profissional.

Ao professor Osvaldo de Freitas, meu tutor, quem muito me inspira por congregar duas grandes virtudes de um ser humano: competência e humildade.

Ao professor Humberto Gomes Ferraz, pelas valiosas sugestões e pela atenção dispensada.

Aos meus companheiros de república e grandes amigos, Fabriciano Pinheiro, Phylmon Solomon, Rafael Menck, Renato Almeida, Tiago Peixe e Sidnei Moura, por tornarem meus dias mais apraziveis.

Aos meus irmãos de consideração, Manuel Guimarães, Rafael Lombello, Marcelo Monteiro, Matheus Palma, Lucas Veloso e Henrique Kinker, pelo fraternalismo.

Aos meus amigos de Ribeirão Preto, Guilherme, Helder, Fernando, Thiago, Rafael, Ricardo, Vicente, Walter, Mauricio, Carina, Milena, Diana, Rubiana, Lizziane, Susi, Gracieli e muitos outros, com quem dividi anos incríveis da minha vida.

Um agradecimento especial à minha grande amiga M.Sc. Maria Paula Garofo, pela pessoa maravilhosa que é, e pela amizade sincera que compartilhamos.

Aos colegas de pós-graduação, George, Vânia, Fabiana, Tiago, Evelyn, André, Bianca, Ruth, Tatiana, Simone, Maurício, João Paulo, Renata, Virgínia, Valeska, Samantha, Viviane, Rogério e Elisângela, que muito me incentivaram.

Aos colegas, Kátia Botelho e Márcio Zaim, pela ajuda com os ensaios analíticos.

Aos secretários da Comissão de Pós-Graduação da FCF-USP, Jorge e Elaine, pela competência profissional e prestatividade com que sempre me atenderam.

Às técnicas do laboratório de farmacotécnica, Carla e Claudinéia, pela colaboração com a realização deste trabalho.

À Eurofarma Laboratórios, nas pessoas de Marcelo Nita, André Luiz Haddade Mikiko Inoue, por acreditar e investir na capacitação de recursos humanos. 


\section{LISTA DE ABREVIATURAS}

ABNT-Associação Brasileira de Normas Técnicas

ASC - área sob a curva

$\beta-C D-\beta$-ciclodextrina

CD - ciclodextrina

CGT-ase - ciclodextrina-glucosiltransferase

$\mathrm{CL}_{\mathrm{t}}$ - clearance total

$\mathrm{CL}_{\mathrm{r}}$ - clearance renal

$\mathrm{CM}$ - celulose microcristalina

DSC - differential scaning calorimetry (calorimetria diferencial exploratória)

ED\% - eficiência de dissolução

Est. Mg - estearato de magnésio vegetal

HP- $\beta-C D$ - hidroxipropil- $\beta$-ciclodextrina

HPMC - hidroxipropilmetilcelulose

IV - infravermelho

$K_{d}$ - constante de velocidade de dissolução

MF - mistura física

SBE- $\beta-C D$ - sulfobutiléter- $\beta$-ciclodextrina

$t_{1 / 2}$ - tempo de meia-vida de eliminação

$t_{50}$ - tempo de meia-vida de dissolução

UV - ultravioleta 


\section{LISTA DE TABELAS}

Tabela 1. Características das principais ciclodextrinas (Szejtli \& Osa, 1996)

Tabela 2. Solubilidade $(\mathrm{mg} / 100 \mathrm{~mL})$ da warfarina a partir de produtos de mistura binária com $\beta$-ciclodextrina em pH 1,2 e pH 5,0 (Zingone \& Rubessa, 2005)

Tabela 3. Classificação do Methoce $\left.\right|^{\circledR}$ (HPMC) de acordo com o grau de viscosidade (Colorcon, 2000)

Tabela 4. Composição percentual das formulações dos comprimidos matriciais avaliados

Tabela 5. Equações dos modelos cinéticos empregados na determinação da cinética de dissolução do fármaco

Tabela 6. Critério de avaliação de formas farmacêuticas de ação prolongada de oito horas segundo Prista et al. (1996)

Tabela 7. Resultados da quantificação do teor de furosemida em produtos obtidos por mistura física, malaxagem e liofilização com $\beta-C D$ ou HP- $\beta$-CD

Tabela 8. Porcentagem de furosemida dissolvida em função do tempo a partir dos produtos obtidos por mistura física, malaxagem ou liofilização com $\beta$-CD em meio $\mathrm{HCl} \mathrm{0,1} \mathrm{N} \mathrm{pH} \mathrm{1,2}$

Tabela 9. Porcentagem de furosemida dissolvida em função do tempo a partir dos produtos obtidos por mistura física, malaxagem e liofilização com $\beta-C D$ em meio tampão fosfato $0,05 \mathrm{M} \mathrm{pH} 4,5$

Tabela 10. Porcentagem de furosemida dissolvida em função do tempo a partir dos produtos obtidos por mistura física, malaxagem e liofilização com $\beta$ $\mathrm{CD}$ em meio tampão fosfato $0,05 \mathrm{M} \mathrm{pH} \mathrm{6,8}$

Tabela 11. . Porcentagem de furosemida dissolvida em função do tempo a partir dos produtos obtidos por mistura física, malaxagem e liofilização com $\mathrm{HP}-\beta-\mathrm{CD}$ em meio $\mathrm{HCl} 0,1 \mathrm{~N} \mathrm{pH} \mathrm{1,2}$

Tabela 12. Porcentagem de furosemida dissolvida em função do tempo a partir dos produtos obtidos por mistura física, malaxagem e liofilização com HP- $\beta$-CD em meio tampão fosfato $0,05 \mathrm{M} \mathrm{pH} \mathrm{4,5}$ 
Tabela 13. Porcentagem de furosemida dissolvida em função do tempo a partir dos produtos obtidos por mistura física, malaxagem e liofilização com HP-ß-CD em meio tampão fosfato $0,05 \mathrm{M} \mathrm{pH} \mathrm{6,8}$

Tabela 14. Porcentagem de furosemida dissolvida em função do tempo por comprimidos matriciais preparados com a formulação $A 2, A 3, B 1, B 2, B 3$ e B2c em meio tampão fosfato $0,05 \mathrm{M} \mathrm{pH} \mathrm{6,8}$

Tabela 15. Porcentagem de furosemida dissolvida em função do tempo por comprimidos matriciais preparados com as formulações $A 2, C 1, C 2, C 3$ e C2C em meio tampão fosfato $0,05 \mathrm{M} \mathrm{pH} \mathrm{6,8}$

Tabela 16. Porcentagem de furosemida dissolvida em função do tempo por comprimidos matriciais preparados com as formulações A2, D1, D2 e D3 em meio tampão fosfato $0,05 \mathrm{M} \mathrm{pH} \mathrm{6,8}$

Tabela 17. Valores de área sob a curva (ASC) e eficiência de dissolução $(E D \%)$ calculados a partir dos perfis de dissolução da furosemida pelas formulações A2, A3, B1, B2, B3 e B2c

Tabela 18. Influência da porcentagem de HPMC, pela comparação dos valores de ED\% da furosemida por comprimidos preparados com as formulações $A 2$ e $A 3$

Tabela 19. Influência da adição de $\beta-C D$, pela comparação dos valores de ED\% da furosemida por comprimidos preparados com as formulações A2, B1, B2 e B3

Tabela 20. Valores de área sob a curva (ASC) e eficiência de dissolução $(E D \%)$ calculados a partir dos perfis de dissolução da furosemida pelas formulações $A 2, C 1, C 2, C 3$ e C2c

Tabela 21. Influência da adição de HP-ß-CD pela comparação dos valores de ED\% da furosemida por comprimidos preparados com as formulações $A 2, C 1$, $\mathrm{C} 2, \mathrm{C} 2 \mathrm{c}$ e $\mathrm{C} 3$

Tabela 22. Valores de área sob a curva (ASC) e eficiência de dissolução (ED\%) calculados a partir dos perfis de dissolução da furosemida empregando-se as formulações A2, D1, D2 e D3 
Tabela 23. Influência da adição de lactose monohidratada, pela comparação dos valores de ED\% da furosemida por comprimidos preparados com as formulações A2, D1, D2 e D3

Tabela 24. Valores do coeficiente de correlação $\left(\mathrm{r}^{2}\right)$ para os três modelos matemáticos utilizados na linearização das curvas de dissolução

Tabela 25. Valores das constantes cinéticas determinadas a partir da equação definida pelo modelo matemático com maior índice de correlação

Tabela 26. Porcentagem de furosemida dissolvida em função do tempo a partir de três réplicas de comprimidos preparados com a formulação $A 2, B 2$, $\mathrm{B} 2 \mathrm{c}, \mathrm{C} 2$ e C2c sob variação de $\mathrm{pH}$

Tabela 27. Valores da média da área sob a curva (ASC) e eficiência de dissolução (ED\%) calculados a partir dos perfis de dissolução da furosemida nas formulações $\mathrm{A} 2$, B2, B2c, C2 e C2c sob variação de $\mathrm{pH}$

Tabela 28. Comparação dos valores de eficiência de dissolução (ED\%) da furosemida, obtidos em ensaio de dissolução sob variação de $\mathrm{pH}$, a partir dos comprimidos preparados com as formulações A2, C1, C2, C2c e C3

Tabela 29. Ensaios físicos dos comprimidos preparados com as formulações A1, A2, A3, B1, B2, B3, B2c, C1, C2, C3, C2c, D1, D2 e D3

Tabela 30. Resultados referentes à curva de calibração da furosemida em meio $\mathrm{HCl} 0,1 \mathrm{~N} \mathrm{pH} \mathrm{1,2}$

Tabela 31. Parâmetros relacionados à curva de calibração de furosemida obtida por espectrofotometria a $274 \mathrm{~nm}$ a partir de diluições volumétricas da solução-padrão em $\mathrm{HCl} 0,1 \mathrm{~N} \mathrm{pH} \mathrm{1,2}$

Tabela 32. Resultados referentes à curva de calibração da furosemida em meio tampão fosfato $0,05 \mathrm{M} \mathrm{pH} \mathrm{4,5}$

Tabela 33. Parâmetros relacionados à curva de calibração de furosemida obtida por espectrofotometria a $276 \mathrm{~nm}$ a partir de diluições volumétricas da solução-padrão em tampão fosfato $0,05 \mathrm{M} \mathrm{pH} \mathrm{4,5}$

Tabela 34. Resultados referentes à curva de calibração da furosemida em meio tampão fosfato $0,05 \mathrm{M} \mathrm{pH} \mathrm{6,8}$ 
Tabela 35. Parâmetros relacionados à curva de calibração de furosemida obtida por espectrofotometria a $276 \mathrm{~nm}$ a partir de diluições volumétricas da solução-padrão em tampão fosfato $0,05 \mathrm{M} \mathrm{pH} \mathrm{6,8}$

Tabela 36. Precisão do método espectrofotométrico a $274 \mathrm{~nm}$ em meio $\mathrm{HCl}$ $0,1 \mathrm{~N} \mathrm{pH} 1,2$

Tabela 37. Precisão do método espectrofotométrico a $276 \mathrm{~nm}$ em meio tampão fosfato $0,05 \mathrm{M} \mathrm{pH} \mathrm{4,5}$

Tabela 38. Precisão do método espectrofotométrico a $276 \mathrm{~nm}$ em meio tampão fosfato $0,05 \mathrm{M} \mathrm{pH} \mathrm{6,8}$ 


\section{LISTA DE FIGURAS}

Figura 1. Estrutura molecular da furosemida $\left(\mathrm{C}_{12} \mathrm{H}_{11} \mathrm{CIN}_{2} \mathrm{O}_{5} \mathrm{~S}\right)$.

$\begin{array}{ll}\text { Figura 2. Estruturas das ciclodextrinas naturais. } & 10\end{array}$

Figura 3. Desenho esquemático da formação de complexos de inclusão em 11

Figura 4. Curvas termoanalíticas de DSC referente à furosemida, $\beta-C D$ e produtos obtidos por mistura física (MF), malaxagem e liofilização em quantidades equimolares.

Figura 5. Curvas termoanalíticas de DSC referente à furosemida, HP- $\beta-C D$ e produtos obtidos por mistura física (MF), malaxagem e liofilização em quantidades equimolares

Figura 6. Espectro de absorção da furosemida, $\beta-C D$ e produtos obtidos por mistura física (MF), malaxagem e liofilização em quantidades equimolares na região do infravermelho $\left(400-4.000 \mathrm{~cm}^{-1}\right)$.

Figura 7. Espectro de absorção da furosemida, HP- $\beta-C D$ e produtos obtidos por mistura física (MF), malaxagem e liofilização em quantidades equimolares na região do infravermelho $\left(400-4000 \mathrm{~cm}^{-1}\right)$.

Figura 8. Perfis de dissolução da furosemida a partir dos produtos obtidos por mistura física, malaxagem e liofilização com $\beta-C D$ em meio $\mathrm{HCl} 0,1 \mathrm{~N} \mathrm{pH} \mathrm{1,2.}$

Figura 9. Perfis de dissolução da furosemida a partir dos produtos obtidos por mistura física, malaxagem e liofilização com $\beta-C D$ em meio tampão fosfato $0,05 \mathrm{M} \mathrm{pH} 4,5$.

Figura 10. Perfis de dissolução da furosemida a partir dos produtos obtidos por mistura física, malaxagem e liofilização com $\beta-C D$ em meio tampão fosfato $0,05 \mathrm{M} \mathrm{pH} 6,8$.

Figura 11. Perfis de dissolução da furosemida a partir dos produtos obtidos por mistura física, malaxagem e liofilização com $\mathrm{HP}-\beta-\mathrm{CD}$ em meio $\mathrm{HCl} 0,1 \mathrm{~N}$ $\mathrm{pH} 1,2$.

Figura 12. Porcentagem de furosemida dissolvida em função do tempo a partir dos produtos obtidos por mistura física, malaxagem e liofilização com HP- $\beta-C D$ em meio tampão fosfato $0,05 \mathrm{M} \mathrm{pH} \mathrm{4,5}$ 
Figura 13. Perfis de dissolução da furosemida a partir dos produtos obtidos por mistura física, malaxagem e liofilização com HP- $\beta$-CD em meio tampão fosfato $0,05 \mathrm{M} \mathrm{pH} 6,8$.

Figura 14. Sumário dos perfis de dissolução da furosemida a partir de comprimidos preparados com a formulação A2, A3, B1, B2, B3 e B2c em meio tampão fosfato $0,05 \mathrm{M} \mathrm{pH} \mathrm{6,8.}$

Figura 15. Sumário dos perfis de dissolução da furosemida a partir de comprimidos preparados com as formulações $\mathrm{A} 2, \mathrm{C} 1, \mathrm{C} 2, \mathrm{C} 3$ e C2c em meio tampão fosfato $0,05 \mathrm{M} \mathrm{pH} \mathrm{6,8}$

Figura 16. Sumário dos perfis de dissolução da furosemida a partir de comprimidos preparados com as formulações A2, D1, D2 e D3 em meio tampão fosfato $0,05 \mathrm{M} \mathrm{pH} \mathrm{6,8.}$

Figura 17. Sumário dos valores de eficiência de dissolução (ED\%) da furosemida a partir de comprimidos preparados com as formulações $A 2, A 3$, $B 1, B 2, B 3$ e B2C

Figura 18. Sumário dos valores médios de eficiência de dissolução (ED\%) da furosemida a partir de comprimidos preparados com as formulações $A 2, C 1$, $\mathrm{C} 2, \mathrm{C} 3$ e $\mathrm{C} 2 \mathrm{c}$.

Figura 19. Sumário dos valores de eficiência de dissolução (ED\%) da furosemida a partir de comprimidos preparados com as formulações A2, D1, D2 e D3.

Figura 20. Curvas obtidas pela aplicação do modelo matemático de linearização de ordem zero aos perfis de dissolução da furosemida empregando-se as formulações A2, A3, B1, B2 , B3 e B2c.

Figura 21. Curvas obtidas pela aplicação do modelo matemático de linearização de primeira ordem aos perfis de dissolução da furosemida empregando-se as formulações A2, A3, B1, B2, B3 e B2c.

Figura 22. Curvas obtidas pela aplicação do modelo matemático de linearização de Higuchi aos perfis de dissolução da furosemida empregandose as formulações $A 2, A 3, B 1, B 2$, B3.e B2c. 
Figura 23. Curvas obtidas pela aplicação do modelo matemático de linearização de ordem zero aos perfis de dissolução da furosemida empregando-se as formulações A2, C1, C2, C3 e C2c.

Figura 24. Curvas obtidas pela aplicação do modelo matemático de linearização de primeira ordem aos perfis de dissolução da furosemida empregando-se as formulações A2, C1, C2, C3 e C2c.

Figura 25. Curvas obtidas pela aplicação do modelo matemático de linearização de Higuchi aos perfis de dissolução da furosemida empregandose as formulações $\mathrm{A} 2, \mathrm{C} 1, \mathrm{C} 2, \mathrm{C} 3$ e C2c.

Figura 26. Curvas obtidas pela aplicação do modelo matemático de linearização de ordem zero aos perfis de dissolução da furosemida empregando-se as formulações A2, D1, D2 e D3.

Figura 27. Curvas obtidas pela aplicação do modelo matemático de linearização de primeira ordem aos perfis de dissolução da furosemida empregando-se as formulações A2, D1, D2 e D3.

Figura 28. Curvas obtidas pela aplicação do modelo matemático de linearização de Higuchi aos perfis de dissolução da furosemida empregandose as formulações A2, D1, D2 e D3.

Figura 29. Quantidade de furosemida dissolvida até 60,240 e 480 minutos a partir do comprimidos preparados com as formulações A2-D3. Valores esperados segundo Prista et al. (1996): $20-40 \%$ em 60min; $50-70 \%$ em 240min; 80 - 100\% em 480min.

Figura 30. Perfil de dissolução da furosemida a partir de comprimidos preparados com a formulação $\mathrm{A} 2, \mathrm{~B} 2, \mathrm{~B} 2 \mathrm{c}, \mathrm{C} 2$ e C2c em gradiente de $\mathrm{pH}$, sendo os primeiros $60 \mathrm{~min} \mathrm{em} \mathrm{pH} \mathrm{1,2;} \mathrm{os} 120$ min subsequentes em pH 4,5 e 300 min subsequentes em pH 6,8.

Figura 31. Sumário dos valores médios de eficiência de dissolução (ED\%) da furosemida, obtidos em ensaio de dissolução sob variação de $\mathrm{pH}$, a partir de comprimidos preparados com as formulações A2, B2, B2c, C2 e C2c. 
Figura 32. Espectro de absorção na região do ultravioleta de solução de furosemida a $2 \mu \mathrm{g} / \mathrm{mL}$ em HCl 0,1 N pH 1,2.

Figura 33. Espectro de absorção na região do ultravioleta de solução de furosemida a $2 \mu \mathrm{g} / \mathrm{mL}$ em tampão fosfato $0,1 \mathrm{M} \mathrm{pH} 4,5$.

Figura 34. Espectro de absorção na região do ultravioleta de solução de furosemida a $2 \mu \mathrm{g} / \mathrm{mL}$ em tampão fosfato $0,05 \mathrm{M} \mathrm{pH}$ 6,8.

Figura 35. Curva de calibração de furosemida obtida por espectrofotometria a $274 \mathrm{~nm}$ a partir de diluições volumétricas da solução padrão em $\mathrm{HCl} \mathrm{0,1} \mathrm{N} \mathrm{pH}$ $1,2$.

Figura 36. Curva de calibração de furosemida obtida por espectrofotometria a $276 \mathrm{~nm}$ a partir de diluições volumétricas da solução-padrão em tampão fosfato $0,05 \mathrm{M} \mathrm{pH} 4,5$.

Figura 37. Curva de calibração de furosemida obtida por espectrofotometria a $276 \mathrm{~nm}$ a partir de diluições volumétricas da solução-padrão em tampão fosfato $0,05 \mathrm{M} \mathrm{pH} 6,8$.

Figura 38. Especificidade do método analítico em meio $\mathrm{HCl} 0,1 \mathrm{~N} \mathrm{pH} \mathrm{1,2.}$

Figura 39. Especificidade do método analítico em tampão fosfato $0,05 \mathrm{M} \mathrm{pH}$ 4,5 .

Figura 40. Especificidade do método analítico em tampão fosfato $0,05 \mathrm{M} \mathrm{pH}$ 6,8 . 


\section{RESUMO}

Formas farmacêuticas de liberação prolongada são especialmente eficazes no controle da hipertensão. A incorporação da furosemida neste tipo de sistema é adicionalmente justificável por se manter as vantagens de um diurético de alça, porém, com efeito menos intenso e mais duradouro, gerando menor desconforto ao paciente crônico e diminuição no número de administrações diárias.

Considerando-se a limitada solubilidade da furosemida $e$ as vantagens tecnológicas das ciclodextrinas (CD) e dos comprimidos matriciais hidrofílicos, procuro-se averiguar a influência da $\beta$-ciclodextrina $(\beta-C D)$ ou hidroxipropil- $\beta$ ciclodextrina (HP- $\beta-C D)$, incorporadas às formulações como misturas físicas ou complexadas ao fármaco, no perfil de liberação de comprimidos à base de hidroxipropilmetilcelulose (HPMC), desenvolvidos para modular adequadamente a liberação da furosemida por um período de oito horas.

Para tanto, complexos de inclusão foram obtidos por liofilização e caracterizados por análise térmica e espectrofotometria. Comprimidos de 500 $\mathrm{mg}$ foram preparados por compressão direta. Mantiveram-se constantes nas formulações: furosemida (10\%), HPMC (25\%) e agente lubrificante $(0,5 \%)$, variando-se a concentração do diluente. Avaliou-se, estatisticamente (ANOVA), a influência da adição de $\beta-C D$ ou HP- $\beta-C D$ ou lactose, nas eficiências de dissolução (ED) do fármaco. As ED foram calculadas a partir dos perfis de liberação, determinados após submissão dos comprimidos à dissolução, por 8 horas, utilizando-se meio tamponado $\mathrm{pH} 6,8$ ou gradiente de $\mathrm{pH}$. Os mecanismos de liberação foram indiretamente estimados por modelos matemáticos (ordem zero, primeira ordem ou Higuchi).

A presença de ciclodextrinas nas formulações, tanto em mistura física quanto complexadas, gerou aumento significativo na velocidade e extensão de liberação da furosemida pelos comprimidos, propiciando cinética de acordo com o modelo de Higuchi. Adicionalmete, a complexação foi capaz de prover uma liberação $\mathrm{pH}$-independente, representando significativa vantagem tecnológica. 


\begin{abstract}
Extended release dosage forms are especially effective for hypertension control. Additionally, the advantages of incorporating furosemide in such system is to keep the features of a loop diuretic, however, with a less intense and more lasting effect. Moreover, less discomfort to chronic patients and decreased number of daily administrations could be provided.

Considering the limited solubility of furosemide and the technological advantages of cyclodextrins (CD) and hydrophilic matrix tablets, this work evaluates the influence of $\beta$-cyclodextrin $(\beta-C D)$ or hydroxypropyl- $\beta$-cyclodextrin (HP- $\beta-C D)$ on the release profile of hydroxypropylmethylcellulose (HPMC) tablets, aimed to modulate the drug release during an eight hour period The CD were incorporated to the formulations as physical mixtures or complexed with the drug.

Thus, inclusion complexes were obtained by freeze-drying and characterized by thermal analysis and spectrophotometry. Tablets of $500 \mathrm{mg}$ were prepared by direct compression. Furosemide (10\%), HPMC (25\%) and lubricant agent $(0,5 \%)$ were kept constant in the formulations, varying the diluent concentration. The influence of $\beta-C D$ or HP- $\beta-C D$ or lactose addition, on the dissolution efficiency (DE) of the drug, was evaluated statistically by ANOVA. The DE were calculated performing dissolution assays of the tablets for 8 hours, using phosphate buffer at $\mathrm{pH} 6,8$ or $\mathrm{pH}$ gradient as milieu. The release mechanisms were indirectly estimated by mathematical models (zero order, first order or Higuchi).

The presence of $C D$ in the formulations, even in physical mixture or complexed with the furosemide, demonstrated significant increase of the velocity and extension of the drug release, according to Higuchi's model. Nevertheless, the complexation was able to provide a $\mathrm{pH}$-independent release, representing significant technological advantage.
\end{abstract}


1. INTRODUÇÃO 
Nos últimos anos, tem aumentado significativamente o interesse no desenvolvimento de novas formas farmacêuticas capazes de promover a liberação do fármaco de maneira mais lenta e controlada, mantendo-o na circulação sangüínea em níveis terapêuticos mais adequados às necessidades clínicas e farmacocinéticas, propiciando, deste modo, maiores eficácia e segurança na terapia medicamentosa (Prista et al., 1996).

$\mathrm{Na}$ terapia anti-hipertensiva, as formas de liberação prolongada de fármacos podem ser especialmente vantajosas por possibilitarem melhor controle farmacológico da pressão arterial em períodos críticos como o despertar (Ortega et al., 2000).

A incorporação da furosemida, um potente diurético, em uma forma de liberação prolongada é adicionalmente justificável por se manter as vantagens de um diurético de alça, porém, com efeito menos pronunciado e mais duradouro, gerando menor desconforto ao paciente crônico bem como a diminuição no número de administrações diárias (Ebihara et al., 1983; Hylander et al., 1987; Verhoeven et al., 1987).

Limitações de solubilidade dos fármacos nos meios fisiológicos, como observado na furosemida, traduzem-se, freqüentemente, em problemas de biodisponibilidade, elevada variabilidade interindivíduo, grande interferência do estado alimentar e liberação incompleta a partir de formas farmacêuticas (Hite et al., 2003).

A aplicação das ciclodextrinas é um recurso farmacotécnico que vem sendo testado extensivamente no aumento da solubilidade de diversos fármacos (Loftsson \& Brewster, 1997). Pode possibilitar, inclusive, melhorias nas propriedades de liberação de fármacos a partir de formas farmacêuticas, funcionando, neste caso, como promotoras de liberação (Bibby et al., 2000). 
Os comprimidos matriciais hidrofílicos estão entre as formas mais convenientes para o desenvolvimento de produtos de ação prolongada de uso oral, devido à sua composição simples, baixos custos de preparação e flexibilidade no controle da velocidade e extensão de liberação dos fármacos neles contidos (Collett \& Moreton, 2005).

Dentro do contexto acima apresentado, o presente trabalho pretendeu averiguar a influência da complexação da furosemida, ou sua simples mistura, com ciclodextrinas, no perfil de liberação in vitro do fármaco a partir de comprimidos matriciais hidrofílicos à base de um derivado celulósico, desenvolvidos com intuito de modular adequadamente a liberação da furosemida por um período de oito horas. 
2. REVISÃO DA LITERATURA 


\subsection{Etiologia da hipertensão}

A hipertensão arterial é definida, convencionalmente, como pressão arterial maior ou igual a 140/90 mmHg, não havendo causa específica para sua ocorrência. É o principal fator de risco para doenças cardiovasculares, que incluem doenças isquêmicas do coração e doenças cerebrovasculares, entre as quais: insuficiência cardíaca e coronariana, angina pectoris, infarto agudo do miocárdio, acidente vascular encefálico (AVE) e aneurisma (Oates, 1996).

Doenças cardiovasculares são, comprovadamente, a maior causa de morte em indivíduos com mais de 40 anos. Na América Latina, são responsáveis por $31 \%$ do total de óbitos registrados nesta faixa etária (OPAS/OMS, 2000).

Estudos indicam que $15 \%$ dos adultos são portadores de hipertensão arterial e estima-se que exista um hipertenso para cada três pessoas com idade superior a 40 anos. Entende-se, portanto, a importância do controle desta manifestação crônica na melhoria da saúde pública (OPAS/OMS, 2000).

Mudanças em hábitos alimentares e comportamentais como: redução na ingestão de cloreto de sódio, álcool e gorduras saturadas; prática diária de atividades físicas e interrupção do tabagismo são os primeiros passos para o controle da hipertensão e, muitas vezes, suficientes para o controle do estágio 1 da doença. No entanto, a terapia medicamentosa se faz necessária principalmente para casos de estágio 2 (moderada - pressão sistólica acima de $160 \mathrm{mmHg}$ e diastólica acima de $100 \mathrm{mmHg}$ ) ou superiores (Mion et al., 2005).

Estudos clínicos de longo prazo, realizados em grupos populacionais com idade igual ou superior a 65 anos, demonstraram que o controle farmacológico da hipertensão pôde reduzir a incidência de doenças cerebrovasculares em até $34 \%$ e das doenças isquêmicas do coração em $19 \%$, 
- que implica em redução de $23 \%$ de todas as mortes por causas cardiovasculares (MacMahon \& Rodgers, 1993).

Sabe-se que o maior número de mortes por infarto agudo do miocárdio e AVE isquêmico ocorre pela manhã, logo após o despertar, período no qual o hipertenso manifesta abrupto aumento na pressão arterial devido às condições fisiológicas naturais, como aumento do tônus simpático, características do padrão circadiano humano (Muller, 1999). Torna-se evidente, portanto, que uma terapia adequada deva assegurar o controle farmacológico da pressão arterial, principalmente, neste período mais crítico (Ortega et al., 2000).

Neste sentido, as formas farmacêuticas de liberação prolongada podem trazer importante contribuição por possibilitar melhor sincronia dos efeitos farmacológicos com as manifestações sintomáticas do curso natural da doença hipertensiva, reduzindo, conseqüentemente, o risco de eventos clínicos (Ortega et al., 2000).

As classes terapêuticas mais utilizadas na terapia anti-hipertensiva são: diuréticos, bloqueadores adrenérgicos, inibidores de enzimas conversoras de angiotensina, bloqueadores de angiotensina 2, antagonistas de canal de cálcio e antagonistas do receptor AT1 da All, sendo que a associação de dois ou mais destes fármacos geralmente é necessária para se obter controle adequado, principalmente nos estágios 2 e 3 (Mion et al., 2005).

Os diuréticos são os fármacos mais empregados no controle da hipertensão, podendo ser utilizados em monoterapias ou em associações, já que potencializam a ação de praticamente todos os outros agentes antihipertensivos (Oates, 1996). Dentre os diuréticos, os derivados tiazídicos são eleitos como primeira escolha e, havendo resposta inadequada, utilizam-se os diuréticos de alça, tais como a furosemida (Jackson, 1996). 


\subsection{Furosemida}

A furosemida (Figura 1), quimicamente denominada Ácido 5-(aminosulfonil)-4-cloro-2-((furanilmetil)amino)benzóico, é um ácido fraco (pKa 3,9 ), com peso molar de $330,77 \mathrm{~g} / \mathrm{mol}$, ponto de fusão em $206^{\circ} \mathrm{C}$, praticamente insolúvel em água ( $<1 \mathrm{mg} / \mathrm{mL}$ ) e meios ácidos, pouco solúvel em clorofórmio e éter e livremente solúvel em soluções alcalinas, etanol, metanol, acetona e dimetilformamida (The Merck Index, 1996). Inclui-se na classificação biofarmacêutica II, dada sua limitada solubilidade em $\mathrm{pH}$ fisiológicos e considerável permeabilidade transmembrana (CFNP, 2002).

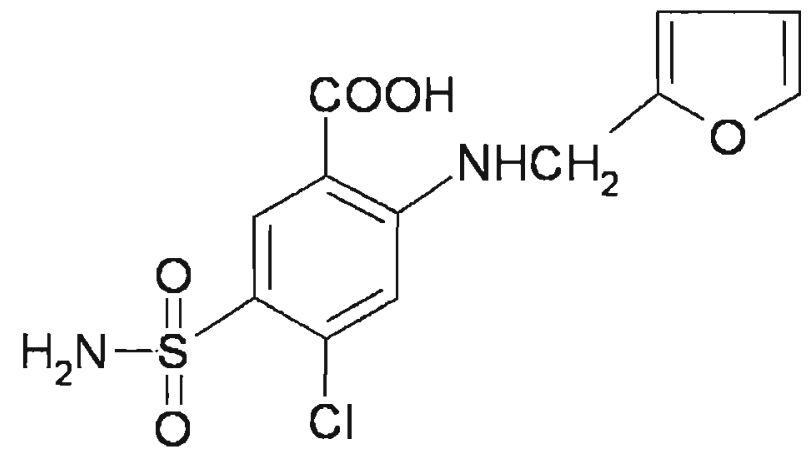

Figura 1. Estrutura molecular da furosemida $\left(\mathrm{C}_{12} \mathrm{H}_{11} \mathrm{CIN}_{2} \mathrm{O}_{5} \mathrm{~S}\right)$.

A furosemida é um fármaco da família das sulfonamidas e atua como inibidor do transporte simultâneo de $\mathrm{Na}^{+}-\mathrm{K}^{+}-2 \mathrm{Cl}^{-}$, no ramo ascendente espesso da alça de Henle, causando a parada reversível da reabsorção passiva de sódio neste segmento do néfron e resultando, conseqüentemente, em aumento do volume urinário e redução do volume intravascular (Jackson, 1996).

Em indivíduos saudáveis, o clearance total $\left(\mathrm{CL}_{t}\right)$ da furosemida é reportado entre 153 e $174 \mathrm{~mL} / \mathrm{min}$ e o clearance renal $\left(\mathrm{CL}_{\mathrm{r}}\right)$ entre 68 e 118 $\mathrm{mL} / \mathrm{min}$. O volume de distribuição no estado de equilíbrio varia entre 7,9 e 9,4 L. O tempo de meia-vida $\left(t_{1 / 2}\right)$ é de aproximadamente $90 \mathrm{~min}$, sendo que $60 \%$ do fármaco é eliminado pelos rins na forma inalterada. Seu principal metabólito 
é o glicuronato de furosemida. Sua biodisponibilidade oral chega a $70 \%$ e seu tempo médio de absorção em estado de jejum foi determinado como 84 min, sendo pouco absorvida nas porções distais do trato gastrintestinal (Hammarlund \& Benet, 1988; Boles \& Shoenwald, 1990).

Uma dose de $40 \mathrm{mg}$ de furosemida causa início de diurese após $30 \mathrm{~min}$ da sua administração oral, sendo que o efeito máximo é atingido após 2 horas. Sua atividade diurética perdura em média por 6 horas (Reubi, 1966; Hammarlund \& Benet, 1988).

Assim como os outros diuréticos de alça, entre eles, bumetanida, torsemida e ácido etacrínico, a furosemida é capaz de causar diurese intensa, sendo indicada, principalmente, no controle do edema pulmonar agudo e da insuficiência cardíaca congestiva. É aplicada também na redução da pressão intracraniana e intra-ocular antes e depois de procedimentos cirúrgicos e durante ataques de glaucoma (Jackson, 1996).

A furosemida, ao contrário dos diuréticos tiazídicos como a hidroclorotiazida, não apresenta desvantagens, como baixa eficácia em pacientes com disfunção renal (comum em idosos e diabéticos), depreciação da filtração glomerular no uso crônico e curva dose-resposta achatada. No entanto, sua ação é muito acentuada e de curta duração (Reubi, 1966; Hylander et al., 1987; Oates, 1996).

A furosemida, assim como outros diuréticos de alça, é utilizada no controle da hipertensão arterial como fármaco de segunda escolha, quando o paciente não responde bem aos diuréticos tiazídicos (Oates, 1996). Na prática clínica, os diuréticos tiazídicos são freqüentemente substituídos pelos de alça para se alcançar o devido controle pressórico em pacientes diabéticos, os quais geralmente apresentam lesão renal em decorrência da hiperglicemia (Faria, 2002). 
Geralmente, inicia-se o tratamento com um comprimido de $40 \mathrm{mg}$ ao dia, podendo-se aumentar para até três (FURP, 1998). Por causar intensa atividade diurética sua aplicação pode gerar desconforto ao paciente, principalmente se administrada em períodos noturnos (Ebihara et al., 1983).

A furosemida é comercializada no mercado brasileiro na forma de comprimidos de liberação imediata contendo $40 \mathrm{mg}$ e soluções injetáveis de 2 $\mathrm{mL}$ contendo $20 \mathrm{mg}$ do fármaco (DEF, 2005/2006). Formas de ação prolongada, contendo $30 \mathrm{mg}$ de furosemida, são comercializadas no mercado europeu com o nome de Lasix ${ }^{\circledR}$ Long.

Formas de liberação prolongada de furosemida são de grande interesse na terapia anti-hipertensiva por se manter as vantagens de um diurético de alça, porém, com efeito menos pronunciado e mais duradouro, gerando menor desconforto ao paciente crônico (Ebihara et al., 1983; Hylander et al., 1987; Verhoeven et al., 1987). No entanto, a incorporação e bom desempenho de liberação da furosemida a partir de sistemas de liberação podem ser especialmente dificultosos por esta apresentar baixa solubilidade, pobre fluidez e pouca compressibilidade (Smal et al., 1996).

Problemas de solubilidade dos fármacos, freqüentemente, traduzem-se em baixa biodisponibilidade, elevada variabilidade interindivíduo, grande interferência do estado alimentar e liberação incompleta por formas farmacêuticas. Adicionalmente, existem limitadas alternativas tecnológicas para controle da liberação de fármacos pouco solúveis (Horter \&. Dressman, 2001; Hite et al., 2003).

Dentre os recursos tecnológicos mais empregados para resolução de problemas de solubilidade destacam-se: a redução do tamanho de partícula, adição de tensoativos, obtenção de dispersões sólidas com compostos de alta solubilidade e a complexação com ciclodextrinas (Horter \&. Dressman, 2001). 


\subsection{Ciclodextrinas}

As ciclodextrinas (Figura 2) são oligossacarídeos cíclicos obtidos por meio da degradação enzimática do amido pela ciclodextrina-glucosiltransferase (CGT-ase). Apresentam estrutura molecular em forma de cone truncado, cujos grupos hidroxílicos $(\mathrm{OH})$ secundários ligados aos átomos de carbono C-2 e C-3 estão localizados na parte externa da base maior, enquanto que os grupos $\mathrm{OH}$ primários ligados ao átomo de carbono C-6 estão posicionados no lado oposto (base menor) (Szejtli \& Osa, 1996).

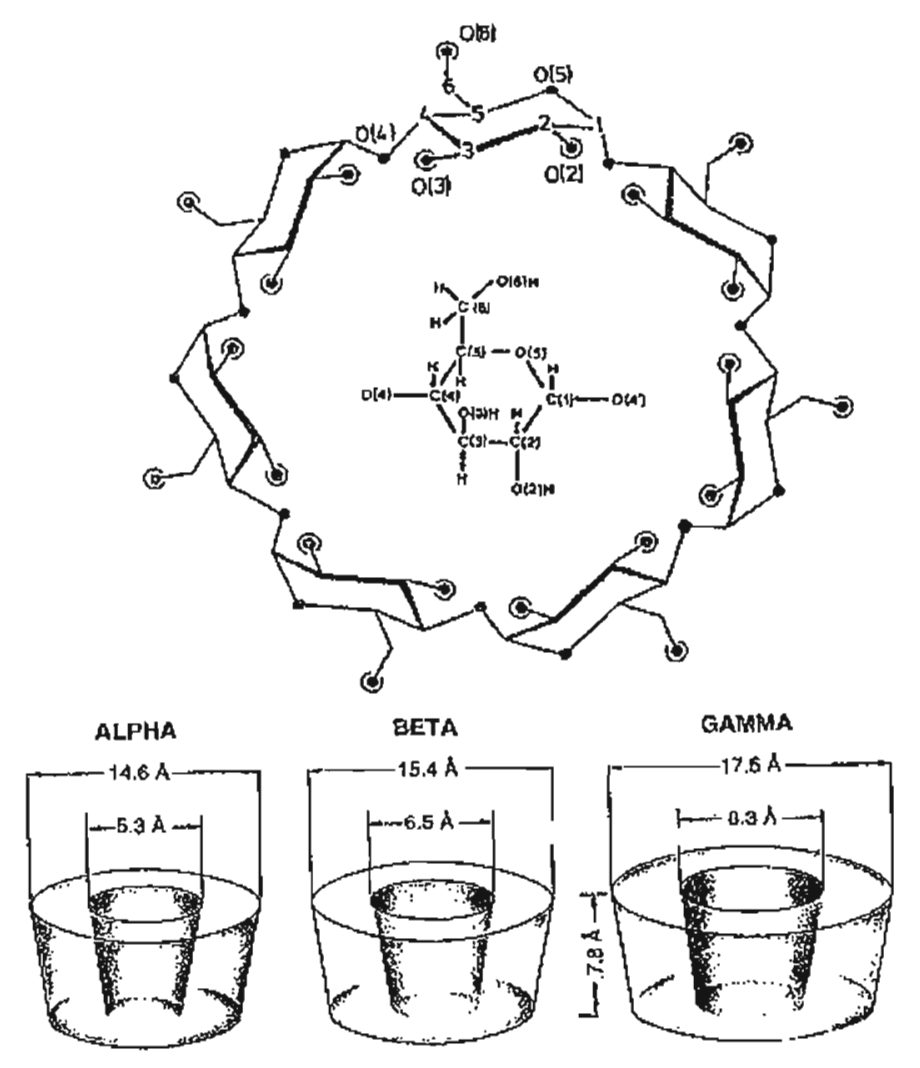

Figura 2. Estruturas das ciclodextrinas naturais

Os grupos hidroxilas são voltados para a parte externa da molécula, tornando essa face hidrofílica. O interior do cone, por não estar revestido com grupos $\mathrm{OH}$, oferece ambiente apolar, o que permite considerar que as ciclodextrinas possuem uma cavidade hidrofóbica, revestida por dois anéis de 
grupos $\mathrm{CH}$ e por um anel de átomos de oxigênio glucosídico, em ligações éter (Szejtli \& Osa, 1996).

A propriedade mais notável das ciclodextrinas é a capacidade de sua cavidade hidrofóbica acomodar compostos orgânicos compatíveis com suas dimensões, formando-se assim os complexos de inclusão (Figura 3) (Loftsson \& Brewster, 1996).

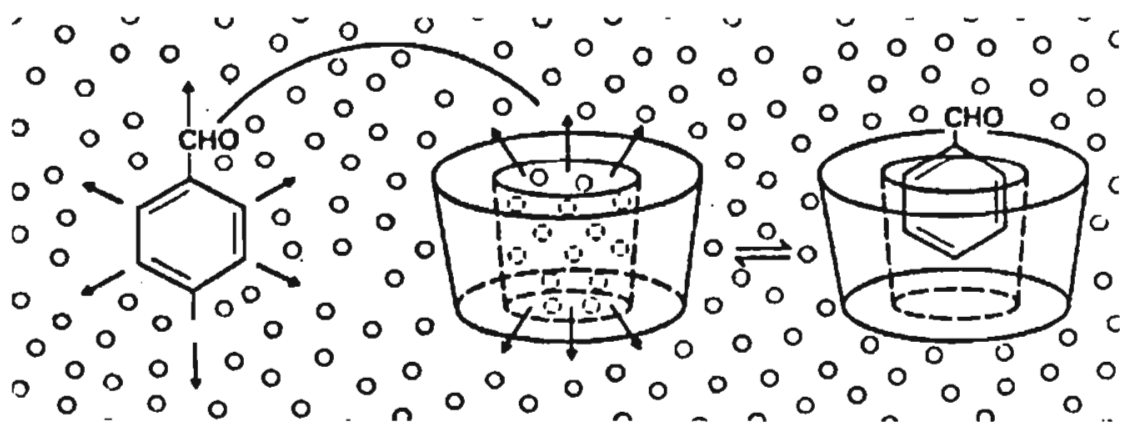

Figura 3. Desenho esquemático da formação de complexos de inclusão em solução.

As três principais ciclodextrinas são a $\alpha, \beta$ e $\gamma$, também chamadas de ciclodextrinas naturais, compostas respectivamente por seis, sete e oito unidades de $\mathrm{D}$-(+)-glucopiranose. Uma vez hidratadas, as $\alpha, \beta$ e $\gamma$ ciclodextrinas (Figura 2, Tabela 1) contêm 6, 11 e 17 moléculas de água, respectivamente (Szejtli, 1988).

As moléculas de água no interior da cavidade podem ser substituídas por moléculas de compostos apolares ou menos polares do que a água. Tal substituição é favorecida pela diminuição da energia livre (menor entalpia) do sistema. Por meio de interações hidrofóbicas, a molécula hóspede tende a aproximar-se e alocar-se na cavidade, expulsando as moléculas de água presentes, em uma reação rápida e reversível, na qual há ganho de energia, formando-se assim os complexos de inclusão (Duchéne \& Wouessidjewe, 1990). 
Tabela 1. Características das principais ciclodextrinas (Szejtli \& Osa, 1996)

\begin{tabular}{cccc}
\hline Características & $\alpha-\mathrm{CD}$ & $\beta-\mathrm{CD}$ & $\gamma$-CD \\
\hline № de unidades de glicose & 6 & 7 & 8 \\
Fórmula mínima anidra & $\mathrm{C}_{38} \mathrm{H}_{60} \mathrm{O}_{30}$ & $\mathrm{C}_{42} \mathrm{H}_{70} \mathrm{O}_{35}$ & $\mathrm{C}_{48} \mathrm{H}_{80} \mathrm{O}_{40}$ \\
Peso Molecular & 972,85 & 1134,99 & 1297,14 \\
Solubilidade (água, $\left.25^{\circ} \mathrm{C}\right), \mathrm{g} / \mathrm{L}$ & 118,17 & 18,5 & 219,9 \\
Diâmetro da cavidade $(\mathrm{nm})$ & $47-52$ & $60-65$ & $75-83$ \\
Altura do tronco $(\mathrm{nm})$ & $79 \pm 1$ & $79 \pm 1$ & $79 \pm 1$ \\
Diâmetro externo $(\mathrm{nm})$ & $148 \pm 4$ & $154 \pm 4$ & $175 \pm 4$ \\
Volume da cavidade $\left(\mathrm{nm}{ }^{3}\right):$ & 1740 & 2620 & 4270 \\
por mol de CD $(\mathrm{mL})$ & 104 & 157 & 256 \\
por g de CD $(\mathrm{mL})$ & 0,10 & 0,14 & 0,20 \\
Ponto de Fusão $\left({ }^{\circ} \mathrm{C}\right)$ & $\approx 275$ & $\approx 280$ & $\approx 275$ \\
Moléculas de água na cavidade & 6 & 11 & 17 \\
\hline
\end{tabular}

As forças envolvidas na inclusão molecular, como Van der Waals e pontes de hidrogênio, não são suficientes para estabelecer um complexo estável. Em meio líquido co-existem as espécies associadas e não associadas. A complexação de um fármaco com uma ciclodextrina pode, portanto, ser definida por uma constante de associação (Ka) (Loftsson \& Brewster, 1997).

Os complexos com as ciclodextrinas podem se formar de maneiras diferentes. O fármaco pode ficar totalmente dentro da cavidade, parcialmente ou se ligar com grupos hidroxila da ciclodextrina fora da cavidade, formando um composto de associação. Complexos equimolares são mais comuns; no entanto, dependendo da estrutura do fármaco, o mesmo pode complexar-se com duas ou mais moléculas de ciclodextrina (Szejtli, 1988).

Um fármaco com coeficiente de solubilidade menor que 0 da ciclodextrina, quando incluso, pode ter sua taxa de dissolução aumentada e, conseqüentemente, sua biodisponibilidade. $\mathrm{O}$ aumento da biodisponibilidade 
pode levar a uma diminuição da dose administrada com a mesma possibilidade de atividade biológica (Korolkovas, 1991; Loftsson \& Brewster, 1997).

Como as interações entre a molécula hóspede e a cavidade das ciclodextrinas são sempre fracas, a aproximação do complexo com uma mucosa ou membrana lipídica, como a das células epiteliais da parede intestinal, permite a "saída" do fármaco, por sua maior afinidade pela mesma. Além disso, igualmente à reação de inclusão, quando o complexo está em meio aquoso, este se dissocia com a mesma constante. Conseqüentemente, existem sempre algumas moléculas do fármaco fora da cavidade, as quais são livres e prontas para transporem à membrana. $O$ equilíbrio é então deslocado e novas moléculas do fármaco deixam a ciclodextrina. A presença de substâncias endógenas e exógenas (p.ex. alimentos) no trato gastrintestinal também pode favorecer a dissociação dos complexos, pelo fato de tais substâncias concorrerem com o fármaco pela cavidade das ciclodextrina. A elevada hidrofilicidade da face externa das ciclodextrinas, aliada ao seu alto peso molecular, geram baixa taxa de absorção das mesmas pelo trato gastrintestinal (Duchêne \& Wouessidjewe, 1990).

As aplicações da $\beta$-ciclodextrina ( $\beta-C D)$, a mais abundante das ciclodextrinas, são restritas pela baixa solubilidade em água (185 mg/100 mL), devido, especialmente, à sua forma cristalina. $A \beta-C D$ possui vinte e um grupos hidroxila disponíveis como ponto de partida para modificações estruturais pela introdução de grupos funcionais, sendo a metilação, a hidroxialquilação, a ramificação e a adição de grupamentos ionizáveis, as modificações mais comuns. Tais reações também dificultam a cristalização das ciclodextrinas, favorecendo a forma amorfa, a qual possui maior solubilidade (Uekema et al., 1998).

As ciclodextrinas modificadas mais comuns são: 3-metil-ciclodextrina; 2,6-dimetil-ciclodextrina; 2,3,6-trimetil-ciclodextrina; 2-hidroxietil-ciclodextrina; 
2-hidroxipropil-ciclodextrina; 2,3-dihidroxipropil-ciclodextrina; 6-O-glucosiciclodextrina; 6-O-maltosil-ciclodextrina; 6-O-dimaltosil-ciclodextrina; 6-O-carboximetil-ciclodextrina; sulfobutiléter-ciclodextrina e sulfato de ciclodextrina (Szejtli, 1988; Loftsson \& Brewster, 1997).

Os complexos são preparados, geralmente, em soluções aquosas ou hidroalcóolicas, com posterior eliminação do solvente por diversas técnicas, tais como liofilização, spray-drying ou evaporação lenta. Métodos de mistura no estado sólido, tais como: mistura física, co-moagem e malaxagem, também vêm sendo utilizados para aplicação das ciclodextrinas na formação de complexos. A real inclusão molecular por tais técnicas é bastante dificultosa, sendo mais comuns formas de associação. No entanto, é possivel aumentar a hidrofilicidade da superfície de partículas de fármaco e, conseqüentemente, melhorar sua solubilidade aparente (Duchêne \& Wouessidjewe, 1989).

As ciclodextrinas vêm sendo aplicadas amplamente no aumento da solubilidade de fármacos pouco solúveis, na melhoria da estabilidade química e para mascarar odores e sabores desagradáveis de certos fármacos (Loukas et al., 1998; Özkan et al., 2000).

Zingone \& Rubessa (2005) avaliaram o emprego das técnicas de mistura física, malaxagem, co-evaporação e liofilização no preparo de complexos de inclusão de warfarina com $\beta$-ciclodextrina. Estudaram também a solubilidade da warfarina, pura ou complexada com $\beta$-ciclodextrina, em pH 1,2 e pH 5,0. Observaram que a formação de complexos aumentou expressivamente a solubilidade do fármaco, sendo capaz, inclusive, de prover uma dissolução $\mathrm{pH}$-independente. $\mathrm{O}$ complexo obtido pela técnica de liofilização apresentou os melhores resultados, como observado na Tabela 2, a seguir. 
Tabela 2. Solubilidade $(\mathrm{mg} / 100 \mathrm{~mL})$ da warfarina a partir de produtos de complexação com $\beta$-ciclodextrina em pH 1,2 e pH 5,0 (Zingone \& Rubessa, 2005)

\begin{tabular}{lcc}
\hline & $\mathrm{pH} \mathrm{1,2}$ & $\mathrm{pH} 5,0$ \\
\hline Warfarina & $0,86 \pm 0,13$ & $1,77 \pm 0,35$ \\
Mistura Física & $6,56 \pm 0,41$ & $10,18 \pm 1,35$ \\
Produto de malaxagem & $13,98 \pm 0,12$ & $16,45 \pm 1,22$ \\
Produto de co-evaporação & $14,87 \pm 0,21$ & $18,75 \pm 1,78$ \\
Produto de liofilização & $24,8 \pm 0,65$ & $34,5 \pm 0,04$ \\
\hline
\end{tabular}

Ammar et al. (1999) avaliaram as propriedades de dissolução de complexos de inclusão de furosemida com $\alpha-C D, \beta-C D, \gamma-C D$, dimetil- $\beta-C D$ e trimetil- $\beta-C D$ preparados pela técnica da malaxagem e caracterizados por espectrofotometria no ultravioleta e infravermelho. $\mathrm{Em} \mathrm{pH} \mathrm{5,8,} \mathrm{a} \mathrm{eficiência} \mathrm{de}$ dissolução da furosemida pura, ou a partir dos complexos furosemida/ $\alpha-C D, / \beta-$ $C D, / \gamma-C D$, /dimetil- $\beta-C D$ e /trimetil- $\beta-C D$, foi determinada como sendo 25,55 , $70,76,76$ e 54\%, respectivamente. Pelas constantes de estabilidade e diagramas de solubilidade de fase, elucidaram a estequiometria do processo de inclusão molecular da furosemida e concluíram que o fármaco forma complexos equimolares com as ciclodextrinas empregadas.

A presença de ciclodextrinas em sistemas de liberação poliméricos pode influenciar os mecanismos pelos quais o fármaco é liberado. Estes oligossacarídeos podem potencializar a liberação, por exemplo, pelo aumento da concentração de espécies difusíveis dentro de uma matriz (Samy \& Safwat, 1994) ou, de outro modo, atuando como agentes formadores de canais ou promotores de hidratação e erosão (Bibby et al., 2000; Hirayama \& Uekama, 1998).

A combinação tecnológica entre ciclodextrinas e sistemas de liberação já foi avaliada em diversos estudos na tentativa de melhorar o perfil de liberação 
dos fármacos (Wang et al., 1993; Giunchedi et al., 1994; Sangalli et al., 2001; Rao et al., 2002; Ikeda et al., 2002; Koester et al., 2003; Vilarnovo et al., 2004; Jug et al., 2004; Ribeiro et al., 2005).

Ikeda et al. (2002) investigaram o efeito da hidroxipropil- $\beta$-ciclodextrina (HP- $\beta-C D)$, não complexada, no perfil de liberação do metropolol por comprimidos à base de misturas ternárias de fármaco, HP- $\beta-C D$ e etilcelulose. Constataram que a velocidade de liberação do metropolol foi dependente da proporção de HP- $\beta-C D$ nos comprimidos. Observaram que, quando presente em pequenas quantidades nas formulações, a HP- $\beta-C D$ foi capaz de retardar a liberação do fármaco, enquanto que grandes porcentagens da mesma propiciaram rápida liberação do metropolol. A menor velocidade de liberação foi observada com a proporção de 30/10/60 p/p de metropolol/HP- $\beta$ $\mathrm{CD} /$ etilcelulose. $\mathrm{O}$ estudo de penetração de água aliado às observações macro e microscópicas sugeriram que o efeito retardante da HP- $\beta-C D$, quando em pequenas proporções, é atribuído à elevação da viscosidade do gel formado na superfície dos comprimidos, funcionando como uma consistente barreira física para a penetração da água nos comprimidos e transposição do fármaco. Concluíram que a combinação de HP- $\beta$-CD com etilcelulose compõe-se de uma alternativa viável para modular a liberação do metropolol.

Vilarnovo et al. (2004) avaliaram o efeito da presença de $\beta$-CD e HP- $\beta-C D$ no comportamento difusional e perfil de liberação do diclofenaco de sódio e da sulfametiazol em géis e comprimidos matriciais preparados com HPMC K4M. A influência das ciclodextrinas na difusão dos fármacos foi particularmente evidente em géis preparados com $2 \%$ de polímero. Nestes sistemas, observaram que 0 excesso de ciclodextrinas livres no meio geleificado, em especial a HP- $\beta-C D$, promoveu a difusão mais facilitada do fármaco pouco solúvel (sulfametiazol) enquanto que dificultou a difusão do diclofenaco de sódio (solúvel). Paralelamente, a crescente proporção de ciclodextrinas na composição dos comprimidos matriciais aumentou proporcional e significativamente a velocidade de liberação do fármaco 
hidrofóbico (sulfametiazol); no entanto, comportamento contrário foi constatado com o fármaco hidrofílico (diclofenaco de sódio). Concluíram que a presença de ciclodextrinas pode ser especialmente útil na modulação da liberação de fármacos por géis e comprimidos de HPMC, dependendo do fármaco empregado e do desempenho de liberação desejado.

Alguns autores sugerem a possível formação de complexos entre fármacos e ciclodextrinas in situ, ou seja, dentro das formas matriciais, uma vez hidratadas pelo meio circundante. Tal complexação seria responsável por aumentar a solubilidade aparente do fármaco, favorecendo sua dissolução e difusão e elevando a sua taxa de liberação (Sangalli et al., 2001; Rao et al., 2002; Ribeiro et al., 2005).

\subsection{Sistemas de liberação de fármacos}

\subsubsection{Considerações gerais}

Os fármacos raramente são administrados em sua forma inata. Geralmente, são associados a excipientes ou adjuvantes farmacotécnicos, que viabilizem sua administração, dando origem às formas farmacêuticas (Ansel et al., 2000).

Uma terapia eficiente só é possivel se o fármaco encontrar-se em seu local de ação em concentração adequada e por um período suficiente. Neste sentido, as formas farmacêuticas exercem papel fundamental na terapêutica, já que são os recursos mais utilizados para tornar os fármacos disponíveis ao organismo (Remignton, 2000).

A quantidade de fármaco presente nos tecidos é conseqüência das velocidades relativas, envolvendo, por um lado, o processo de absorção e, opostamente, os processos de biotransformação e eliminação. O nível do 
fármaco no organismo pode permanecer constante se as velocidades destes processos opostos forem iguais (Prista et al., 1996).

No que diz respeito à absorção entérica, a grande maioria dos fármacos transpõe a membrana do epitélio pelo processo de difusão passiva, ou seja, sem gasto de energia, seguindo um gradiente de concentração, conforme descrito pela primeira Lei de Fick. É, portanto, essencial que o fármaco encontre-se solubilizado ou, em outros termos, esteja disponível no local de absorção para que ocorra a difusão (Ansel et al., 2000; Lordi, 2001).

A velocidade de difusão através da membrana é proporcional à diferença do gradiente de concentração do fármaco, como exemplificado pela equação a seguir:

$$
-d c / d t=p \cdot(C 1-C 2)
$$

na qual:

- $d c / d t=$ velocidade de difusão

- $p=$ coeficiente de permeabilidade

- $C 1$ e $C 2$ = concentração do fármaco em cada lado da membrana

Um dos artifícios usados para alterar a velocidade de absorção de um fármaco é o do controle da sua velocidade de dissolução pela sua incorporação a uma forma farmacêutica apropriada (Prista et al., 1996). Em concordância com este fato, algumas formas são desenvolvidas para liberar o fármaco no organismo de modo rápido e completo (ex. comprimidos e cápsulas de liberação convencional) e outras, no entanto, são formuladas para liberarem o fármaco de maneira contínua e por período de tempo maior após a administração de uma dose, visando-se obter uma ação terapêutica prolongada (Remington, 2000).

Para identificar estas últimas formas citadas, encontram-se na literatura diversas denominações, utilizadas, no entanto, de forma um pouco confusa e 
quase sempre como sinonímias, tais como: liberação controlada, liberação lenta, liberação estendida, liberação modificada, liberação retardada, liberação repetida, liberação sustentada, liberação prolongada e liberação programada. Deste modo, alguns autores tentam esclarecer de maneira mais precisa a real identificação de cada uma destas formas.

A denominação "liberação modificada" é um termo generalista que congrega diversas formas farmacêuticas caracterizadas por prover a liberação do fármaco de modo diferente da forma farmacêutica convencional, geralmente destinada a liberação imediata.

Ansel et al. (2000) sugerem que os termos "liberação prolongada" e "liberação controlada" signifiquem desempenhos diferentes. Nas formas de liberação prolongada, a liberação do fármaco se dá por período de tempo maior quando comparado às formas convencionais. Entretanto, nas de liberação controlada, a velocidade de liberação do fármaco é mantida de maneira mais constante e precisa que nas formas de liberação prolongada.

Collett \& Moreton (2005) definem forma de "liberação sustentada" como aquela capaz de liberar certa quantidade do fármaco assim que administrada, visando atingir a concentração terapêutica, seguida de liberação gradual do fármaco para manutenção desta primeira dose.

As formas de "liberação repetida" são capazes de liberar doses equivalentes do fármaco em intervalos repetidos. Neste tipo de preparação uma dose inicial da droga é imediatamente liberada após a administração, a qual, geralmente, é igual a dose convencional. Depois de certo período, segunda dose, de igual teor, é liberada. Dependendo da formulação e do fármaco, pode-se liberar até uma terceira dose. Invariavelmente, serão observados perfis plasmáticos com "pico e vale", característicos da administração de formas convencionais. A ação repetida é conseguida, por 
exemplo, por meio de cápsulas preenchidas com grânulos/péletes com diferentes tipos de revestimentos, sendo que cada revestimento é capaz de prover liberação do fármaco em intervalos distintos após a administração (Chien, 1992; Lordi, 2001).

Já nas formas de liberação retardada, a liberação do fármaco é intencionalmente postergada por diversos motivos, até que o comprimido ou cápsula atinja uma determinada porção do trato gastrintestinal. Entre os objetivos das formas de liberação retardada estão: 1. proteger o fármaco de sua degradação pelo suco gástrico; 2. proteger a mucosa gástrica da ação irritante do fármaco; 3. propiciar liberação em porções distais do trato gastrintestinal como, por exemplo, o cólon. As formas de liberação retardada também têm sido classificadas como "gastro-resistentes", "liberação entérica" ou ainda de "liberação colônica" (Prista et al., 1996; Lordi, 2001; Collett \& Moreton, 2005).

Segundo a Farmacopéia Americana XXVIII (USP - 2006), os sistemas farmacêuticos de liberação modificada de fármacos apresentam características de liberação em tempo e/ou localização planejada para atingir um objetivo conveniente, o que não é possível se obter com as formas de liberação convencional. Assim, são descritos dois tipos: extended release (liberação estendida), aquela que permite, no mínimo, a redução pela metade do número de administrações em relação à forma convencional, e delayed release (liberação retardada), aquela que não libera o fármaco imediatamente após a administração.

\subsubsection{Fármacos candidatos à incorporação em formas de liberação prolongada}

Nem todos os fármacos são bons candidatos a serem incorporados em formas farmacêuticas de liberação modificada. É importante que a meia-vida 
biológica do fármaco não seja nem muito curta nem muito longa. No caso de fármacos com valores de meia-vida inferiores a duas horas, há necessidade de se incorporar à formulação quantidades muito grandes dos mesmos, de modo a garantir níveis plasmáticos desejados, o que pode aumentar o risco de intoxicação caso haja alguma falha no sistema de liberação. No caso dos fármacos com meia-vida superior a oito horas, a preparação de uma forma de liberação estendida não é justificada, já que a sua atividade é intrinsecamente prolongada (Collett \& Moreton, 2005).

É importante que o fármaco apresente boa margem de segurança, evitando riscos de toxicidade caso ocorra alguma falha na forma farmacêutica que possa ocasionar a liberação excessiva do fármaco. Fármacos com índice terapêutico estreito, no qual a dose terapêutica é muito próxima à dose tóxica, não são bons candidatos à incorporação na forma de liberação modificada (Lordi, 2001).

O fármaco deve apresentar considerável solubilidade e absorção no trato gastrintestinal. Fármacos com biodisponibilidade limitada, como aqueles de bioclassificação IV, com baixa solubilidade e baixa permeabilidade transmembrana, possuem, inerentemente, tempo prolongado de absorção e, portanto, sua incorporação a uma forma farmacêutica de liberação prolongada não se faz justificável (Hite et al., 2003).

Os fármacos devem exibir, também, absorção uniforme em todo o trato gastrintestinal. Aqueles que apresentam absorção em regiões específicas do trato, não devem ser incorporados em uma forma de liberação prolongada, uma vez que poderão ser liberados em local impróprio à sua absorção, levando a ineficácia do tratamento (Ansel et al., 2000).

É importante também que o fármaco apresente boa compatibilidade com os excipientes da formulação, já que problemas de estabilidade da forma 
farmacêutica podem afetar significativamente seu perfil de liberação (Prista et al., 1996).

\subsubsection{Vantagens e desvantagens das formas de liberação prolongada}

Entre as vantagens das formas de liberação prolongada podem-se citar: 1. redução da freqüência de administração, que pode melhorar a comodidade do paciente com redução do risco de esquecimento; 2 . supressão de administrações noturnas ou durante a madrugada; 3. obtenção de níveis plasmáticos mais uniformes $e$, como conseqüência, redução dos efeitos colaterais; 4. menor acúmulo de fármaco no organismo. Conjuntamente, estas vantagens podem melhorar a adesão do paciente ao tratamento, especialmente na terapia crônica, bem como gerar maior economia em longo prazo, já que se diminui consideravelmente o tempo e o pessoal requeridos para dispensar, administrar e monitorar os pacientes (Prista et al., 1996; Ansel et al., 2000; Collett \& Moreton, 2005).

As desvantagens que estas formas podem apresentar são: 1. a quantidade de fármaco numa forma de liberação modificada é duas a quatro vezes maior que nas formas convencionais, o que, em caso de uso inapropriado, pode conduzir à intoxicação; 2 . dificuldade ou impossibilidade de interromper rapidamente a ação farmacológica no caso de falha acidental na administração do produto; 3. no caso de problemas gastrintestinais ou renais, o uso destas formulações é inapropriado; 4. menor flexibilidade no ajuste de doses, sendo pouco indicados em condições agudas; 5 . são geralmente mais custosos por unidade que as formas de liberação convencional (Ansel et al., 2000; Collett \& Moreton, 2005; Prista et al., 1996). 


\subsubsection{Formas farmacêuticas perorais de liberação prolongada}

A administração via oral é a mais usada e conveniente para a administração dos fármacos, sendo os comprimidos as formas farmacêuticas mais empregadas para tal (Ansel et al., 2000).

A grande maioria dos sistemas de liberação prolongada disponíveis no mercado atualmente é destinada à administração oral. Estas formas incluem grânulos revestidos, péletes, comprimidos matriciais, comprimidos revestidos, complexos de troca iônica e bombas osmóticas.

Nos produtos orais de liberação prolongada, a velocidade com a qual o fármaco é liberada pela forma farmacêutica e disponibilizado para absorção pode ser modificada por vários mecanismos, tais como difusão, pressão osmótica e troca iônica (Ansel et al., 2000).

Nas formas farmacêuticas de liberação prolongada, o controle da velocidade de dissolução do fármaco após a administração é de grande relevância; deste modo, características referentes às propriedades físicoquímicas do fármaco, tais como solubilidade, estabilidade, coeficiente de partição, peso molecular e compatibilidade, devem ser consideradas para o desenvolvimento de um sistema de liberação adequado e eficaz (Costa \& Lobo, 2000).

De modo ideal, uma forma farmacêutica oral de liberação prolongada deve garantir a disponibilidade do fármaco durante todo seu trajeto pelo trato gastrintestinal (TGI), sendo capaz de manter-se independente às diferentes condições de $\mathrm{pH}$ e condições enzimáticas (Timmins et al., 1997). 


\subsubsection{Sistema reservatório}

Nos sistemas reservatório, um núcleo geralmente sólido, que contém o fármaco disperso, é envolto por uma membrana polimérica semipermeável, que regula a taxa de liberação do fármaco para seu exterior. Em contato com o meio líquido, a água transpõe a membrana e solubiliza o fármaco contido no núcleo, o qual difunde-se para o exterior uma vez estabelecido um gradiente de concentração dos dois lados da membrana. Estes sistemas podem ser monolíticos ou multiparticulados, como no caso dos péletes (Collett \& Moreton, 2005).

A quantidade de fármaco liberada em função do tempo depende da sua solubilidade, da área, espessura e porosidade da membrana (Rosoff, 1989). De forma alternativa, parte do fármaco pode ser incorporada na camada de revestimento para possibilitar a liberação de uma primeira dose (Chien, 1992).

No sistema reservatório, o revestimento deve ser insolúvel nos fluidos gástrico e intestinal, ser permeável à água e ao fármaco, resistente (para não se erodir) e suficientemente flexível, para possibilitar a possível expansão do núcleo devido à hidratação. Os materiais mais empregados para composição da membrana de revestimento são polímeros plásticos insolúveis (também chamados de agentes filmógenos), agentes modificadores de filme, plastificantes e corantes. Os polímeros insolúveis podem ser de origem semisintética, tais como os derivados de celulose (p.ex. metilcelulose, etilcelulose, hidroxipropilmetilcelulose), e sintética, como os copolímeros do ácido metacrílico, álcool polivinílico, entre outros. Agentes modificadores de membrana, tais como: lactose, trietanolamina, polivinilpirrolidona, polietilenoglicóis sólidos e citrato de magnésio, são utilizados para aumentar a porosidade da membrana. Já os plastificantes, como o citrato de trietila, a triacetina e os derivados da celulose de baixa viscosidade, conferem maior flexibilidade ao revestimento, além de propiciar uma camada mais lisa e 
uniforme (Ansel et al., 2000; Collett \& Moreton, 2005; Chien, 1992; Liberman et al., 1990).

\subsubsection{Sistemas de bomba osmótica}

Os sistemas de bomba osmótica são formas farmacêuticas sofisticadas compostas por um núcleo comprimido envolto por um revestimento semipermeável no qual é produzido um orifício por raio laser, que possibilita a saída do fármaco. Os produtos obtidos com esta tecnologia funcionam pelo princípio de pressão osmótica como nos sistemas reservatórios. A membrana semipermeável possibilita a entrada de água presente nos sucos digestivos, a qual dissolve o fármaco presente no núcleo. A pressão que se desenvolve subseqüentemente força ou bombeia a solução de fármaco para fora através do orifício. As velocidades de penetração da água e afluxo do fármaco são controladas pelas propriedades da membrana, tamanho do orifício e viscosidade da solução formada no núcleo. Apenas o fármaco dissolvido é capaz de passar pelo orifício, ficando o restante retido no interior do dispositivo. Os materiais mais utilizados para constituição da membrana são o álcool polivinílico, acetato de celulose, entre outros (Chien, 1992; Ansel et al., 2000; Collett \& Moreton, 2005).

\subsubsection{Sistemas matriciais}

Os sistemas matriciais estão entre os recursos farmacotécnicos mais utilizados para o desenvolvimento de formas orais de liberação prolongada, devido à simplicidade e rapidez de preparação, baixos custos e flexibilidade na modulação da liberação de diversos fármacos (Prista et al., 1996; Ansel et al., 2000; Lordi, 2001).

São unidades monolíticas compostas por um agente formador de matriz, geralmente insolúvel, no qual o fármaco encontra-se disperso. Ao contrário dos 
comprimidos convencionais, as formas matriciais resistem à desintegração imediata, funcionando como um suporte para o fármaco. Dependendo das características do material suporte, as matrizes têm sido classificadas em três categorias principais: inertes, hidrofóbicas e hidrofilicas (Liberman et al., 1990; Prista et al., 1996; Ansel et al., 2000; Lordi, 2001).

Higuchi (1963) desenvolveu as bases matemáticas que descrevem o processo de liberação do fármaco por estruturas matriciais sólidas, podendo ser definido pela seguinte equação:

$$
Q=\left[D \cdot \varepsilon / \tau\left(2 A-a \cdot C_{s}\right) \cdot C \varepsilon \cdot t\right]^{1 / 2}
$$

na qual:

- $Q=$ quantidade de fármaco liberado no tempo $t$

- $D=$ coeficiente de difusão do fármaco

- $\varepsilon=$ porosidade da matriz

- $\tau=$ fator de tortuosidade

- $A=$ quantidade total de fármaco na matriz

- $C_{s}=$ coeficiente de solubilidade no meio de liberação

- $t=$ tempo

O processo de liberação nos comprimidos matriciais ocorre, principalmente, por conta da passagem do fármaco solubilizado de uma região de elevada concentração (interior do sistema) para outra de baixa concentração (meio circundante). Esse gradiente de concentração é a força motriz para difusão do fármaco dissolvido para fora da matriz. Entende-se, portanto, que o controle da penetração da água no sistema matricial é de grande relevância no controle global de liberação do fármaco (Collett \& Moreton, 2005). 
De modo geral, a quantidade de fármaco liberado por um sistema matricial diminui em função do tempo de exposição ao meio de dissolução. A razão para que isso ocorra é o fato do fármaco ser liberado, inicialmente, a partir de uma região superficial na qual a via de difusão é curta. Conforme progride o processo de dissolução, a área de fármaco exposta ao meio de dissolução diminui, formando-se uma zona de depleção crescente no interior da matriz, o que leva a aumento na extensão e no tempo de percurso de difusão, diminuindo, portanto, a velocidade de liberação (Higuchi, 1963; Colombo et al., 1995).

O grande número de compostos existentes no mercado capazes de modificar a velocidade de liberação de um fármaco abrange substâncias de origem natural, semi-sintética e sintética. Nas últimas décadas, o uso dos polímeros no controle da liberação dos fármacos tem sido de grande importância no desenvolvimento de formas matriciais.

\subsection{Matrizes inertes}

Também chamadas de matrizes plásticas, são consideradas sistemas porosos, desenvolvidos de modo que sua estrutura não se desagregue em contato com meios líquidos, funcionando como um esqueleto para o fármaco. Geralmente, estes comprimidos são designados para serem eliminados intactos, sem sofrerem modificações físicas durante o trajeto pelo trato gastrintestinal. De forma resumida, a liberação do fármaco neste tipo de matriz pode ser atingida em três etapas: 1. penetração dos líquidos dentro dos poros da matriz; 2. dissolução do fármaco e 3 . difusão lenta dentro dos canais formados até o meio de dissolução. Entende-se, portanto, que a solubilidade do fármaco se torna fator limitante para sua incorporação nestes sistemas (Chien, 1992). 
A velocidade de liberação de um fármaco a partir de uma matriz inerte pode ser modificada por mudanças na porosidade e tortuosidade do sistema. A adição de sais ou excipientes solúveis, capazes de aumentar a molhabilidade da matriz além de favorecer a formação de canais, tem influência significativa na liberação do fármaco. Variáveis de processo de fabricação, como a força de compressão e tamanho de partícula do material suporte, também possuem grande relevância. De modo geral, uma matriz mais rígida e menos porosa libera o fármaco mais lentamente que uma matriz menos consolidada (Gabr, 1992).

Os excipientes mais usados na obtenção destas são: derivados de polietileno, derivados de poliamida, cloreto de polivinilo, polivinilacetato, fosfato de cálcio, etilcelulose e copolímeros acrílicos, caracterizados por sua inércia em termos de hidrofilicidade. As matrizes inertes são obtidas principalmente por compressão direta, sendo que a granulação a seco é pouco usada (Liberman et al., 1990).

Lafuente et al. (2002) prepararam, por compressão direta, comprimidos matriciais inertes para liberação prolongada de didanosina. Utilizaram misturas, em diferentes proporções, de uma resina metracrílica (Eudragit ${ }^{\circledR} R S$ ) e etilcelulose (Ethocel ${ }^{\circledast}$ 100), ambos insolúveis e pH-independentes. Os resultados mostraram a viabilidade da combinação dos polímeros na modificação da velocidade e na extensão de liberação da didenosina.

Kranz \& Wagner (2005) utilizaram uma mistura de polivilacetato e polivinilpirrolidona, em proporção de 8:1, para propiciar a liberação prolongada de um novo fármaco, antagonista do receptor humano de quimiocina, por um período de dez horas. Constataram que a presença de um acidificante interno (ácido fumárico) foi suficiente para propiciar liberação $\mathrm{pH}$ independente. Observaram, também, que a adição de diluentes solúveis, como lactose e amido pré-gelatinizado, aumentou significativamente a velocidade de liberação 
do fármaco e que o processo de compressão direta resultou em maior liberação do fármaco em comparação à granulação via úmida quanto ao perfil de dissolução do fármaco.

\subsection{Matrizes hidrofóbicas}

Também conhecidas como matrizes graxas ou cerosas, estas são constituídas por diferentes excipientes lipídicos que incluem mono, di e triglicerídeos, ácidos e álcoois graxos, ésteres diversos e ceras de origem natural, como de abelha e de carnaúba. Nessas matrizes, o processo de liberação pode ocorrer por dois mecanismos concomitantes, começando com a difusão do princípio ativo dentro do núcleo poroso e depois pela erosão da matriz pela ação das lipases (Buri, 1984).

A liberação total ou completa dos fármacos nelas contidos não é possivel se certa porcentagem do fármaco ficar recoberta com um filme graxo impermeável. Portanto, a liberação é mais facilmente controlada com a adição de tensoativos, os quais promovem a penetração de água e melhoram a dissolução do fármaco (Buri, 1984; Liberman et al., 1990).

Essas matrizes podem ser obtidas por diversas formas, por exemplo, utilizando-se a técnica de evaporação do solvente. Neste caso, a solução ou dispersão que contém o fármaco e os aditivos é incorporada na fase graxa fundida e, conseqüentemente, o solvente é removido por evaporação. Outra forma de prepará-las é usando a técnica de fusão, a qual permite obter uma dispersão mais uniforme, na qual o fármaco e os aditivos são misturados à matriz graxa fundida, à uma temperatura ligeiramente superior à temperatura de fusão da graxa (Buri, 1984; Liberman et al., 1990). 


\subsection{Matrizes hidrofílicas}

As matrizes hidrofílicas recebem esta denominação pela capacidade que suas estruturas possuem de hidratar-se e formar barreiras intumescidas $e$ geleificadas (Salsa et al., 1997; Collett \& Moreton, 2005).

A aplicação dos polímeros hidrofílicos, individualmente ou misturados, tem sido muito comum no controle da velocidade de liberação dos fármacos a partir de formas sólidas. A sua facilidade de compressão, a habilidade de acomodar grandes quantidades de fármaco e a influência mínima exercida pelas variáveis do processo nas velocidades de liberação são as principais razões para a sua popularidade (Veiga, 1988; Velasco et al., 1999).

Como suporte das formas de liberação prolongada, as matrizes hidrofílicas apresentam vantagens similares às anteriores, não só quanto à sua tecnologia, mas também no que se refere ao processo de liberação. Elegendose adequadamente o agente geleificante e adaptando-se a formulação às propriedades físico-químicas do fármaco, a liberação não é influenciada por parâmetros fisiológicos, tais como $\mathrm{pH}$, motilidade do trato gastrintestinal, força iônica e composição enzimática dos sucos digestivos (Veiga, 1988; Salsa et al., 1997).

O mecanismo de liberação do fármaco nesse tipo de sistema envolve o intumescimento do agente formador de matriz, formação de gel, dissolução do fármaco e difusão do mesmo pela barreira geleificada, a qual se opõe à rápida liberação da molécula. A viscosidade da barreira tem, portanto, grande influência neste processo. As camadas mais externas do gel formado podem também se dissolver, dependendo do polímero, propiciando outra frente de liberação do fármaco (Veiga, 1988; Salsa et al., 1997; Collett \& Moreton, 2005). 
A velocidade de liberação do fármaco a partir das formas matriciais pode ser constante se as frentes de intumescimento e dissolução do gel forem sincronizadas, propiciando uma cinética de liberação de ordem zero. No entanto, se os dois processos não forem concomitantes, observa-se uma cinética não linear, caracterizada pela diminuição da velocidade de liberação do fármaco em função do tempo (Pather et al., 1997; Colombo et al., 1995).

Se o fármaco possui solubilidade limitada, significa que não se dissolve completamente durante a hidratação do polímero e, portanto, sua liberação ocorre, preferencialmente, pela erosão ou dissolução da estrutura matricial (Mehta et al., 2001; Collett \& Moreton, 2005).

No primeiro contato com os fluidos digestivos, pequena fração do fármaco pode ser rapidamente dissolvida, já que a hidratação e a geleificação do polímero ocorre de forma progressiva, dando lugar à formação de uma estrutura viscosa que constitui a matriz. Enquanto a camada gelatinosa estiver intacta, a liberação do fármaco ocorre principalmente pela difusão do fármaco solubilizado e não pela dissolução da estrutura matricial. Entende-se, portanto, que a solubilidade do fármaco em água é muito relevante nessas formas farmacêuticas (Colombo et al., 1995; Collett \& Moreton, 2005).

As matrizes hidrofílicas podem ser preparadas pelos métodos gerais de obtenção de comprimidos. A compressão direta é usada quando as partículas do agente geleificante apresentam propriedades de coesão e fluidez suficientes. A granulação por via úmida é realizada usando um umidificante de natureza alcoólica, visto que as soluções aquosas podem propiciar misturas com características aderentes de difícil manipulação. A granulação por via seca é pouco empregada (Liberman et al., 1990).

Inúmeros fatores podem alterar a velocidade de liberação do fármaco contido nos comprimidos matriciais hidrofílicos, entre os principais, citam-se: 1. 
concentração do agente formador de matriz; 2. natureza do agente formador de matriz; 3. peso molecular do agente formador de matriz, 4. granulometria do agente formador de matriz; 5 . granulometria e solubilidade do fármaco; 6 . mistura de polímeros; 7. força de compressão; 8 . formato e espessura do comprimido; 9. ar retido na estrutura do comprimido; 10. adição de lubrificante; 11. presença de adjuvantes solúveis ou insolúveis e 12. presença de agentes acidificantes ou alcalinizantes (Veiga, 1988; Huang \& Shwartz, 1995).

Os materiais mais encontrados na literatura para formação de matrizes hidrofílicas estão listados a seguir:

a) Derivados de celulose:

- Metilcelulose

- Hidroxietilcelulose

- Hidroxipropilmetilcelulose

- Carboximetilcelulose sódica

b) Polissacarídeos não celulósicos:

- Galactomanoses

- Goma guar

- Goma karaya

- Alginato de sódio e de potássio

- Ágar-ágar

- Goma arábica

- Pectinas e pectinatos

c) Polímeros sintéticos:

- Carbopol ${ }^{\circledR} 934 p$ (derivado do ácido metacrílico)

- Poliox ${ }^{\circledR}$ (derivado de polietileno)

- Kolidon ${ }^{\circledast}$ SR (poliviniacetato/polivilpirrolidona) 
Os agentes formadores de matrizes derivados da celulose apresentam-se na forma sólida e, em função de características, como ramificações, grupos químicos presentes e forma cristalina das partículas, têm diferentes comportamentos durante o processo de intumescimento. Possuem natureza não iônica, o que minimiza a influência do $\mathrm{pH}$ no seu comportamento (Reynolds et al., 1998).

Dentre os materiais geleificantes de natureza celulósica, a hidroxipropilmetilcelulose (HPMC) é dos mais utilizados. O Methocel ${ }^{\circledR}$, como é conhecido comercialmente, é um éter semi-sintético derivado de celulose, não tóxico e não iônico. É solúvel em água e, quando disperso, é capaz de modificar o comportamento reológico dos meios nos quais é incorporado, sendo que variações do $\mathrm{pH}$ não afetam sua viscosidade. Apresenta fácil compressibilidade e capacidade de incorporar grandes quantidades de fármaco. A HMPC caracteriza-se de acordo com a natureza dos substituintes, seu grau de substituição e viscosidade nominal. Apresenta diferentes graus de hidratação, em decorrência dos graus de substituição, identificados pelas letras $\mathrm{E}, \mathrm{F}$ e K. O tipo $\mathrm{K}$ é o mais indicado para preparação de matrizes devido à sua rápida hidratação, a qual é essencial para a imediata formação de uma camada homogênea de gel e retenção do fármaco (Colorcon, 2000). 
Tabela 3. Classificação do Methoce ${ }^{\circledast}{ }^{\text {(HPMC) }}$ de acordo com o grau de viscosidade (Colorcon, 2000)

\begin{tabular}{cc}
\hline Tipo & Viscosidade* $(\mathbf{c P})$ \\
\hline E5 & 5 \\
E15 & 15 \\
E50 & 50 \\
E4M & 4.000 \\
F50 & 50 \\
F4M & 4.000 \\
K100 & 100 \\
K4M & 4.000 \\
K15M & 15.000 \\
K100M & 100.000 \\
\hline
\end{tabular}

* viscosidade nominal de solução aquosa a $2 \%$, a $20^{\circ} \mathrm{C}$.

Hoje é grande o número de trabalhos encontrados na literatura que descrevem a aplicação dos derivados de celulose para obtenção de matrizes hidrofílicas.

Ford et al. (1985) estudaram a importância da solubilidade do fármaco, concentração do diluente e forma do comprimido usado, na cinética de liberação da aminofilina ou do propanolol a partir de matrizes de HPMC. Verificaram que as formulações contendo o fármaco pouco solúvel (propanolol) desempenharam velocidade de liberação inferior em comparação àquelas que continham o fármaco solúvel (aminofilina). Observaram, também, que o aumento da porcentagem de contribuição do diluente solúvel nas matrizes provocou elevação da velocidade de liberação dos fármacos. Quanto à forma do comprimido, constataram que as matrizes esféricas apresentaram liberação mais linear dos fármacos. 
Baveja \& Ranga (1986) desenvolveram comprimidos matriciais de liberação prolongada de centperazina à base de HPMC e carboximetilcelulose (CMC). Observaram que a proporção 1:0,7:4:4 de centperazina, aerosil 200, HPMC e CMC foi a melhor composição dentre as formulações testadas, sendo capaz de prover liberação linear do fármaco por um período de 12 horas. Notaram uma relação não linear entre a dureza e a liberação do fármaco pelas matrizes testadas, sugerindo a independência deste tipo de sistema frente à força de compressão.

Xu \& Sunada (1995) observaram que o aumento da proporção de HPMC levou à diminuição da taxa de liberação da indometacina por comprimidos matriciais. Tal resultado foi justificado pelo aumento do caminho difusional e viscosidade da barreira nas matrizes com maior concentração de polímero, diminuindo a quantidade de fármaco liberado.

Smal et al. (1996) obtiveram uma liberação prolongada e pHindependente da furosemida a partir de matrizes de HPMC. No estudo, visouse o desenvolvimento de comprimidos eficientes para administração em cães, nos quais se observa prolongado período de residência gástrica. Os autores utilizaram o carbonato de cálcio como agente alcalinizante e observaram que o mesmo foi suficiente para se manter $\circ \mathrm{pH}$ do microambiente matricial em condições propícias à dissolução, difusão e liberação da furosemida em meio ácido. Paralelamente, estudos in vivo empregando-se furosemida carbonomarcada e técnicas radiológicas demostraram que 0 fármaco foi adequadamente liberado no ambiente gástrico pelos comprimidos desenvolvidos, em concordância com as observações de liberação in vitro.

Ishikawa et al. (2000) avaliaram a influência da adição de Macrogol ${ }^{\circledR}$ 6.000 no perfil de liberação do nifedipino, fármaco de baixa solubilidade, por comprimidos matriciais de HMPC. Verificaram que o aumento crescente da proporção de Macrogol ${ }^{\circledR}$ elevou a velocidade e a extensão de liberação do 
fármaco, por acentuar o processo de erosão da matriz, propiciando cinética de liberação de ordem zero.

Rao et al. (2002), trabalhando com matrizes hidrofilicas à base de HPMC $\mathrm{K} 15 \mathrm{M}$ e K100, constataram que a presença de sulfobutiléter-7- $\beta$-ciclodextrina, como mistura física ou complexada ao fármaco, teve influência significativa no aumento da velocidade e extensão de liberação da prednisolona. Os resultados com a ciclodextrina foram superiores àqueles com lactose e sucrose como promotoras de liberação. Formulações contendo mistura física do fármaco com a ciclodextrina foram tão eficientes quanto àquelas contendo os complexos de inclusão na melhoria do perfil de liberação da prednisolona pelos comprimidos testados. Os autores atribuíram tal performance à complexação do fármaco com a ciclodextrina in situ.

Ribeiro et al. (2005) avaliaram o efeito da complexação multicomponente da vimpocetina, fármaco álcali-insolúvel, com $\beta$-ciclodextrina ( $\beta-C D$ ) ou sulfobutiléter- $\beta$-ciclodextrina (SBE- $\beta-C D$ ), ácido tartárico (agente acidificante), polivinilpirrolidona (PVP) ou HPMC, alternativamente, na performance de liberação do fármaco, sob variação de $\mathrm{pH}$, a partir de matrizes hidrofílicas à base de HPMC. Observaram que a complexação múltipla com os diversos componentes foi capaz de otimizar a liberação do fármaco, com destaque para as formulações contendo multicomplexos vimpocetina-ciclodextrina-ácido tartárico, as quais apresentaram a melhor eficiência de dissolução dentre todas as testadas, provendo, inclusive, perfis de liberação independentes do $\mathrm{pH}$. A extensão de liberação da vimpocetina foi menor nos comprimidos preparados com ácido tartárico isoladamente, comparada aos comprimidos contendo as ciclodextrinas (CD). Concluíram que comprimidos à base de HPMC foram eficientes para prolongar a liberação da vimpocetina, e que as características de dissolução em diferentes $\mathrm{pH}$ podem ser moduladas pela complexação multicomponente do fármaco. 
3. OBJETIVOS 


\subsection{Objetivo geral}

Investigar a influência da complexação da furosemida, ou sua simples mistura, com duas ciclodextrinas no perfil de liberação in vitro do fármaco a partir de comprimidos matriciais hidrofílicos à base de um derivado celulósico, desenvolvidos com intuito de modular, adequadamente, a liberação da furosemida por um período de oito horas.

\subsection{Objetivos específicos}

A) Preparar e caracterizar complexos de inclusão entre furosemida e as ciclodextrinas empregadas.

B) Preparar e avaliar comprimidos de liberação prolongada contendo complexos de inclusão ou misturas físicas de furosemida e as ciclodextrinas empregadas.

C) Determinar o perfil e a cinética de liberação da furosemida in vitro a partir de diferentes formulações.

D) Avaliar a influência da complexação ou da mistura da furosemida com as ciclodextrinas no perfil de liberação do fármaco. 
4. MATERIAL E MÉTODOS 


\subsection{Material}

\subsubsection{Matérias-primas}

Todas as matérias-primas empregadas apresentavam grau farmacêutico e estão listadas a seguir:

- Furosemida (Ipca Labs - Índia)

- Hidroxipropilmetilcelulose - Methoce ${ }^{\circledR}$ K4M CR (Colorcon - EUA)

- $\beta$-ciclodextrina - Cavamax ${ }^{\circledR}$ W7 (Wacker - Alemanha)

- 2-hidroxipropil- $\beta$-ciclodextrina - Cavasol ${ }^{\circledR}$ W7 (Wacker - Alemanha)

- Celulose Microcristalina tipo 102 - Vivapur ${ }^{\circledR}$ (JKS - Alemanha)

- Lactose monohidratada - Flowlac ${ }^{\circledR} 100$ (Meaggle - Alemanha)

- Estearato de Magnésio Vegetal (Casa Americana - Brasil)

\subsubsection{Substância de referência}

Empregou-se, como padrão nas determinações analíticas, furosemida com teor de pureza de 99,34\%, produzida pela Ipca Labs (Lote: $3063 \mathrm{HRII}$ ).

\subsubsection{Reagentes}

Todos os reagentes empregados apresentavam grau analítico e estão listados a seguir:

- Metanol PA (Synth)

- Etanol Absoluto PA (Synth)

- Hidróxido de sódio PA (Merck)

- Ácido Clorídrico PA (Casa Americana)

- Fosfato de sódio dibásico anidro (Casa Americana)

- Fosfato de sódio monobásico anidro (Casa Americana) 
- Silicagel com indicador (Synth)

- Brometo de potássio (Merck)

\subsubsection{Equipamentos}

- Balança analítica eletrônica (Sartorius - Alemanha)

- Balança semi-analítica (Ohaus - EUA)

- Agitador magnético (Fisatom - Brasil)

- Dissolutor (Hanson Research Corp. D-800 - EUA)

- Dissolutor BioDis (Vankel - EUA)

- Espectrofotômetro (Beckman Coulter DU-640 - EUA)

- Friabiliômetro (Ética - Brasil)

- Compressora excêntrica com punções planas de 11,0mm (FABBE - Brasil)

- Durômetro (Nova-Ética Mod. 298 - Brasil)

- Tamis com abertura de 0,250 mm (Granutest - Brasil)

- Almofariz automático (MLV - Alemanha)

- Roto-evaporador (Tecnal - Brasil)

- Equipamento de análise térmica (Shimadzu DSC-50 - Japão)

- Espectrofotômetro Infravermelho (Bomem FT-IR, série Michelson - EUA)

- Prensa manual (Carver - EUA)

- Equipamento liofilizador (Christ Alpha 1-2 - Alemanha)

\subsection{Métodos}

\subsubsection{Obtenção de complexos de inclusão de furosemida}

\subsubsection{Malaxagem}

Para preparação de 3 gramas de uma mistura binária equimolar (1:1) de furosemida e ciclodextrina procedeu-se do seguinte modo: pesaram-se em balança analítica $0,677 \mathrm{~g}$ de furosemida $(P M=330,77 \mathrm{~g} / \mathrm{mol})$ e $2,323 \mathrm{~g}$ de $\beta$ - 
$C D(P M=1135 \mathrm{~g} / \mathrm{mol})$. Em seguida, transferiu-se a $\beta$-CD para $\circ$ almofariz automático e adicionaram-se $5 \mathrm{~mL}$ de solução hidroalcoólica $(50: 50 \mathrm{v} / \mathrm{v})$, sendo a pasta resultante malaxada por 30 minutos. Na seqüência, a furosemida foi adicionada em 6 pequenas porções com simultânea adição de $1 \mathrm{~mL}$ de solvente sob malaxagem constante. Procedeu-se com o processamento da pasta resultante por um período de 3 horas. A mistura foi levada à completa secagem em equipamento roto-evaporador a $60^{\circ} \mathrm{C}$. Depois de seco, o material sólido foi removido da parede interna do balão de vidro sendo, em seguida, pulverizado manualmente com auxílio de grau e pistilo e dessecado sob sílica gel por 24 horas. Do mesmo modo, procedeu-se com a mistura de furosemida e HP- $\beta$-CD $(P M=1300 \mathrm{~g} / \mathrm{mol}$ ). Para tanto, foram pesadas $0,607 \mathrm{~g}$ de furosemida e $2,393 \mathrm{~g}$ de $\mathrm{HP}-\beta-\mathrm{CD}$.

\subsubsection{Liofilização}

Para preparação de $3 \mathrm{~g}$ de mistura binária equimolar (1:1) de furosemida e ciclodextrina procedeu-se do seguinte modo: foram preparados $100 \mathrm{~mL}$ de uma solução etanólica de furosemida a $2,05 \times 10^{-4} \mathrm{M}$ e $200 \mathrm{~mL}$ de uma solução aquosa de $\beta$-CD a $1,023 \times 10^{-2} \mathrm{M}$. As soluções de furosemida e $\beta$-CD foram misturadas em balão de fundo chato e deixadas sob agitação durante 12 horas. Em seguida, promoveu-se a remoção do solvente alcoólico por rotoevaporação a $60^{\circ} \mathrm{C}$. A solução restante foi então congelada com auxílio de nitrogênio líquido e liofilizada a $-40^{\circ} \mathrm{C}$. Depois de seco, o material sólido foi removido da parede interna do balão de vidro sendo, em seguida, pulverizado manualmente com auxílio de grau e pistilo e dessecado sob sílica gel por 24 horas. Do mesmo modo, procedeu-se com a mistura de furosemida e HP- $\beta-C D$. Para tanto, foram preparados $100 \mathrm{~mL}$ de uma solução etanólica de furosemida a $1,84 \times 10^{-4} \mathrm{M}$ e $200 \mathrm{~mL}$ de uma solução aquosa de HP- $\beta-C D$ a $0,92 \times 10^{-2} \mathrm{M}$. De modo a excluir a influência do processo, submeteu-se a furosemida pura às mesma condições de processamento, acima descrito. 


\subsubsection{Mistura física}

Para preparação de $3 \mathrm{~g}$ de mistura binária equimolar (1:1) de furosemida e ciclodextrina procedeu-se do seguinte modo: pesaram-se em balança analítica $0,677 \mathrm{~g}$ de furosemida e 2,323 $\mathrm{g}$ de $\beta-C D$. Em seguida, as quantidades foram acondicionadas em recipiente plástico de $200 \mathrm{~mL} e$ misturadas manualmente por 15 minutos, seguida de pulverização em tamis de malha 60 (ABNT) e agitação por mais 15 minutos. Do mesmo modo, procedeuse com a mistura de furosemida e HP- $\beta-C D$. Para tanto, foram pesadas $0,607 \mathrm{~g}$ de furosemida e 2,393 $\mathrm{g}$ de HP- $\beta-C D$.

\subsubsection{Caracterização dos complexos de inclusão de furosemida}

\subsubsection{Teor de furosemida}

Para determinação do teor de furosemida nos produtos de processamento com ambas ciclodextrinas, procedeu-se do seguinte modo: 1 . pesou-se, em balança analítica, quantidade de pó equivalente a 50,0 mg de furosemida; 2. transferiu-se a amostra para um balão volımétrico de $100 \mathrm{~mL} e$ adicionou-se hidróxido de sódio 1M; 3. agitou-se por 30 min e completou-se o volume; 4. diluiu-se a solução com tampão fosfato $0,05 \mathrm{M} \mathrm{pH} 6,8$ até a concentração de $5 \mu \mathrm{g} / \mathrm{mL}$; 5. paralelamente, preparou-se o padrão nas mesmas condições; 6. executou-se a quantificação do fármaco por espectrofotometria a $276 \mathrm{~nm}$.

As análises foram realizadas em triplicata e calculou-se o teor de furosemida pela seguinte equação:

$$
T \%=C \times F d \times V d \times 100 / 50
$$

na qual: 
- $T \%=$ teor em porcentagem

- $C=$ concentração do fármaco na solução de leitura $(\mathrm{mg} / \mathrm{mL})$

- $F d=$ fator de diluição das alíquotas (igual a 1 caso não houve diluição)

- $V d=$ volume do meio de dissolução $(\mathrm{mL})$

\subsubsection{Ensaios termoanalíticos}

De maneira a avaliar a formação de complexos entre o fármaco e as ciclodextrinas pelas técnicas acima descritas, amostras de furosemida, $\beta-C D$, $H P-\beta-C D$, mistura física, produto de malaxagem e do produto de liofilização foram submetidas, em triplicata, à análise por calorimetria diferencial exploratória (DSC). Para tanto, empregou-se a célula DSC-50 (Shimadzu) no intervalo de temperatura de 25 a $300{ }^{\circ} \mathrm{C}$. Utilizou-se cápsulas de alumínio hermeticamente fechadas, massa de amostra de aproximadamente $3,0 \mathrm{mg}$, razão de aquecimento de $10^{\circ} \mathrm{C} / \mathrm{min}$ e atmosfera dinâmica de nitrogênio com vazão de $50 \mathrm{~mL} / \mathrm{min}$.

\subsubsection{Espectrofotometria na região do infravermelho}

De maneira a avaliar a formação de complexos entre o fármaco e as ciclodextrinas pelas técnicas acima mencionadas, amostras de furosemida, $\beta$-ciclodextrina, hidroxipropil- $\beta$-ciclodextrina, mistura física, produto de malaxagem e do produto de liofilização foram submetidas, em triplicata, à análise espectrofotométrica na região do infravermelho (IV), no intervalo de 4.600-400 $\mathrm{cm}^{-1}$. Para tanto, empregou-se equipamento espectrofotômetro Perkin-Elnmer modelo e prensa manual para preparo de pastilhas de $\mathrm{KBr}$.

\subsubsection{Ensaios de dissolução dos complexos de inclusão}

Os estudos de dissolução do fármaco puro, da mistura física, do produto de malaxagem e do produto de liofilização complexo de inclusão foram 
realizados em equipamento dissolutor baseado nas indicações da USP XXVIII (2006) utilizando-se aparato 2 (pá).

Amostras de $60 \mathrm{mg}$ do fármaco puro ou sua quantidade equivalente em mistura binária com as ciclodextrinas foram acrescentadas às cubas de dissolução contendo $900 \mathrm{~mL}$ de meios $\mathrm{HCl} 0,1 \mathrm{~N} \mathrm{pH} \mathrm{1,2;} \mathrm{tampão} \mathrm{fosfato} \mathrm{0,05} \mathrm{M}$ $\mathrm{pH} 4,5$ ou tampão fosfato $0,05 \mathrm{M} \mathrm{pH} 6,8$, desgaseificados, sob agitação de 50 rpm a $37 \pm 0,5^{\circ} \mathrm{C}$. Este estudo foi realizado no tempo total de $60 \mathrm{~min}$, sendo que alíquotas de $2 \mathrm{~mL}$ dos meios de dissolução foram retiradas em intervalos de $5,10,15,20,30,45$ e 60 min e imediatamente repostas por igual volume do meio correspondente. Todas as amostras foram avaliadas em triplicata.

As alíquotas foram filtradas em membrana de poro de $0,2 \mathrm{~mm}$ e, em seguida, quantificadas por espectrofotometria na região do UV em $274 \mathrm{~nm}$, para meio $\mathrm{HCl} 0,1 \mathrm{~N} \mathrm{pH} \mathrm{1,2,} \mathrm{e} 276 \mathrm{~nm}$, para os meios tampão fosfato $0,1 \mathrm{M} \mathrm{pH}$ 4,5 e tampão fosfato $0,05 \mathrm{M} \mathrm{pH} \mathrm{6,8}$. $O$ método foi devidamente validado conforme item 4.2.6.

Os perfis de dissolução foram estabelecidos pela construção de curvas da porcentagem cumulativa de fármaco dissolvido contra o intervalo de tempo correspondente, com auxílio do programa Microsoft Excel ${ }^{\circledast}$.

\subsubsection{Obtenção dos comprimidos matriciais}

Para o preparo dos comprimidos matriciais de furosemida, empregou-se a hidroxipropilmetilcelulose K4M (HPMC K4M) como agente formador de matriz, a celulose microcristalina (CM 102) como diluente, o estearato de magnésio vegetal (Est. $\mathrm{Mg}$ ) como lubrificante $\mathrm{e}$, alternativamente, como promotores de liberação, $\beta$-ciclodextrina $(\beta-C D)$, hidroxipropil- $\beta$-ciclodextrina (HP- $\beta-C D)$, complexadas ou em mistura física com o fármaco, e lactose monohidratada. 
Os comprimidos matriciais foram produzidos com peso final de $500 \mathrm{mg}$, de maneira a conter $50 \mathrm{mg}$ de furosemida, como segue.

Pesaram-se em balança semi-analítica as devidas quantidades dos componentes das formulações. Estes foram acondicionados em recipiente plástico de 0,5 L, com exceção do estearato de magnésio, e procedeu-se com a homogeneização manual por 10 minutos. Em seguida, tamisou-se a mistura em malha de $0,250 \mathrm{~mm}$, de maneira a reduzir a agregação eletrostática. Adicionou-se, em seguida, o estearato de magnésio e procedeu-se com agitação por mais 5 minutos.

Lotes de $20 \mathrm{~g}$ por formulação foram preparados por compactação direta em máquina excêntrica utilizando-se punções planas de $11 \mathrm{~mm}$. Procurou-se manter a dureza dos comprimidos próxima a $8 \mathrm{Kgf}$.

\subsubsection{Formulações}

As formulações dos comprimidos matriciais avaliados estão descritas na Tabela 3. Nas formulações A1, A2 e A3 variou-se a concentração do agente formador de matriz (HPMC) em 15, 25 e $35 \%(p / p)$, respectivamente. As formulações das séries $B, C$ e D foram preparadas de modo a conter $25 \%(p / p)$ de HPMC. As formulações B1, B2 e B3 foram preparadas contendo, respectivamente, 20,40 e $60 \%(p / p)$ de $\beta-C D$, adicionada como mistura física, de maneira a prover proporções molares de aproximadamente $0,5: 1 ; 1: 1 \mathrm{e}$ $1,5: 1$ com relação à quantidade de furosemida. As formulações $C 1, C 2$ e C3 foram preparadas contendo, respectivamente, 20,40 e $60 \%$ (p/p) de HP- $\beta-C D$, adicionada como mistura física, de maneira a prover proporções molares de aproximadamente $0,5: 1 ; 1: 1$ e 1,5:1 com relação à quantidade de furosemida. Nas formulações da série $D$ variaram-se as concentrações de lactose monohidratada em 20, 40 e $60 \%$ (p/p). Nas formulações B2c e C2c, a furosemida encontra-se complexada à $\beta-C D$ e à $H P-\beta-C D$ respectivamente, na proporção aproximada de $40 \%(\mathrm{p} / \mathrm{p})$ do peso da formulação correspondente. 
Tabela 4. Composição percentual das formulações dos comprimidos matriciais avaliados

\begin{tabular}{|c|c|c|c|c|c|c|c|}
\hline \multirow[b]{2}{*}{ Código } & \multicolumn{7}{|c|}{ Porcentagem de contribuição dos componentes da formulação } \\
\hline & $\begin{array}{c}\text { HPMC } \\
\text { K4M }\end{array}$ & Furosemida & $\beta-C D$ & $H P-\beta-C D$ & Lactose & Est. Mg & CM 102 \\
\hline A1 & 15 & 10 & 0 & 0 & 0 & 0,5 & 74,5 \\
\hline $\mathrm{A} 2$ & 25 & 10 & 0 & 0 & 0 & 0,5 & 64,5 \\
\hline $\mathbf{A} 3$ & 35 & 10 & 0 & 0 & 0 & 0,5 & 54,5 \\
\hline B1 & 25 & 10 & 20 & 0 & 0 & 0,5 & 44,5 \\
\hline B2 & 25 & 10 & 40 & 0 & 0 & 0,5 & 24,5 \\
\hline B3 & 25 & 10 & 60 & 0 & 0 & 0,5 & 4,5 \\
\hline C1 & 25 & 10 & 0 & 20 & 0 & 0,5 & 44,5 \\
\hline $\mathrm{C} 2$ & 25 & 10 & 0 & 40 & 0 & 0,5 & 24,5 \\
\hline C3 & 25 & 10 & 0 & 60 & 0 & 0,5 & 4,5 \\
\hline D1 & 25 & 10 & 0 & 0 & 20 & 0,5 & 44,5 \\
\hline D2 & 25 & 10 & 0 & 0 & 40 & 0,5 & 24,5 \\
\hline D3 & 25 & 10 & 0 & 0 & 60 & 0,5 & 4,5 \\
\hline \multicolumn{8}{|c|}{ Formulações contendo complexo de inclusão furosemida/ciclodextrina } \\
\hline B2c & 25 & 10 & 40 & 0 & 0 & 0,5 & 24,5 \\
\hline C2c & 25 & 10 & 0 & 40 & 0 & 0,5 & 24,5 \\
\hline
\end{tabular}

\subsubsection{Ensaios de dissolução dos comprimidos}

\subsubsection{Determinação dos perfis de dissolução da furosemida em meio tampão fosfato $\mathrm{pH} \mathrm{6,8}$}

Seis réplicas de comprimido por formulação foram submetidas a ensaio de dissolução em equipamento dissolutor, utilizando-se aparato 2 (pá) da USP XXVIII (2006), em $900 \mathrm{~mL}$ de meio de dissolução tampão fosfato $0,05 \mathrm{M} \mathrm{pH} 6,8$ desgaseificado a $100 \mathrm{rpm}$ e $37 \pm 0,5{ }^{\circ} \mathrm{C}$ por um período contínuo de 8 horas, sob condições sink ( $\leq 10 \%$ da concentração de saturação do fármaco). 
Alíquotas de $2 \mathrm{~mL}$ foram retiradas em intervalos de $15,30,60,120,180$, $240,300,360,420$ e 480 minutos, sendo imediatamente repostas por igual volume de meio. Depois de retiradas, as alíquotas foram filtradas em membrana com poro de $0,2 \mathrm{~mm}$.

A quantidade de fármaco dissolvida foi determinada na região do ultravioleta, em comprimento de onda fixo de $276 \mathrm{~nm}$, utilizando-se equipamento espectrofotômetro e cubeta de quartzo com caminho óptico de 10 $\mathrm{mm}$. As amostras foram devidamente diluídas, quando necessário, de maneira a contemplar o intervalo de linearidade do ensaio. O método de quantificação foi devidamente validado conforme descrito no item 4.2.6.

As concentrações do fármaco dissolvido foram calculadas a partir das absorbâncias determinadas e da curva de calibração da furosemida. A porcentagem de furosemida dissolvida nos diferentes intervalos foi calculada com a seguinte fórmula:

$$
\% \text { dissolvida }=C \times F d \times V d \times 100 / m
$$

na qual:

- $C=$ concentração do fármaco na solução de leitura $(\mathrm{mg} / \mathrm{mL})$

- $F d=$ fator de diluição das alíquotas (igual a 1 caso não haja diluição)

- $\quad V d=$ volume do meio de dissolução $(\mathrm{mL})$

- $m=$ massa do fármaco por amostra (mg)

Os perfis de dissolução da furosemida a partir dos comprimidos matriciais foram estabelecidos pela construção de curvas de porcentagem cumulativa de fármaco dissolvido contra o intervalo de tempo em minutos, com auxílio do software Microsoft Exce ${ }^{\circledR}$. 


\subsubsection{Determinação da eficiência de dissolução da furosemida}

A eficiência de dissolução do fármaco (ED\%) foi determinada pela razão entre a área sob a curva de dissolução entre os tempos zero e 480 minutos (ASC 0-480), calculada empregando-se o método dos trapezóides, e a área total do gráfico (superfície) definido pela ordenada (100\% de dissolução) e pela abscissa ( $t=480$ minutos) (Khan \& Rhodes, 1975).

As ED\% da furosemida, a partir das diferentes formulações, foram calculadas empregando-se a seguinte fórmula:

$$
E D \%=A S C / A_{\text {tot. }} \times 100
$$

na qual:

- $E D \%=$ eficiência de dissolução

- $A S C=$ área sob a curva de dissolução no intervalo de tempo avaliado

- $A_{t o t}=$ área total do gráfico (superfície) definido pela ordenada e abscissa

Os valores de ED\% foram submetidos à análise de variância em fator único (ANOVA), com o auxilio do programa GraphPad Instat ${ }^{\circledR}$, para avaliar diferenças significativas entre os mesmos e influência das variáveis avaliadas. O índice de significância utilizado foi $\mathrm{p}<0,05$ (Ferraz et al., 1999).

\subsubsection{Determinação da cinética de dissolução da furosemida}

O estudo da cinética de dissolução foi estabelecido a partir dos perfis obtidos para cada formulação, em $\mathrm{pH}$ único. Os resultados foram submetidos a cálculos matemáticos e estatísticos com o objetivo de determinar a cinética de dissolução da furosemida (Carcamo, 1981; Serra, 1998). Utilizaram-se os modelos de linearização de ordem zero, primeira ordem e Higuchi. Para avaliar os perfis de dissolução com o emprego dos modelos propostos, estabeleceram-se as seguintes relações (Serra, 1998): 
a) Modelo de ordem zero - A partir dos dados do perfil de dissolução contruiu-se um gráfico relacionando tempo $(\mathrm{min})$ versus quantidade total $\left(Q_{t}\right)$ subtraída da quantidade dissolvida $\left(Q_{d}\right)$ de furosemida $(\mathrm{mg})$.

b) Modelo de primeira ordem - A partir dos dados do perfil de dissolução construiu-se um gráfico relacionando tempo $(\mathrm{min})$ versus logarítmo neperiano da porcentagem de furosemida não dissolvida (In\%ND).

c) Modelo de Higuchi - A partir dos dados do perfil de dissolução construiuse um gráfico relacionando a raiz quadrada do tempo (min) versus porcentagem de furosemida dissolvida $(\% \mathrm{D})$.

A Tabela 5 resume as equações que definem os modelos cinéticos estudados.

Tabela 5. Equações dos modelos cinéticos empregados na determinação da cinética de dissolução do fármaco.

\begin{tabular}{|c|c|}
\hline Modelo & Equação \\
\hline Ordem zero & $\begin{array}{l}\qquad \mathbf{Q}_{t}{ }^{-} \mathbf{Q}_{d}=\mathbf{k}_{0} \cdot \mathbf{t} \\
\text { na qual: } \mathbf{Q}_{\mathbf{t}}{ }^{-} \mathbf{Q}_{\mathrm{d}}=\text { quantidade de fármaco não dissolvido } \\
(\mathrm{mg}) ; \mathbf{k}_{0}=\text { constante da velocidade de dissolução para o } \\
\text { modelo de ordem zero; } \mathbf{t}=\text { tempo }(\mathrm{min})\end{array}$ \\
\hline Primeira ordem & $\begin{array}{l}\text { Ln \%ND }=\ln \mathbf{Q}_{\mathbf{0}}-\mathbf{k}_{\mathbf{d}} \mathbf{t} \\
\text { na qual: } \mathbf{L n} \% \mathbf{N D}=\text { logaritmo neperiano da porcentagem } \\
\text { de fármaco não dissolvida; } \ln \mathbf{Q}_{\mathbf{0}}=\text { porcentagem não } \\
\text { dissolvida no tempo zero; } \mathbf{k}_{\mathbf{d}}=\text { constante da velocidade } \\
\text { de dissolução para o modelo de primeira ordem; } \mathbf{t}= \\
\text { tempo (min) }\end{array}$ \\
\hline Higuchi & $\begin{array}{l}\qquad \% \mathbf{D}=\mathbf{k}_{\mathbf{d}} \cdot \sqrt{\mathbf{t}} \\
\text { na qual: \%D = porcentagem de fármaco não dissolvida; } \\
\text { constante da velocidade de dissolução para o modelo de } \\
\text { primeira Higuchi; } \sqrt{ } \mathbf{t}=\text { raiz quadrada do tempo (min) }\end{array}$ \\
\hline
\end{tabular}


O modelo matemático que melhor expressou a cinética de dissolução da furosemida a partir das formulações avaliadas foi selecionado pela análise de regressão linear, estabelecendo-se o índice de correlação $\left(r^{2}\right)$ próximo à unidade como critério de aceitação. Para a análise de regressão, empregaramse os recursos do programa Microsoft Excel ${ }^{\circledR}$.

\subsection{Determinação das constantes cinéticas}

As constantes cinéticas da dissolução foram determinadas a partir das equações definidas pelo modelo matemático que apresentou o maior e mais significativo índice de correlação para cada formulação (Serra, 1998). Os parâmetros cinéticos calculados foram:

- Constante de velocidade de dissolução (k) - correspondente ao coeficiente angular da reta de regressão;

- Quantidade de fármaco dissolvida em 60 minutos (Q60), 240 minutos (Q240) e 480 minutos (Q480) - A partir do tempo 0 das curvas de dissolução estes valores foram definidos matematicamente conforme a equação da reta de regressão que melhor definiu a cinética de dissolução. As quantidades foram avaliadas segundo os critérios de Prista et al. (1996) para uma forma farmacêutica de liberação prolongada, representados na Tabela 6 .

Tabela 6. Critério de avaliação de formas farmacêuticas de ação prolongada de oito horas segundo Prista et al. (1996)

\begin{tabular}{cc}
\hline Tempo $(\min )$ & Quantidade de fármaco liberada $(\%)$ \\
\hline 60 & $30( \pm 10)$ \\
240 & $60( \pm 10)$ \\
480 & $90( \pm 10)$ \\
\hline
\end{tabular}




\subsubsection{Determinação dos perfis de dissolução da furosemida com variação de $\mathrm{pH}$}

Três réplicas de comprimido das formulações $A 2, B 2, B 2 c, C 2$ e C2c foram submetidas a ensaio de dissolução em equipamento dissolutor provido de aparato 3 (BioDis ${ }^{\circledR}$ ) da USP XXVIII (2006), em $250 \mathrm{~mL}$ dos seguintes meios de dissolução: $\mathrm{HCl} 0,1 \mathrm{~N} \mathrm{pH1,2;} \mathrm{tampão} \mathrm{fosfato} 0,05 \mathrm{M} \mathrm{pH} \mathrm{4,5}$ e tampão fosfato 0,05 M pH 6,8; de acordo com as indicações da FIP (1996).

Os comprimidos foram submetidos a 10 mergulhos por minuto e $37 \pm$ $0,5^{\circ} \mathrm{C}$ por um período contínuo de 8 horas, sendo 1,0 hora em $\mathrm{pH} 1,2 ; 2,0$ horas em $\mathrm{pH} 4,5$ e 5 horas em $\mathrm{pH} 6,8$. Alíquotas de $5 \mathrm{~mL}$ foram retiradas em intervalos de $15,30,60,90,120,180,240,300,360,420$ e 480 minutos, sendo imediatamente filtradas. Os perfis e eficiência de dissolução da furosemida obtidos neste ensaios foram determinados similarmente ao exposto nos itens 4.2.4.1 e 4.2.4.2.

\subsubsection{Avaliação física dos comprimidos}

\subsubsection{Peso médio}

O peso médio foi determinado pela média aritmética de 20 comprimidos, individualmente pesados em balança analítica (Farmacopéia Brasileira, 1988). Adotou-se, como critério de aceitação, variação máxima de $\pm 1 \%$ no peso dos comprimidos.

\subsubsection{Friabilidade}

Avaliou-se a resistência ao choque e atrito de 20 comprimidos por formulação com auxílio de equipamento friabiliômetro a 25 rpm por 4 minutos 
(Farmacopéia Brasileira, 1988). Adotou-se, como critério de aceitação, perda máxima $1,5 \%$ do peso.

\subsubsection{Dureza}

Empregando-se um durômetro, avaliou-se a resistência mecânica à pressão contínua de 10 comprimidos para cada formulação (Farmacopéia Brasileira, 1988). Adotou-se, como critério de aceitação, dureza mínima de 5 Kgf.

4.2.6. Validação dos ensaios de quantificação da furosemida por espectrofotometria no UV

Os ensaios de quantificação da furosemida por espectrofotometria na região do UV foram validados quanto à sua linearidade, precisão intra e interensaio, limite de quantificação e especificidade, conforme indicações da USP XXVIII (2006) e recomendações da ANVISA (Brasil, 2003).

\subsubsection{Espectro de absorção do fármaco na região do ultravioleta (UV)}

Para avaliar o comprimento de onda correspondente à máxima absorção da furosemida nos meios de dissolução, empregou-se três soluções de 2 $\mu \mathrm{g} / \mathrm{mL}$ de furosemida em $\mathrm{HCl} 0,1 \mathrm{~N} \mathrm{pH} \mathrm{1,2,} \mathrm{tampão} \mathrm{fosfato} 0,05 \mathrm{M} \mathrm{pH} \mathrm{4,5e}$ tampão fosfato $0,05 \mathrm{M} \mathrm{pH} \mathrm{6,8} \mathrm{como} \mathrm{diluente,} \mathrm{alternativamente.} \mathrm{Procedeu-se} \mathrm{à}$ varredura no espectro da região UV em equipamento espectrofotômetro.

\subsubsection{Linearidade}

Determinou-se a linearidade da metodologia, de modo a avaliar a capacidade da metodologia analítica em demonstrar que os resultados obtidos 
são diretamente proporcionais à concentração do analito na amostra dentro de um intervalo especificado (AOAC, 1995; Marques, 2002; Brasil, 2003).

Para avaliação deste parâmetro, foram construídas curvas de calibração de furosemida, a partir de soluções contendo 0,$5 ; 1,2,4,8,12,16,20$ e 24 $\mu \mathrm{g} / \mathrm{mL}$ do fármaco, preparadas em meio $\mathrm{HCl} 0,1 \mathrm{~N} \mathrm{pH} \mathrm{1,2,} \mathrm{tampão} \mathrm{fosfato} 0,05$ $\mathrm{M} \mathrm{pH} \mathrm{4,5} \mathrm{e} \mathrm{tampão} \mathrm{fosfato} 0,05 \mathrm{M} \mathrm{pH} \mathrm{6,8}$. As soluções foram submetidas à quantificação por espectrofotometria a 274 e $276 \mathrm{~nm}$. Os resultados apresentados no item 5.4.2 correspondem à média de três determinações. Efetuou-se, em seguida, a regressão linear dos valores, da qual se obteve o coeficiente de correlação linear $\left(r^{2}\right)$. Adotou-se, como critério mínimo de aceitação, coeficiente de correlação linear $\left(r^{2}\right)$ maior ou igual a 0,99 (AOAC, 1995; Marques, 2002; Brasil, 2003).

\subsection{Preparo da solução-padrão e soluções de trabalho}

Para o preparo de solução-padrão de $1,0 \mathrm{mg} / \mathrm{mL}$ pesou-se, analiticamente, $50 \mathrm{mg}$ de furosemida (padrão secundário 99,8\%) e transferiu-se para balão volumétrico de $50 \mathrm{~mL}$, adicionando-se metanol PA e agitando-se até completa dissolução. A partir desta, preparou-se solução estoque de 100 $\mu \mathrm{g} / \mathrm{mL}$. Para tanto, pipetou-se volumetricamente $5 \mathrm{~mL}$ da solução-padrão, transferiu-se para balão volumétrico de $50 \mathrm{~mL}$, completou-se o volume com água destilada e agitou-se até completa dissolução. Diluições volumétricas da solução estoque, utilizando-se o meios $\mathrm{HCl} 0,1 \mathrm{M} \mathrm{pH1,2,} \mathrm{tampão} \mathrm{fosfato} \mathrm{pH} 4,5$ e tampão fosfato $\mathrm{pH} 6,8$ como diluentes, originaram as soluções de trabalho de 0,$5 ; 1,2,4,8,12,16,20$ e $24 \mu \mathrm{g} / \mathrm{mL}$.

\subsubsection{Precisão intra e inter-ensaio}

Determinou-se a precisão da metodologia de modo a averiguar a proximidade dos resultados obtidos em uma série de quantificações de uma 
amostragem (AOAC, 1995; Marques, 2002; Brasil, 2003). Contemplando-se o intervalo linear do método, foram determinadas, por espectrofotometria, as absorbâncias de 6 réplicas de 3 concentrações conhecidas, sendo uma baixa, uma média e uma alta $(2,12$ e $24 \mu \mathrm{g} / \mathrm{mL})$. As réplicas foram avaliadas em um mesmo dia (precisão intra-ensaio) e em dias diferentes (precisão intermediária). Os resultados foram expressos por meio da imprecisão dada pelo coeficiente de variação das absorbâncias, calculados pela seguinte expressão:

\section{$C V \%=D P / A M D \times 100$}

na qual:

- $\mathrm{CV} \%=$ coeficiente de variação

- $\mathrm{DP}=$ desvio-padrão

- $A M D=$ absorbância média determinada.

Adotou-se como critério mínimo: CV\% $\leq 5$ (Brasil, 2003; AOAC, 1995; Marques, 2002).

\subsubsection{Limite de quantificação}

O limite de quantificação foi estabelecido por meio da análise de soluções contendo concentrações decrescentes do fármaco até o menor nível determinável com precisão aceitável e com coeficiente de variação (CV\%) menor ou igual a 20\% (Brasil, 2003; AOAC, 1995; Marques, 2002). O limite de quantificação foi utilizado como menor ponto na curva de calibração.

\subsubsection{Especificidade}

Determinou-se a precisão da metodologia, de modo a averiguar capacidade que o método possuía em medir exatamente o fármaco em presença de outras substâncias (Brasil, 2003; AOAC, 1995; Marques, 2002). 
Para este ensaio, foram preparados comprimidos placebo de $1,00 \mathrm{~g}$ contendo todos os excipientes a serem avaliados nas formulações. Os comprimidos placebos foram preparados de maneira a conter: HPMC K4M $(16,5 \%), \quad \beta$-ciclodextrina (16,5\%), HP- $\beta$-ciclodextrina (16,5\%), celulose microcristalina tipo $102(16,5 \%)$, estearato de magnésio vegetal (1\%) e lactose monohidratada spray-drayed (16,5\%). Os comprimidos foram submetidos à completa dissolução em equipamento dissolutor em meio $\mathrm{HCl} \mathrm{0,1} \mathrm{N} \mathrm{pH1,2} \mathrm{e}$ tampão fosfato $0,05 \mathrm{M} \mathrm{pH}$ 6,8. Amostras do meio de dissolução foram microfiltradas e, em seguida, submetidas à varredura espectrofotométrica entre 200 e $3.000 \mathrm{~nm}$. O critério de aceitação adotado para este ensaio foi ausência de absorção nos comprimentos de onda utilizados para quantificação da furosemida. 


\section{RESULTADOS}




\subsection{Caracterização dos complexos de inclusão de furosemida}

\subsubsection{Teor de furosemida}

A tabela 7 sumariza os resultados da quantificação do teor de furosemida em produtos obtidos por mistura física, malaxagem e liofilização com $\beta-C D$ ou HP- $\beta-C D$.

Tabela 7. Resultados da quantificação do teor de furosemida em produtos obtidos por mistura física, malaxagem e liofilização com $\beta-C D$ ou HP- $\beta-C D$

\begin{tabular}{cccc}
\hline Produto & Teor médio (\%) & DP & CV\% \\
\hline Furosemida & 99,110 & 0,102 & 0,103 \\
Furosemida/ $\beta$-CD & & & \\
Mistura física & 98,407 & 1,115 & 1,133 \\
Malaxagem & 97,343 & 0,878 & 0,902 \\
Liofilização & 97,633 & 0,977 & 1,000 \\
Furosemida/HP- $\beta-C D$ & & & \\
Mistura física & 98,233 & 0,657 & 0,669 \\
Malaxagem & 97,320 & 0,954 & 0,981 \\
Liofilização & 97,620 & 0,990 & 1,014 \\
\hline
\end{tabular}

$\mathrm{DP}=$ desvio-padrão da média $(n=3)$

\subsubsection{Ensaios termoanalíticos}

Nas Figuras 4 e 5 a seguir estão apresentadas as curvas termoanalíticas de calorimetria diferencial exploratória (DSC), obtidas sob atmosfera dinâmica de nitrogênio e razão de aquecimento de $10^{\circ} \mathrm{C} \cdot \mathrm{min}^{-1}$, referente à furosemida, $\beta-C D, H P-\beta-C D$ e produtos obtidos por mistura física (MF), malaxagem e liofilização entre o fármaco e as ciclodextrinas, em quantidades equimolares. 


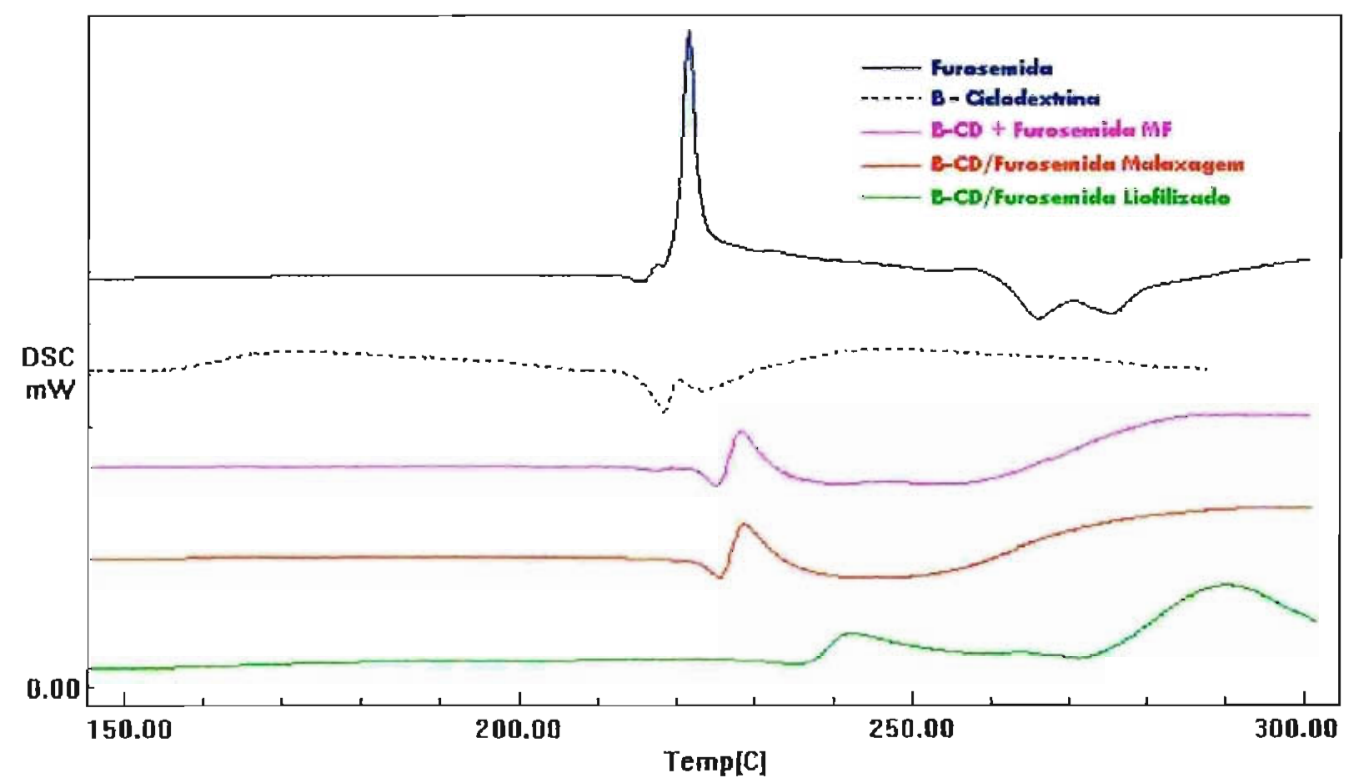

Figura 4. Curvas termoanaliticas de DSC referente à furosemida, $\beta-C D$ e produtos obtidos por mistura física (MF), malaxagem e liofilização em quantidades equimolares.

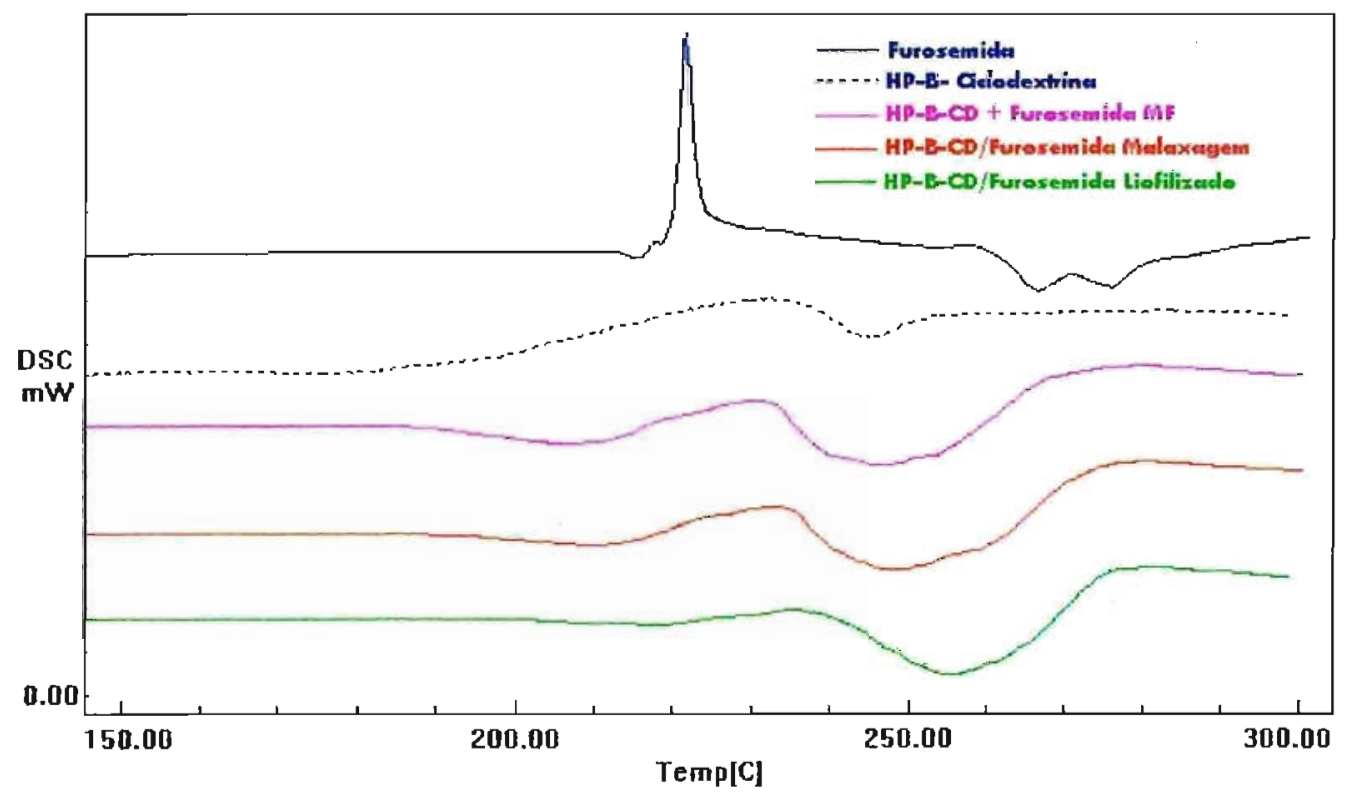

Figura 5. Curvas termoanalíticas de DSC referente à furosemida, HP- $\beta-C D$ e produtos obtidos por mistura física (MF), malaxagem e liofilização em quantidades equimolares. 


\subsubsection{Espectrofotometria na região do infravermelho}

As Figuras 6 e 7 apresentam os espectros de absorção da furosemida, da $\beta-C D$, da HP- $\beta-C D$ isoladas e dos produtos obtidos por mistura física (MF), malaxagem e liofilização entre o fármaco e as ciclodextrinas, em quantidades equimolares, na região do infravermelho $\left(400-4.000 \mathrm{~cm}^{-1}\right)$.

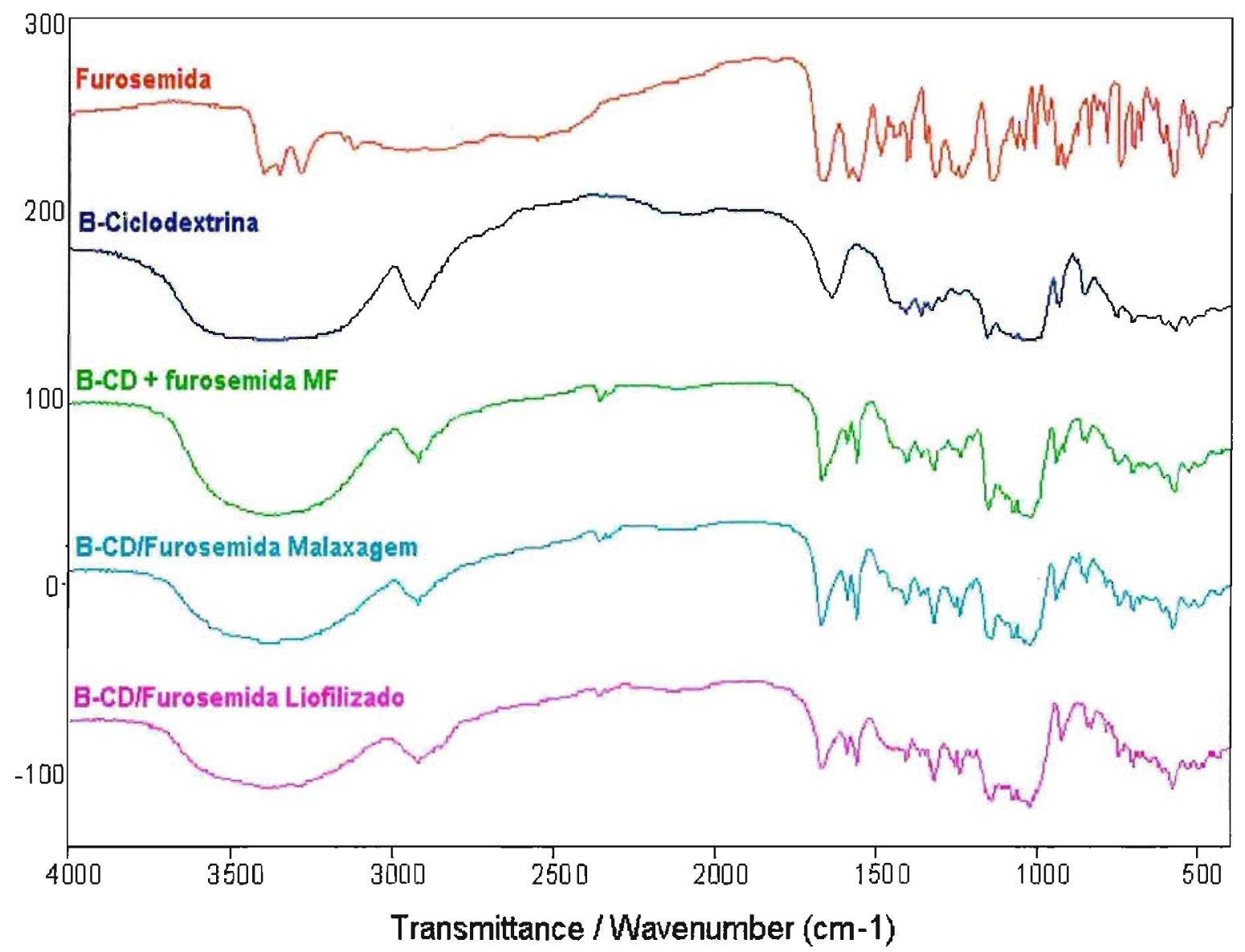

Figura 6. Espectro de absorção da furosemida, $\beta-C D$ e produtos obtidos por mistura física (MF), malaxagem e liofilização em quantidades equimolares na região do infravermelho $\left(400-4.000 \mathrm{~cm}^{-1}\right)$. 


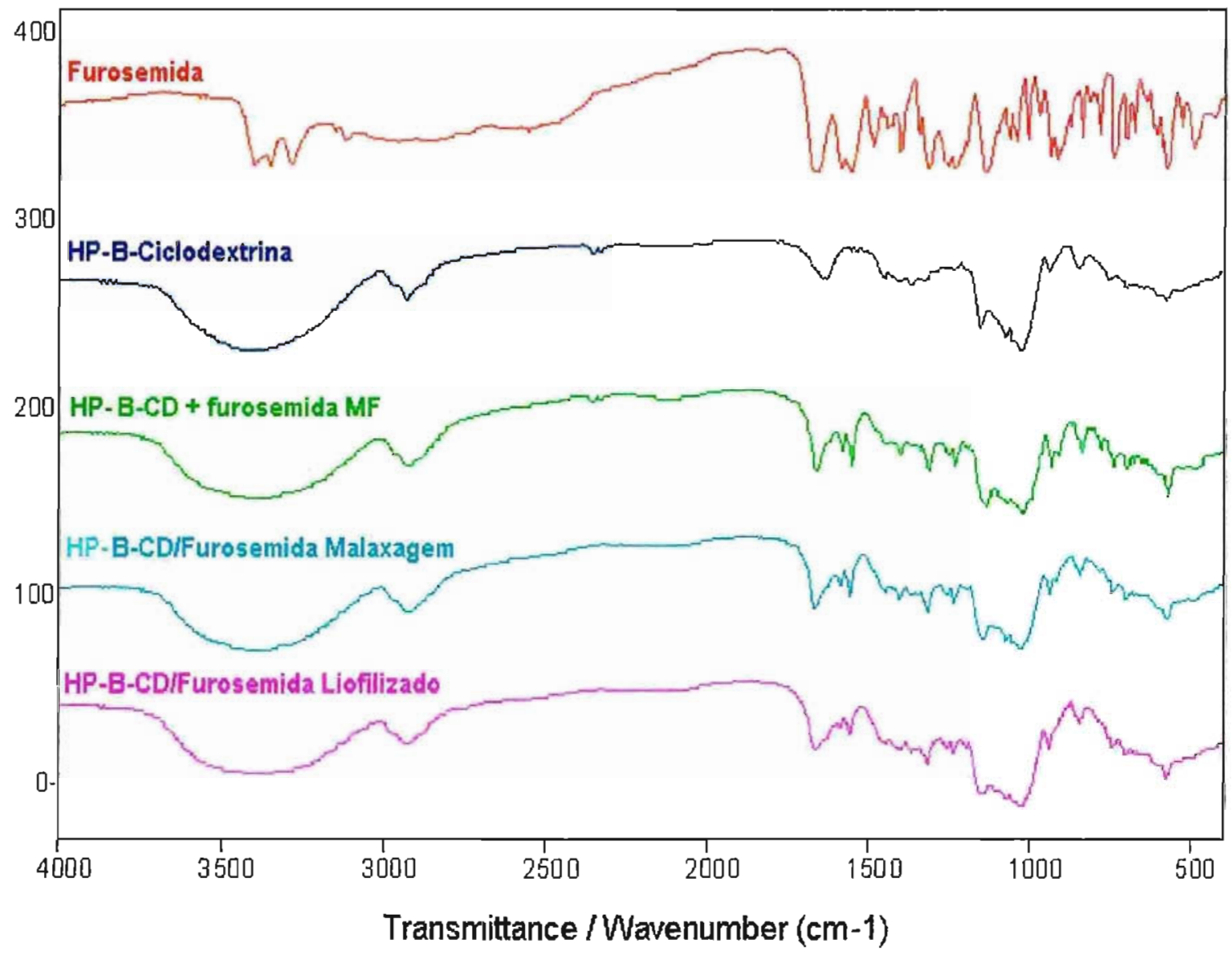

Figura 7. Espectro de absorção da furosemida, $H P-\beta-C D$ e produtos obtidos por mistura física (MF), malaxagem e liofilização em quantidades equimolares na região do infravermelho $\left(400-4000 \mathrm{~cm}^{-1}\right)$.

\subsubsection{Ensaios de dissolução dos complexos de inclusão}

Nas Tabelas 8, 9, 10, 11, 12 e 13 e Figuras 8, 9, 10, 11, 12 e 13 estão apresentados os resultados referentes aos ensaios de dissolução da furosemida e dos produtos obtidos por mistura física, malaxagem ou liofilização do fármaco com $\beta-C D$ ou HP- $\beta-C D$ utilizando-se como meios de dissolução: $\mathrm{HCl} 0,1 \mathrm{~N} \mathrm{pH} \mathrm{1,2;} \mathrm{tampão} \mathrm{fosfato} 0,05 \mathrm{M} \mathrm{pH} \mathrm{4,5}$ ou tampão fosfato $0,05 \mathrm{M} \mathrm{pH}$ 6,8 por um periodo de 60 minutos. 
Tabela 8. Porcentagem de furosemida dissolvida em função do tempo a partir dos produtos obtidos por mistura física, malaxagem ou liofilização com $\beta-C D$ em meio $\mathrm{HCl} \mathrm{0,1} \mathrm{N} \mathrm{pH} \mathrm{1,2}$

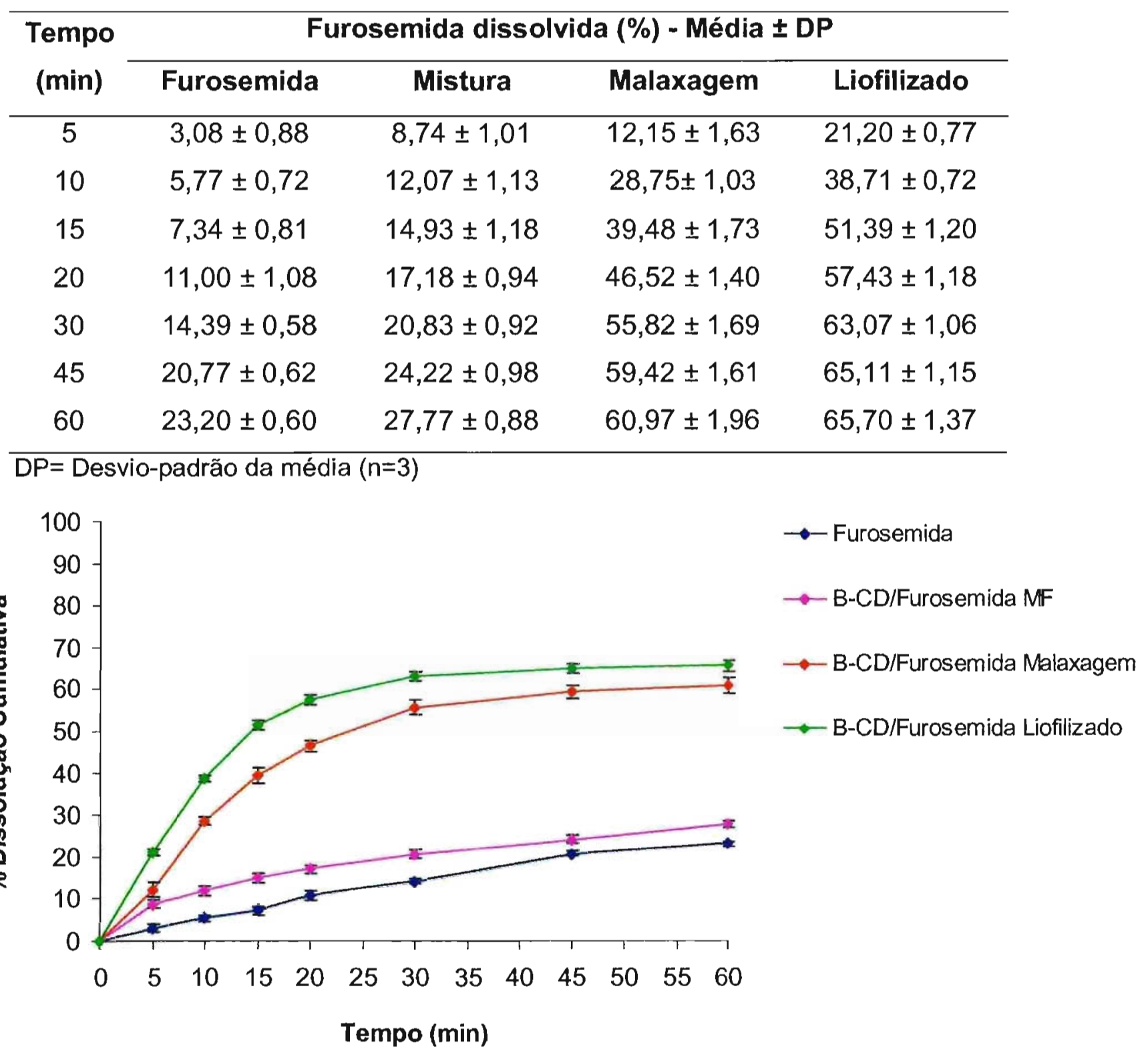

Figura 8. Perfis de dissolução da furosemida a partir dos produtos obtidos por mistura física, malaxagem e liofilização com $\beta-\mathrm{CD}$ em meio $\mathrm{HCl} 0,1 \mathrm{~N}$ pH 1,2. 
Tabela 9. Porcentagem de furosemida dissolvida em função do tempo a partir dos produtos obtidos por mistura física, malaxagem e liofilização com $\beta-C D$ em meio tampão fosfato $0,05 \mathrm{M} \mathrm{pH} \mathrm{4,5}$

\begin{tabular}{ccccc}
\hline \multirow{2}{*}{$\begin{array}{c}\text { Tempo } \\
\text { (min) }\end{array}$} & \multicolumn{4}{c}{ Furosemida dissolvida (\%) - Média \pm DP } \\
\cline { 2 - 5 } & Furosemida & Mistura & Malaxagem & Liofilizado \\
\hline 5 & $4,37 \pm 0,76$ & $12,39 \pm 1,45$ & $33,79 \pm 1,40$ & $52,26 \pm 2,01$ \\
10 & $9,95 \pm 0,68$ & $20,85 \pm 1,86$ & $43,34 \pm 2,03$ & $63,06 \pm 2,04$ \\
15 & $17,95 \pm 0,71$ & $25,23 \pm 1,85$ & $51,47 \pm 2,23$ & $68,80 \pm 2,23$ \\
20 & $24,73 \pm 0,86$ & $32,87 \pm 1,49$ & $56,28 \pm 1,24$ & $75,16 \pm 2,57$ \\
30 & $36,72 \pm 1,01$ & $44,86 \pm 2,26$ & $65,10 \pm 1,30$ & $81,17 \pm 2,79$ \\
45 & $45,44 \pm 1,15$ & $52,06 \pm 2,56$ & $71,99 \pm 1,02$ & $85,41 \pm 3,11$ \\
60 & $51,30 \pm 1,23$ & $56,76 \pm 3,04$ & $77,43 \pm 1,39$ & $88,51 \pm 3,13$ \\
\hline
\end{tabular}

$\mathrm{DP}=$ Desvio-padrão da média $(\mathrm{n}=3)$

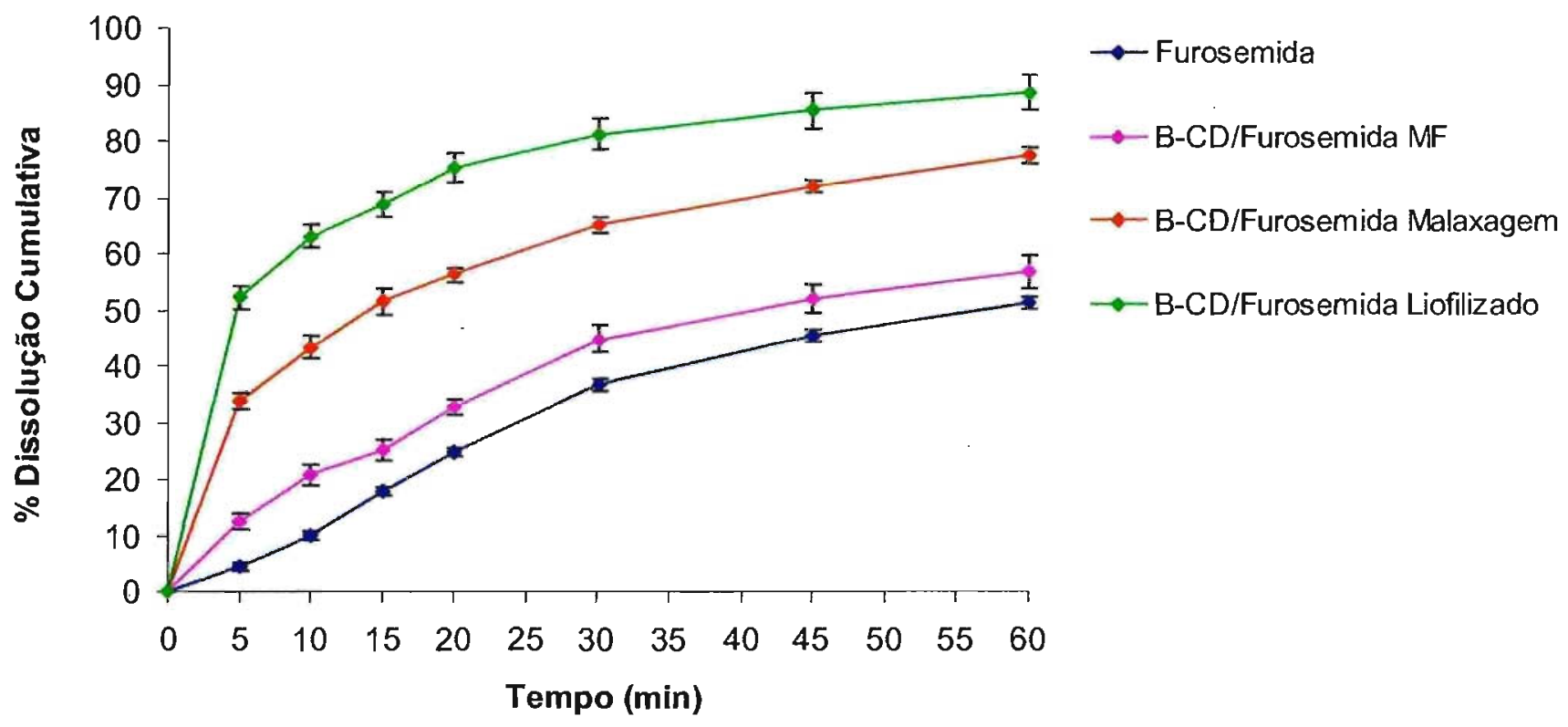

Figura 9. Perfis de dissolução da furosemida a partir dos produtos obtidos por mistura física, malaxagem e liofilização com $\beta-C D$ em meio tampão fosfato 0,05 $\mathrm{M} \mathrm{pH} 4,5$. 
Tabela 10. Porcentagem de furosemida dissolvida em função do tempo a partir dos produtos obtidos por mistura física, malaxagem e liofilização com $\beta-C D$ em meio tampão fosfato $0,05 \mathrm{M} \mathrm{pH} \mathrm{6,8}$

\begin{tabular}{ccccc}
\hline \multirow{2}{*}{$\begin{array}{c}\text { Tempo } \\
\text { (min) }\end{array}$} & \multicolumn{3}{c}{ Furosemida dissolvida (\%) - Média \pm DP } \\
\cline { 2 - 5 } & Furosemida & Mistura & Malaxagem & Liofilizado \\
\hline 5 & $5,83 \pm 0,94$ & $24,79 \pm 1,39$ & $44,99 \pm 3,06$ & $54,76 \pm 2,01$ \\
10 & $16,14 \pm 0,27$ & $35,10 \pm 1,51$ & $57,86 \pm 3,28$ & $67,58 \pm 2,05$ \\
15 & $27,97 \pm 0,82$ & $43,14 \pm 2,50$ & $61,82 \pm 3,39$ & $72,91 \pm 2,19$ \\
20 & $35,80 \pm 1,70$ & $48,21 \pm 2,43$ & $65,61 \pm 3,05$ & $77,68 \pm 2,70$ \\
30 & $46,22 \pm 0,81$ & $55,95 \pm 2,55$ & $70,42 \pm 3,09$ & $82,70 \pm 2,77$ \\
45 & $58,30 \pm 1,70$ & $64,22 \pm 2,57$ & $77,43 \pm 3,47$ & $89,44 \pm 3,11$ \\
60 & $65,25 \pm 1,64$ & $72,54 \pm 2,58$ & $80,90 \pm 3,77$ & $93,00 \pm 3,37$
\end{tabular}

$\mathrm{DP}=$ Desvio-padrão da média $(\mathrm{n}=3)$

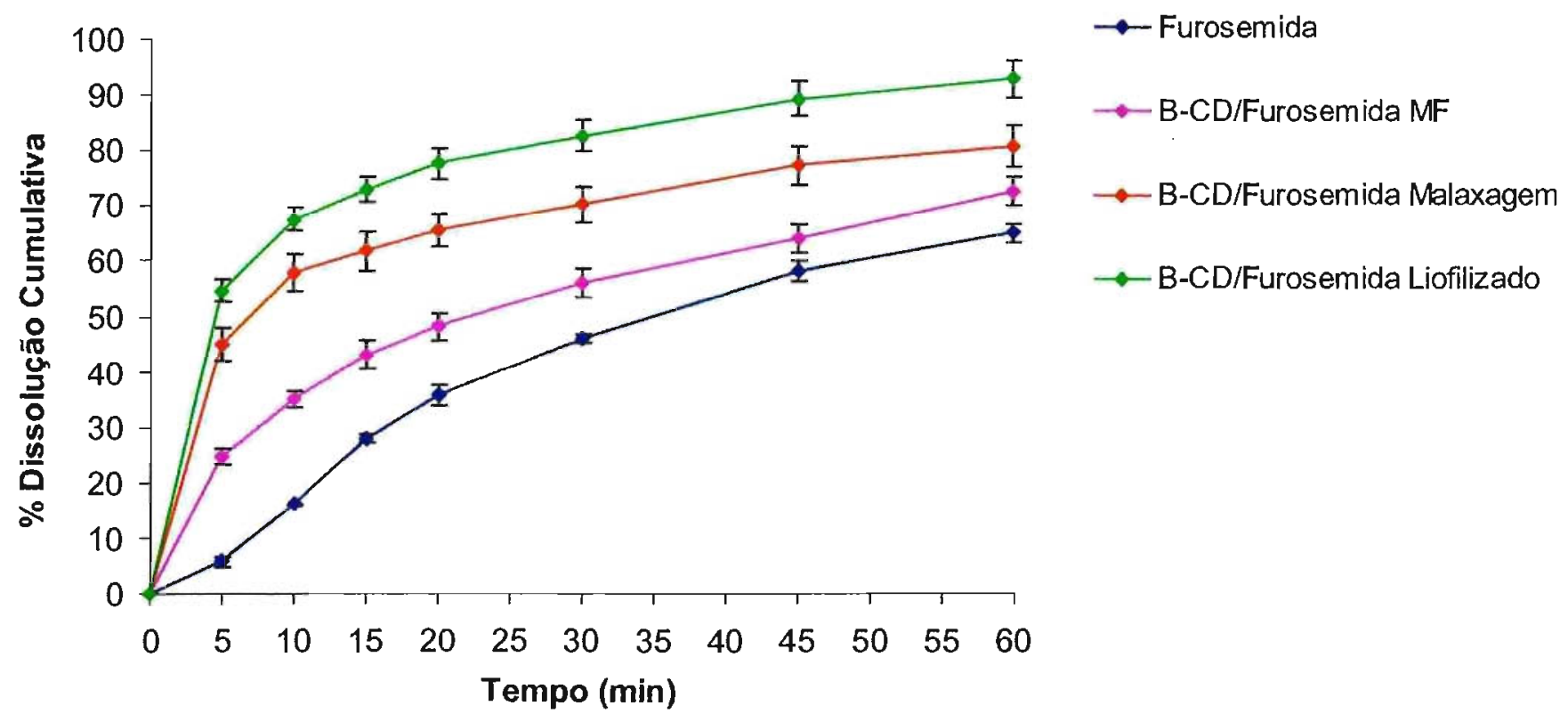

Figura 10. Perfis de dissolução da furosemida a partir dos produtos obtidos por mistura física, malaxagem e liofilização com $\beta-C D$ em meio tampão fosfato 0,05 $\mathrm{M} \mathrm{pH} 6,8$. 
Tabela 11. Porcentagem de furosemida dissolvida em função do tempo a partir dos produtos obtidos por mistura física, malaxagem e liofilização com HP- $\beta-C D$ em meio $\mathrm{HCl} 0,1 \mathrm{~N} \mathrm{pH} \mathrm{1,2}$

\begin{tabular}{ccccc}
\hline \multirow{2}{*}{$\begin{array}{c}\text { Tempo } \\
\text { (min) }\end{array}$} & \multicolumn{3}{c}{ Furosemida dissolvida (\%) - Média \pm DP } \\
\cline { 2 - 5 } & Furosemida & Mistura & Malaxagem & Liofilizado \\
\hline 5 & $3,08 \pm 0,88$ & $12,63 \pm 1,31$ & $29,57 \pm 1,04$ & $35,60 \pm 2,46$ \\
10 & $5,77 \pm 0,72$ & $17,30 \pm 0,69$ & $46,07 \pm 1,42$ & $54,93 \pm 2,44$ \\
15 & $7,34 \pm 0,81$ & $19,01 \pm 0,65$ & $56,78 \pm 1,40$ & $65,38 \pm 1,14$ \\
20 & $11,00 \pm 1,08$ & $20,24 \pm 0,87$ & $65,21 \pm 1,07$ & $69,92 \pm 2,34$ \\
30 & $14,39 \pm 0,58$ & $22,60 \pm 1,22$ & $69,92 \pm 0,63$ & $74,62 \pm 2,14$ \\
45 & $20,77 \pm 0,62$ & $25,04 \pm 0,96$ & $75,53 \pm 0,96$ & $78,70 \pm 2,23$ \\
60 & $23,20 \pm 0,60$ & $28,77 \pm 1,33$ & $79,07 \pm 1,03$ & $82,36 \pm 2,14$ \\
\hline
\end{tabular}

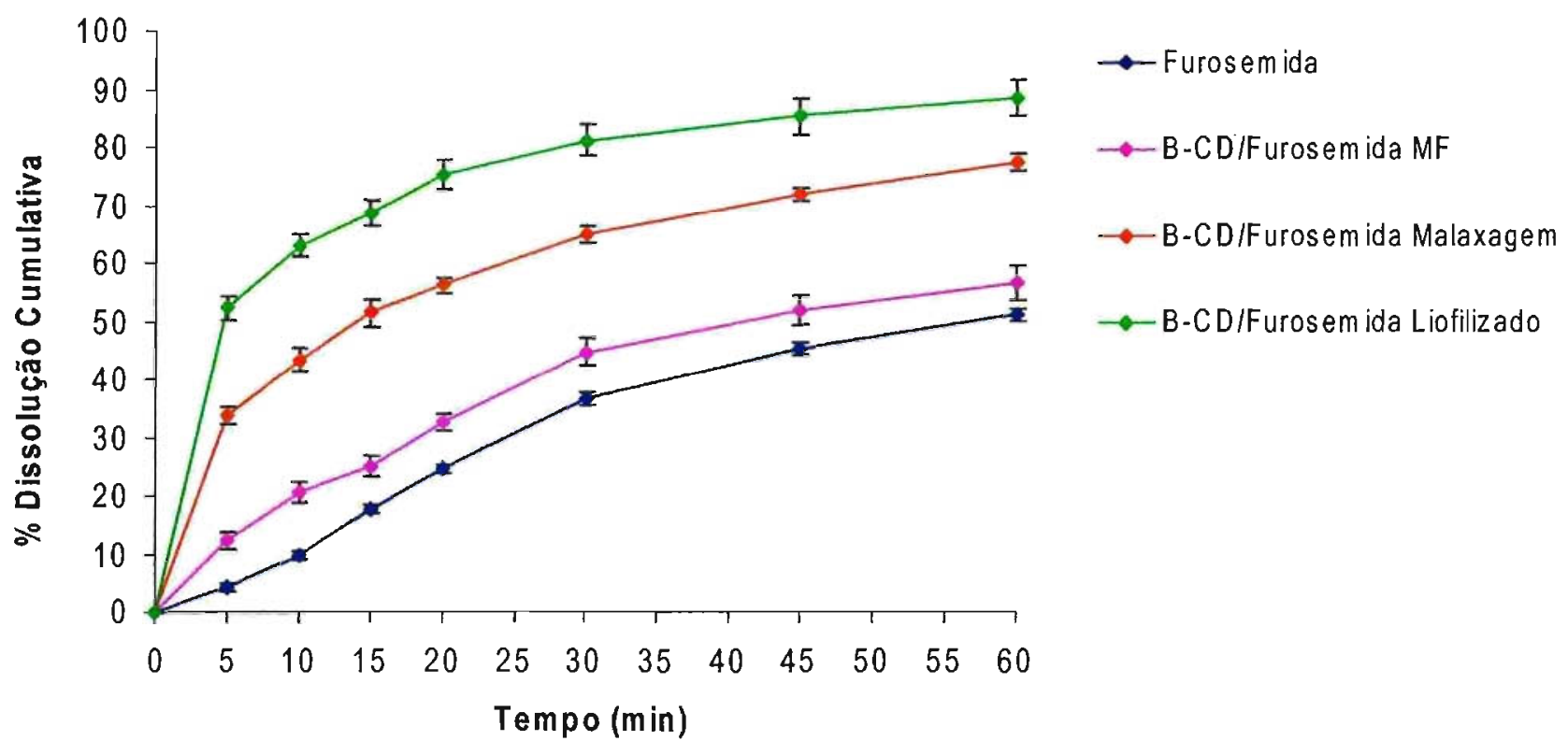

Figura 11. Perfis de dissolução da furosemida a partir dos produtos obtidos por mistura física, malaxagem e liofilização com $\mathrm{HP}-\beta-\mathrm{CD}$ em meio $\mathrm{HCl} 0,1 \mathrm{~N} \mathrm{pH}$ 1,2 . 
Tabela 12. Porcentagem de furosemida dissolvida em função do tempo a partir dos produtos obtidos por mistura física, malaxagem e liofilização com HP- $\beta-C D$ em meio tampão fosfato $0,05 \mathrm{M} \mathrm{pH} 4,5$

\begin{tabular}{ccccc}
\hline \multirow{2}{*}{$\begin{array}{c}\text { Tempo } \\
\text { (min) }\end{array}$} & \multicolumn{3}{c}{ Furosemida dissolvida (\%) - Média \pm DP } \\
\cline { 2 - 5 } & Furosemida & Mistura & Malaxagem & Liofilizado \\
\hline 5 & $4,37 \pm 0,76$ & $19,36 \pm 1,63$ & $41,69 \pm 2,20$ & $60,29 \pm 2,42$ \\
10 & $9,95 \pm 0,68$ & $26,44 \pm 1,47$ & $56,91 \pm 2,48$ & $69,40 \pm 2,25$ \\
15 & $17,95 \pm 0,71$ & $33,30 \pm 1,57$ & $64,09 \pm 2,56$ & $77,49 \pm 2,69$ \\
20 & $24,73 \pm 0,86$ & $37,08 \pm 1,68$ & $68,71 \pm 2,17$ & $82,36 \pm 2,38$ \\
30 & $36,72 \pm 1,01$ & $43,50 \pm 2,08$ & $73,99 \pm 2,31$ & $86,43 \pm 2,60$ \\
45 & $45,44 \pm 1,15$ & $50,01 \pm 1,99$ & $78,24 \pm 2,48$ & $90,91 \pm 3,26$ \\
60 & $51,30 \pm 1,23$ & $56,30 \pm 1,90$ & $83,69 \pm 2,67$ & $94,15 \pm 2,85$ \\
\hline
\end{tabular}

$\mathrm{DP}=$ Desvio-padrão da média $(\mathrm{n}=3)$

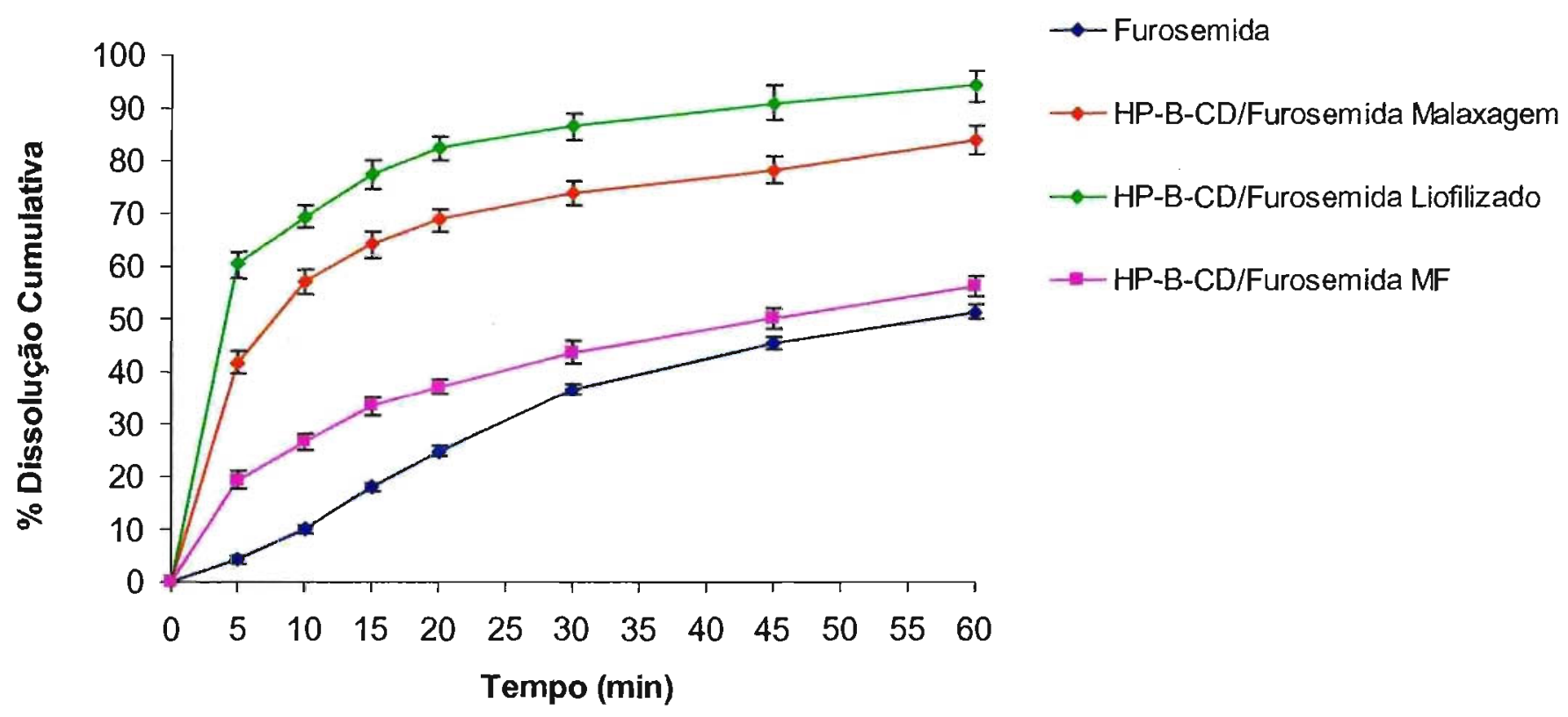

Figura 12. Perfis de dissolução da furosemida a partir dos produtos obtidos por mistura física, malaxagem e liofilização com HP- $\beta-C D$ em meio tampão fosfato $0,05 \mathrm{M} \mathrm{pH} 4,5$. 
Tabela 13. Porcentagem de furosemida dissolvida em função do tempo a partir dos produtos obtidos por mistura física, malaxagem e liofilização com HP- $\beta-C D$ em meio tampão fosfato $0,05 \mathrm{M} \mathrm{pH} \mathrm{6,8}$

\begin{tabular}{ccccc}
\hline \multirow{2}{*}{$\begin{array}{c}\text { Tempo } \\
(\mathbf{m i n})\end{array}$} & \multicolumn{3}{c}{ Furosemida dissolvida (\%) - Média \pm DP } \\
\cline { 2 - 5 } & Furosemida & Mistura & Malaxagem & Liofilizado \\
\hline 5 & $5,83 \pm 0,94$ & $22,71 \pm 1,46$ & $49,21 \pm 1,13$ & $69,53 \pm 1,32$ \\
10 & $16,14 \pm 0,27$ & $34,09 \pm 1,71$ & $66,45 \pm 1,07$ & $90,20 \pm 0,98$ \\
15 & $27,97 \pm 0,82$ & $44,35 \pm 1,99$ & $77,44 \pm 1,65$ & $94,50 \pm 1,90$ \\
20 & $35,80 \pm 1,70$ & $52,09 \pm 0,64$ & $84,33 \pm 2,16$ & $95,97 \pm 1,34$ \\
30 & $46,22 \pm 0,81$ & $58,47 \pm 1,70$ & $93,54 \pm 3,60$ & $96,82 \pm 1,31$ \\
45 & $58,30 \pm 1,70$ & $65,99 \pm 0,90$ & $97,63 \pm 2,28$ & $98,40 \pm 0,74$ \\
60 & $65,25 \pm 1,64$ & $69,75 \pm 0,56$ & $98,97 \pm 2,74$ & $99,75 \pm 1,28$
\end{tabular}

$\mathrm{DP}=$ Desvio-padrão da média $(\mathrm{n}=3)$

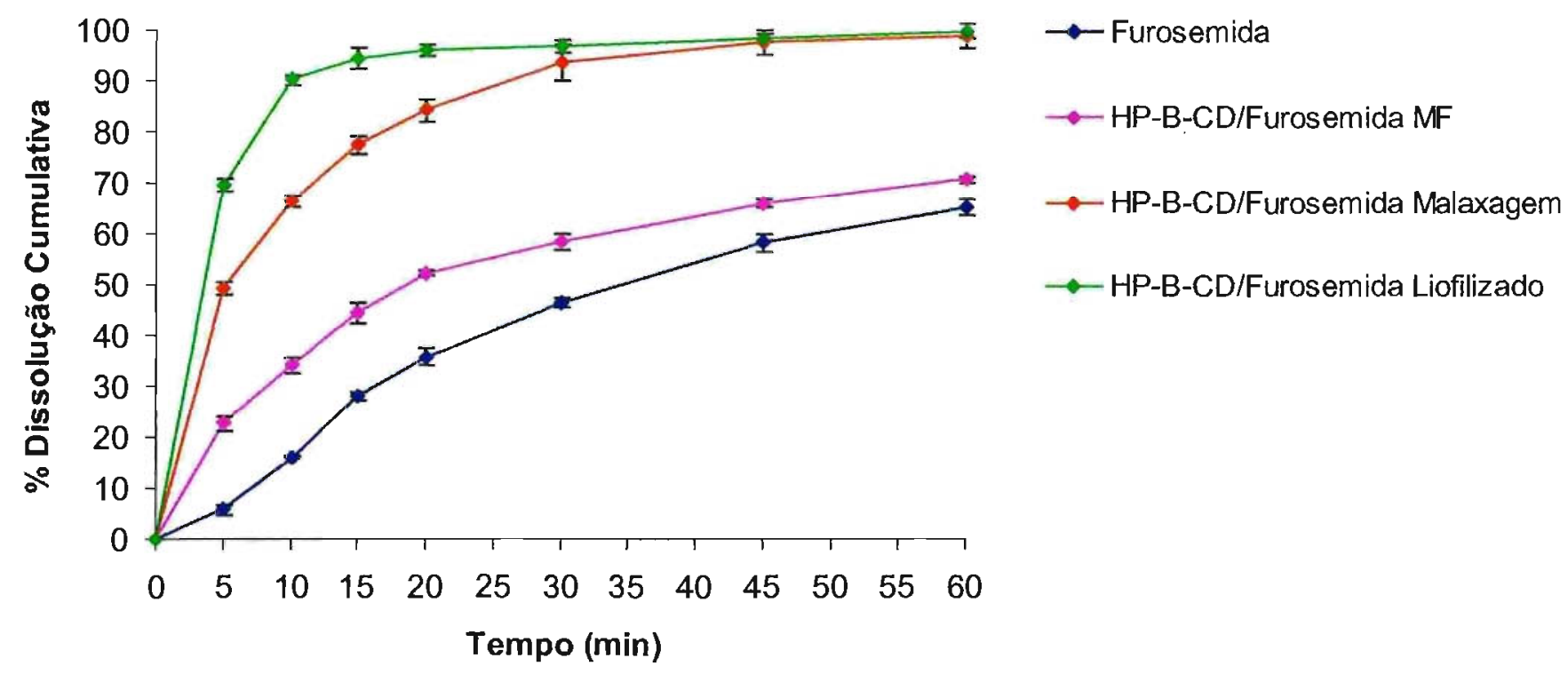

Figura 13. Perfis de dissolução da furosemida a partir dos produtos obtidos por mistura física, malaxagem e liofilização com HP- $\beta-C D$ em meio tampão fosfato $0,05 \mathrm{M} \mathrm{pH} 6,8$. 


\subsection{Ensaios de dissolução dos comprimidos}

5.2.1. Determinação dos perfis de dissolução da furosemida em meio tampão fosfato $\mathrm{pH} 6,8$

Nas Tabelas 15, 16 e 17 e Figuras 14, 15 e 16 estão apresentados os resultados referentes aos ensaios de dissolução dos comprimidos matriciais preparados com as formulações das séries $A, B$ (contendo $\beta-C D$ ), $C$ (contendo HP- $\beta-C D$ ) e $D$ (contendo lactose), em meio tampão fosfato $0,05 \mathrm{M} \mathrm{pH} \mathrm{6,8.} \mathrm{Para}$ efeitos de comparação, convencionou-se a formulação A2 como formulação básica. 


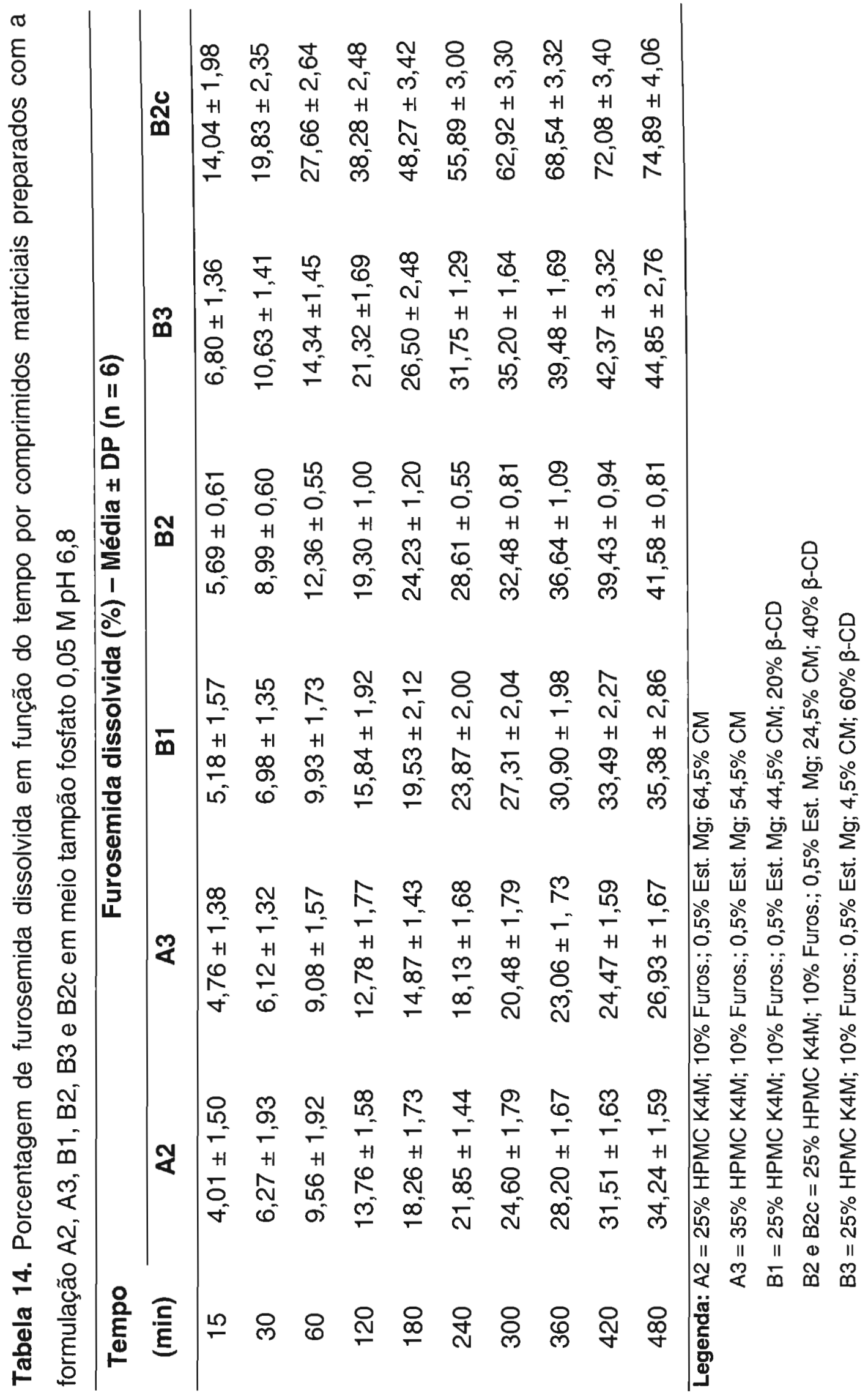




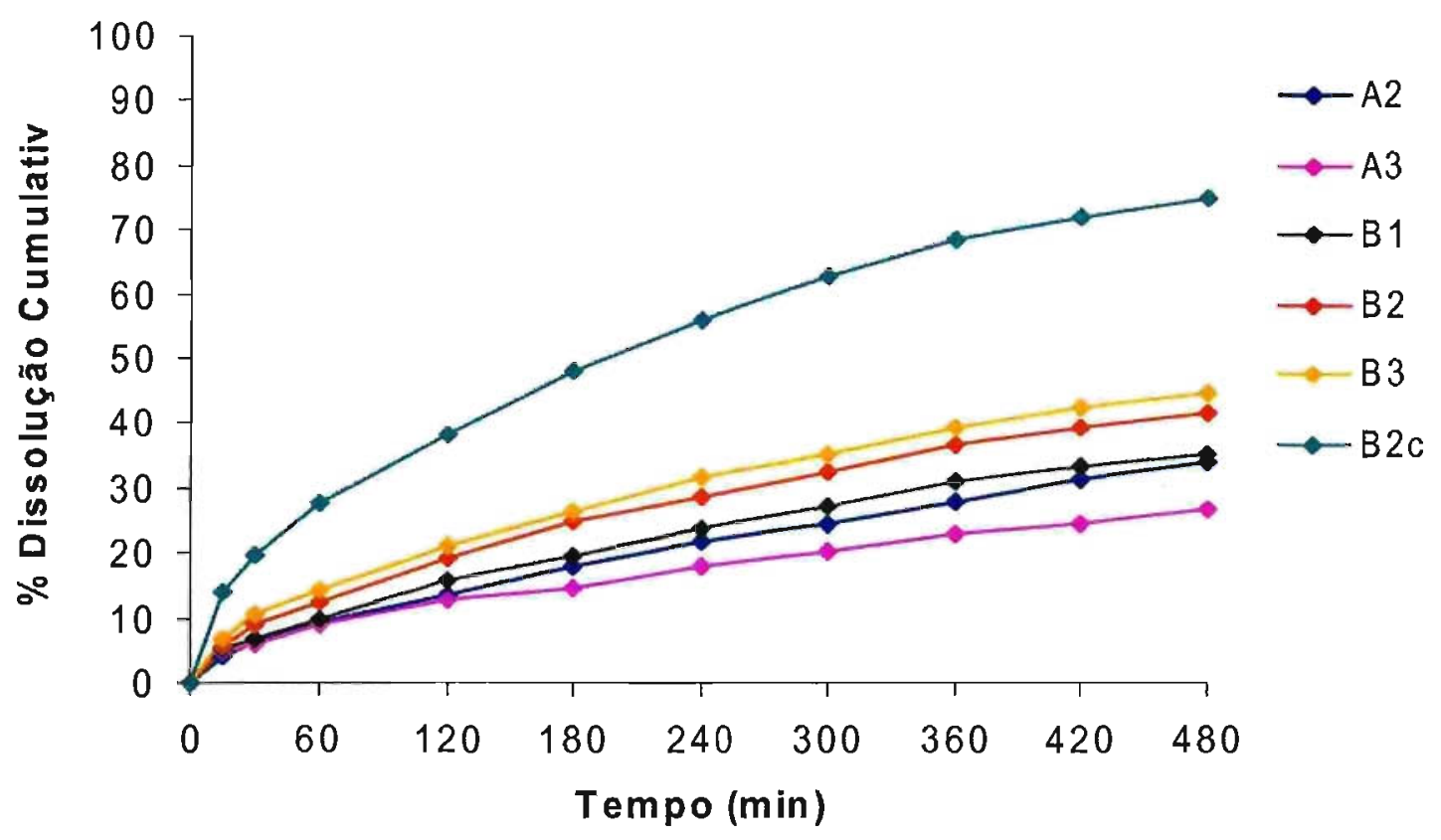

Figura 14. Sumário dos perfis de dissolução da furosemida a partir de comprimidos preparados com a formulação $A 2, A 3, B 1, B 2, B 3$ e B2c em meio tampão fosfato $0,05 \mathrm{M} \mathrm{pH} \mathrm{6,8.}$ 


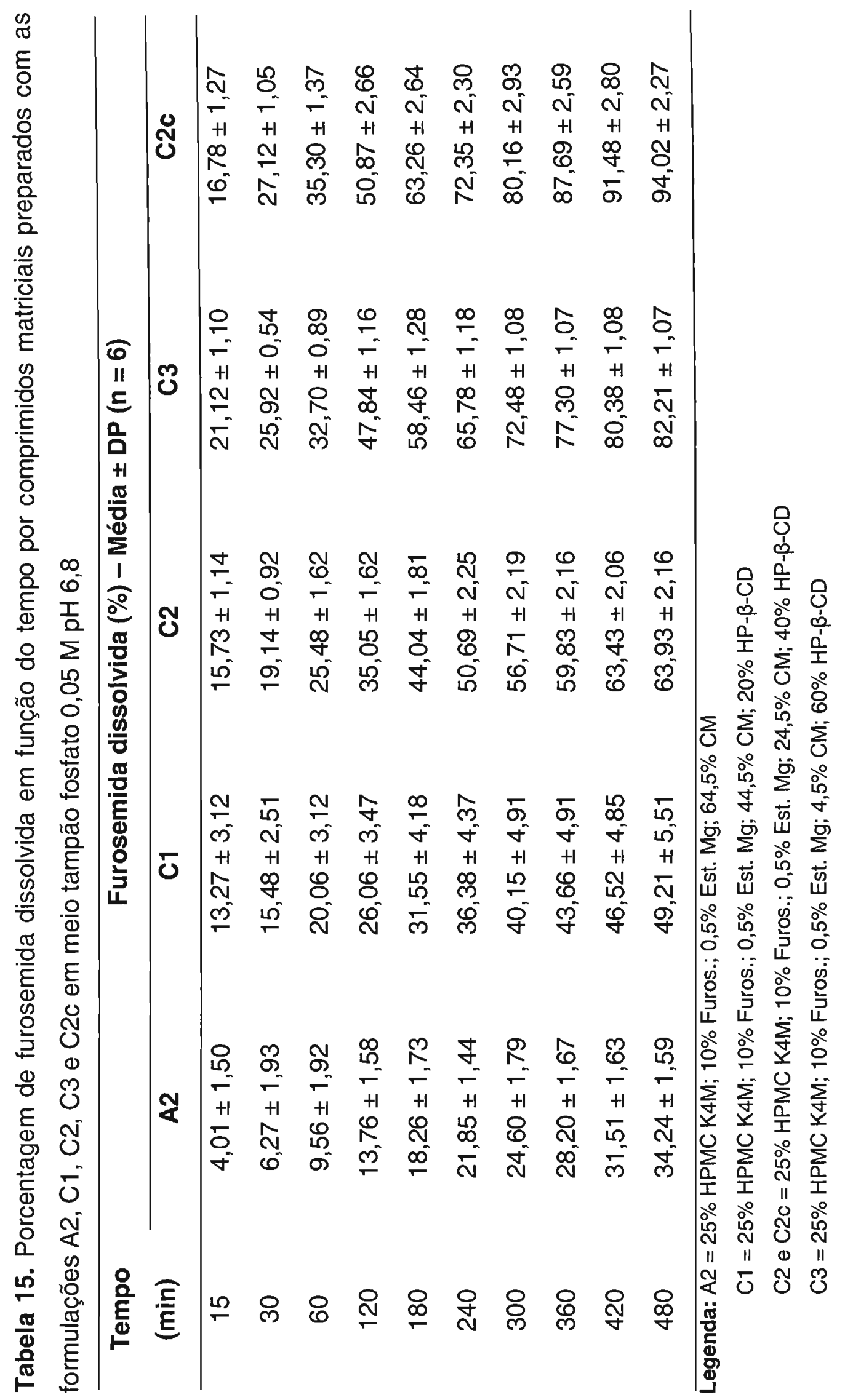




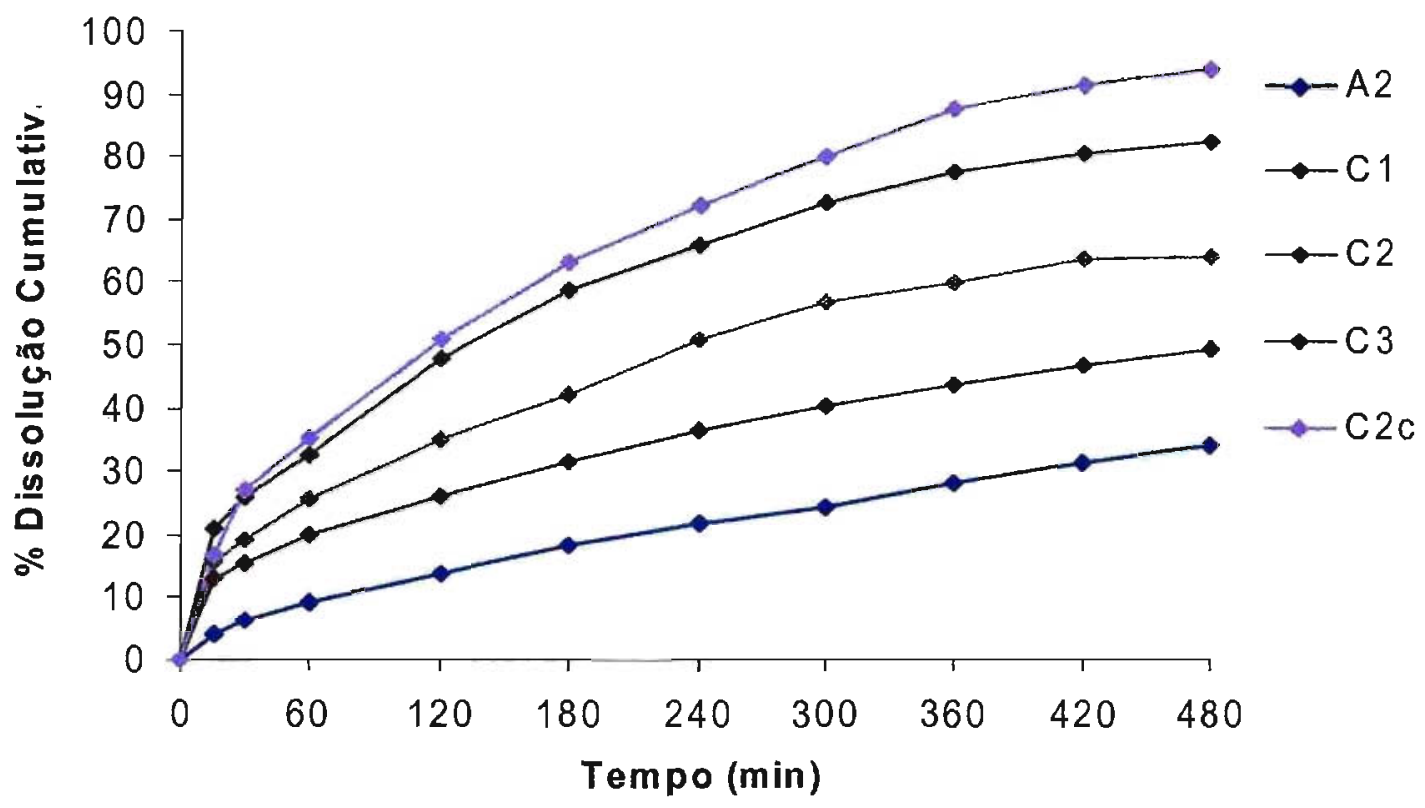

Figura 15. Sumário dos perfis de dissolução da furosemida a partir de comprimidos preparados com as formulações A2, C1, C2, C3 e C2c em meio tampão fosfato $0,05 \mathrm{M} \mathrm{pH} \mathrm{6,8.}$ 


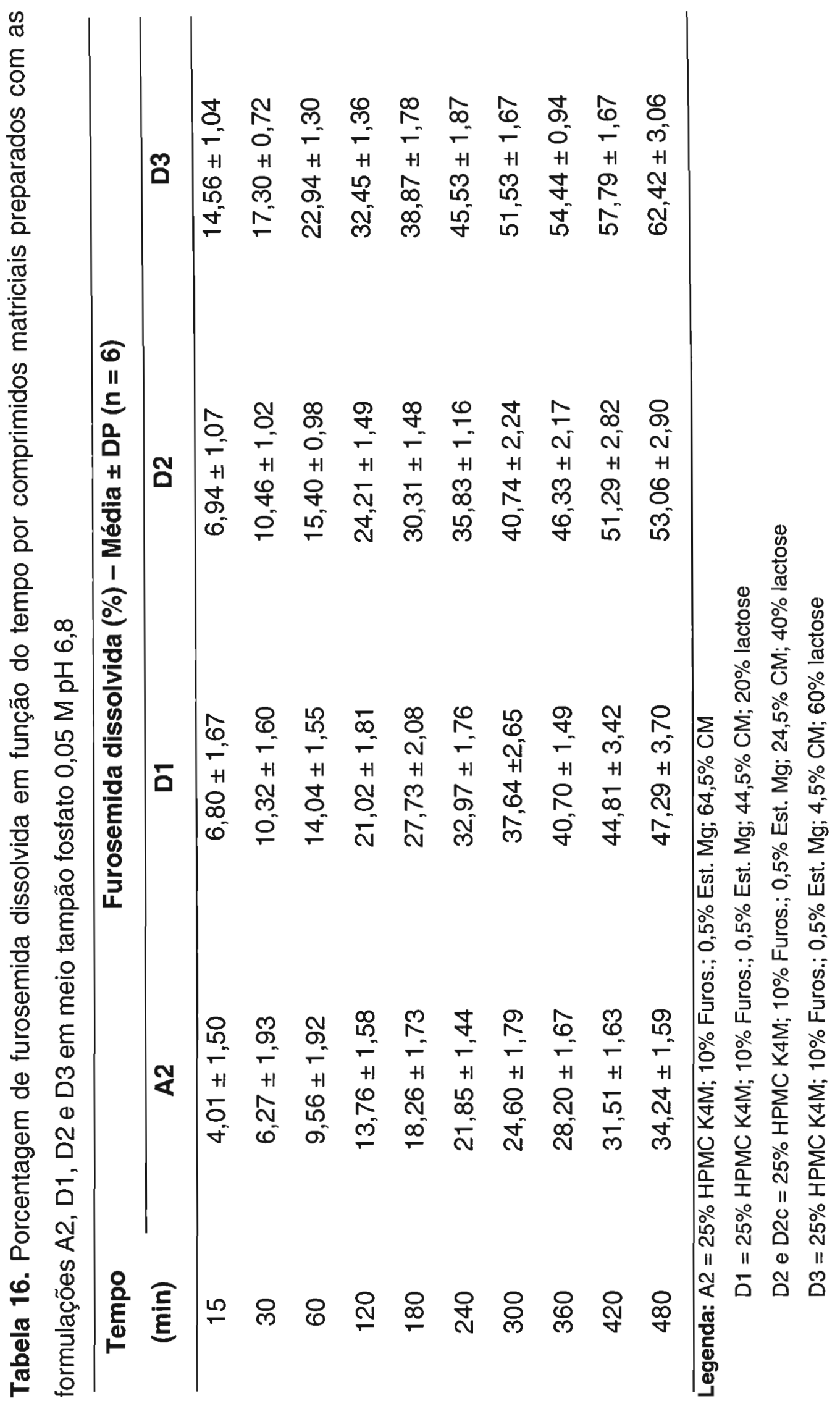




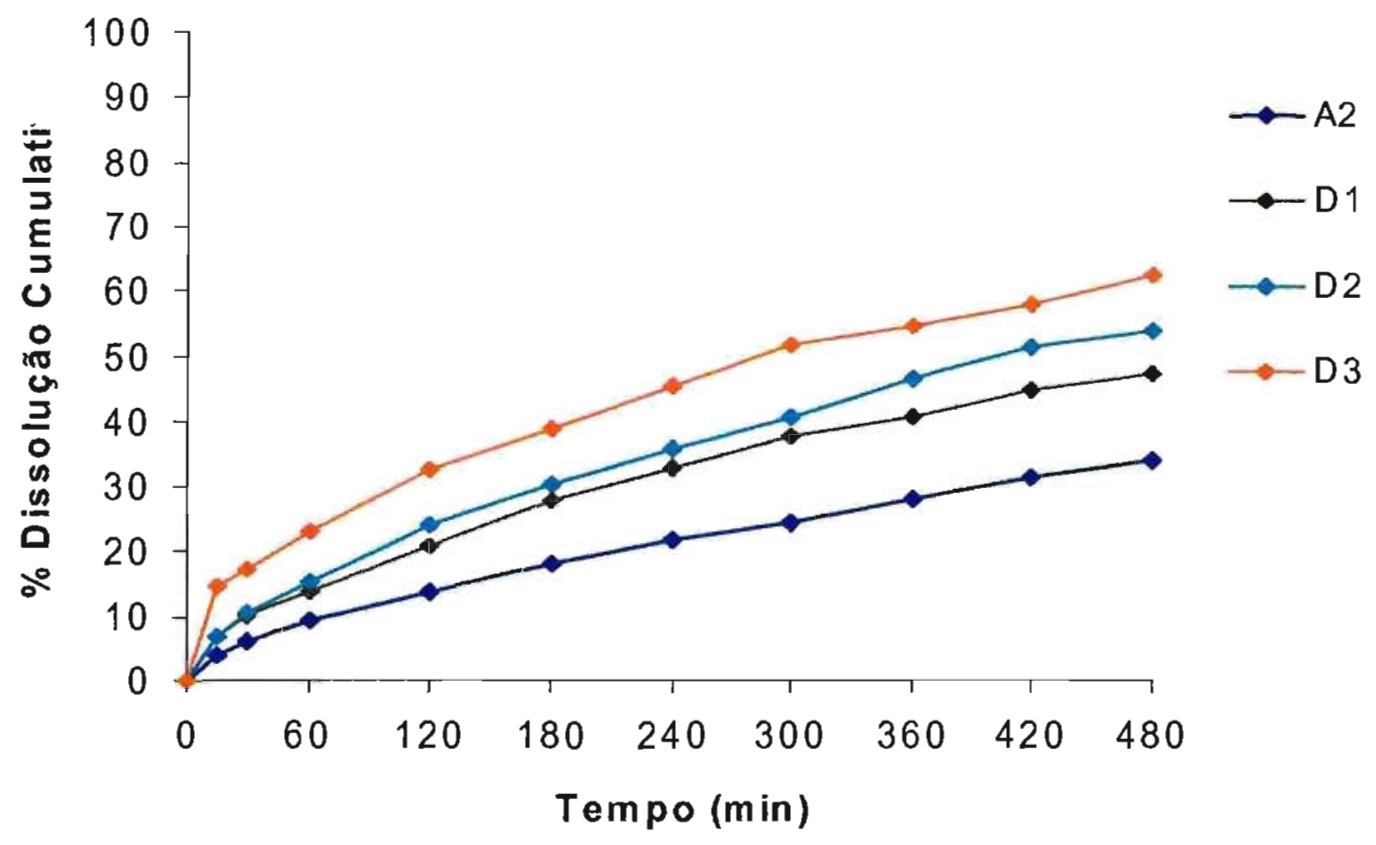

Figura 16. Sumário dos perfis de dissolução da furosemida a partir de comprimidos preparados com as formulações $A 2, D 1, D 2$ e D3 em meio tampão fosfato $0,05 \mathrm{M} \mathrm{pH} \mathrm{6,8.}$ 


\subsubsection{Determinação da eficiência de dissolução da furosemida}

Tabela 17. Valores de área sob a curva (ASC) e eficiência de dissolução (ED\%) calculados a partir dos perfis de dissolução da furosemida pelas formulações A2, A3, B1, B2, B3 e B2C

\begin{tabular}{|c|c|c|c|c|c|c|}
\hline \multirow{2}{*}{$\Delta \mathrm{t}(\min )$} & $\overline{A 2}$ & $\overline{A 3}$ & B1 & B2 & B3 & B2C \\
\hline & \multicolumn{6}{|c|}{ ASC Média } \\
\hline $0-15$ & 30,11 & 35,73 & 38,86 & 42,69 & 51,03 & 105,28 \\
\hline $15-30$ & 77,14 & 81,68 & 91,23 & 110,18 & 130,76 & 253,98 \\
\hline $30-60$ & 237,50 & 228,08 & 253,74 & 320,41 & 374,64 & 712,24 \\
\hline $60-120$ & 699,77 & 655,89 & 773,44 & 950,13 & 1070,13 & 1978,18 \\
\hline $120-180$ & 960,76 & 829,81 & 1061,47 & 1332,04 & 1435,05 & 2596,56 \\
\hline $180-240$ & 1203,38 & 990,29 & 1302,26 & 1611,15 & 1747,96 & 3124,75 \\
\hline $240-300$ & 1393,59 & 1158,38 & 1535,61 & 1832,83 & 2008,83 & 3564,20 \\
\hline $300-360$ & 1584,18 & 1306,21 & 1746,48 & 2073,93 & 2240,83 & 3943,62 \\
\hline $360-420$ & 1791,49 & 1426,03 & 1931,86 & 2282,54 & 2455,99 & 4218,40 \\
\hline $420-480$ & 1972,57 & 1542,07 & 2066,36 & 2430,75 & 2616,87 & 4408,87 \\
\hline \multirow[t]{4}{*}{$0-480$} & 9950,48 & 8254,16 & 10801,31 & 12986,66 & 14132,08 & 24906,08 \\
\hline & \multicolumn{6}{|c|}{$E D \% \pm D P(n=6)$} \\
\hline & 20,73 & 17,20 & 22,50 & 27,06 & 29,44 & 51,89 \\
\hline & $\pm 1,59$ & $\pm 1,58$ & $\pm 1,70$ & $\pm 0,90$ & $\pm 1,68$ & $\pm 2,90$ \\
\hline
\end{tabular}

Legenda: A2 = 25\% HPMC K4M; 10\% Furos.; 0,5\% Est. Mg; 64,5\% CM

$\mathrm{A} 3=35 \%$ HPMC K4M; $10 \%$ Furos.; 0,5\% Est. Mg; 54,5\% CM

B1 $=25 \%$ HPMC K4M; $10 \%$ Furos.; 0,5\% Est. Mg; 44,5\% CM; $20 \% \beta-C D$

B2 e B2c $=25 \%$ HPMC K4M; $10 \%$ Furos.; 0,5\% Est. Mg; $24,5 \%$ CM; 40\% $\beta-C D$

$\mathrm{B} 3=25 \%$ HPMC K4M; $10 \%$ Furos.; 0,5\% Est. Mg; 4,5\% CM; $60 \% \beta-C D$ 


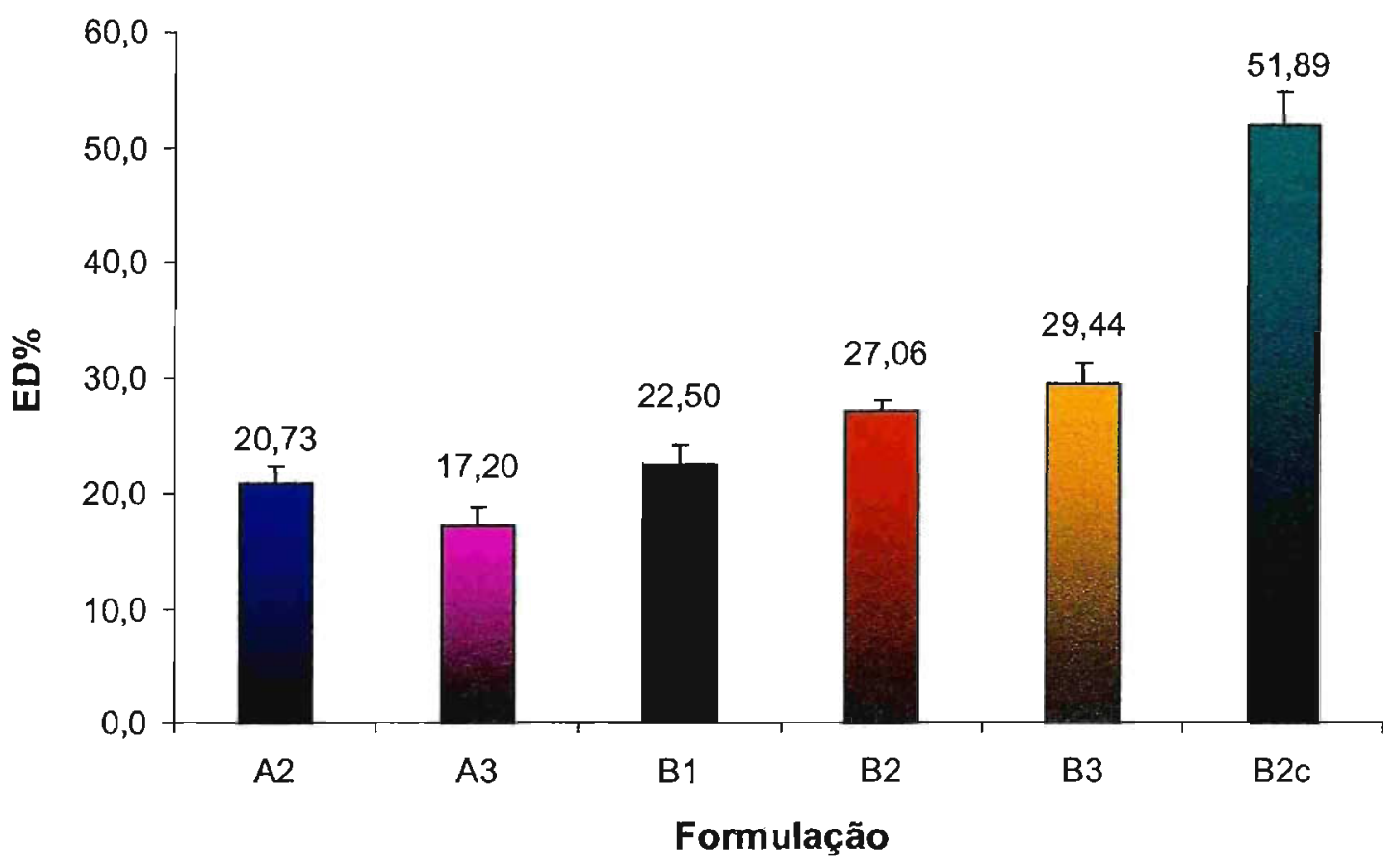

Figura 17. Sumário dos valores de eficiência de dissolução (ED\%) da furosemida a partir de comprimidos preparados com as formulações $A 2, A 3$, $B 1, B 2, B 3$ e B2C.

Tabela 18. Influência da porcentagem de HPMC, pela comparação dos valores de $E D \%$ da furosemida por comprirnidos preparados com as formulações $A 2 \mathrm{e}$ A3

\begin{tabular}{lcccr}
\hline & A2 & A3 & Resultado & Valor-p \\
\hline ED\% $\pm \mathrm{DP}$ & $20,73 \pm 1,59$ & $17,20 \pm 1,58$ & Diferentes & 0,00319 \\
\hline $\mathrm{p}=$ índice de significância ANOVA - fator único; $\mathrm{DP}=$ desvio-padrão da média $(\mathrm{n}=6)$
\end{tabular}


Tabela 19. Influência da adição de $\beta-C D$, pela comparação dos valores de $E D \%$ da furosemida por comprimidos preparados com as formulações $A 2, B 1$, B2 e B3

\begin{tabular}{|c|c|c|c|c|}
\hline & A2 & B1 & Resultado & Valor-p \\
\hline \multirow[t]{2}{*}{$\overline{E D} \% \pm \mathrm{DP}$} & $20,73 \pm 1,59$ & $22,50 \pm 1,70$ & Semelhantes & 0,09283 \\
\hline & A2 & B2 & & \\
\hline \multirow[t]{2}{*}{$\mathrm{ED} \% \pm \mathrm{DP}$} & $20,73 \pm 1,59$ & $27,06 \pm 0,90$ & Diferentes & $<0,00001$ \\
\hline & $\mathbf{A 2}$ & B3 & & \\
\hline \multirow[t]{2}{*}{$\mathrm{ED} \% \pm \mathrm{DP}$} & $20,73 \pm 1,59$ & $29,44 \pm 1,68$ & Diferentes & $<0,00001$ \\
\hline & $\mathbf{A 2}$ & B2c & & \\
\hline \multirow[t]{2}{*}{$E D \% \pm D P$} & $20,73 \pm 1,59$ & $51,89 \pm 2,09$ & Diferentes & $<0,00001$ \\
\hline & B1 & $\mathbf{B 2}$ & & \\
\hline \multirow[t]{2}{*}{$E D \% \pm D P$} & $22,50 \pm 1,70$ & $27,06 \pm 0,90$ & Diferentes & 0,00018 \\
\hline & B1 & B3 & & \\
\hline \multirow[t]{2}{*}{$E D \% \pm D P$} & $22,50 \pm 1,70$ & $29,44 \pm 1,68$ & Diferentes & $<0,00001$ \\
\hline & B1 & B2C & & \\
\hline \multirow[t]{2}{*}{$E D \% \pm D P$} & $22,50 \pm 1,70$ & $51,89 \pm 2,09$ & Diferentes & $<0,00001$ \\
\hline & B2 & B3 & & \\
\hline \multirow[t]{2}{*}{$E D \% \pm D P$} & $27,06 \pm 0,90$ & $29,44 \pm 1,68$ & Diferentes & 0,00017 \\
\hline & B2 & B2c & & \\
\hline \multirow[t]{2}{*}{$E D \% \pm D P$} & $27,06 \pm 0,90$ & $51,89 \pm 2,09$ & Diferentes & $<0,00001$ \\
\hline & B3 & B2C & & \\
\hline$E D \% \pm D P$ & $29,44 \pm 1,68$ & $51,89 \pm 2,09$ & Diferentes & $<0,00001$ \\
\hline
\end{tabular}


Tabela 20. Valores de área sob a curva (ASC) e eficiência de dissolução $(E D \%)$ calculados a partir dos perfis de dissolução da furosemida pelas formulações A2, C1, C2, C3 e C2c.

\begin{tabular}{|c|c|c|c|c|c|}
\hline \multirow{2}{*}{$\Delta t(\min )$} & A2 & C1 & C2 & C2c & C3 \\
\hline & \multicolumn{5}{|c|}{ ASC Média $(n=6)$} \\
\hline $0-15$ & 30,11 & 35,73 & 38,86 & 125,84 & 42,69 \\
\hline $15-30$ & 77,14 & 81,68 & 91,23 & 329,26 & 110,18 \\
\hline $30-60$ & 237,50 & 228,08 & 253,74 & 936,31 & 320,41 \\
\hline $60-120$ & 699,77 & 655,89 & 773,44 & 2585,13 & 950,13 \\
\hline $120-180$ & 960,76 & 829,81 & 1061,47 & 3423,96 & 1332,04 \\
\hline $180-240$ & 1203,38 & 990,29 & 1302,26 & 4068,20 & 1611,15 \\
\hline $240-300$ & 1393,59 & 1158,38 & 1535,61 & 4575,12 & 1832,83 \\
\hline $300-360$ & 1584,18 & 1306,21 & 1746,48 & 5035,43 & 2073,93 \\
\hline $360-420$ & 1791,49 & 1426,03 & 1931,86 & 5375,28 & 2282,54 \\
\hline $420-480$ & 1972,57 & 1542,07 & 2066,36 & 5565,10 & 2430,75 \\
\hline \multirow[t]{4}{*}{$0-480$} & 9950,48 & 8254,16 & 10801,31 & 32019,63 & 12986,66 \\
\hline & \multicolumn{5}{|c|}{$E D \% \pm D P(n=6)$} \\
\hline & 20,73 & 34,14 & 46,49 & 66,708 & 60,36 \\
\hline & $\pm 1,59$ & $\pm 4,10$ & $\pm 1,83$ & $\pm 2,29$ & $\pm 0,84$ \\
\hline
\end{tabular}

Legenda: A2 = 25\% HPMC K4M; 10\% Furos.; 0,5\% Est. Mg; 64,5\% CM

$\mathrm{C} 1=25 \%$ HPMC K4M; $10 \%$ Furos.; 0,5\% Est. Mg; $44,5 \% \mathrm{CM} ; 20 \%$ HP- $\beta-\mathrm{CD}$

$\mathrm{C} 2$ e C2c $=25 \%$ HPMC K4M; $10 \%$ Furos.; 0,5\% Est. Mg; 24,5\% CM; 40\% HP- $\beta-C D$

$\mathrm{C} 3=25 \%$ HPMC K4M; $10 \%$ Furos.; 0,5\% Est. Mg; 4,5\% CM; $60 \%$ HP- $\beta-C D$ 


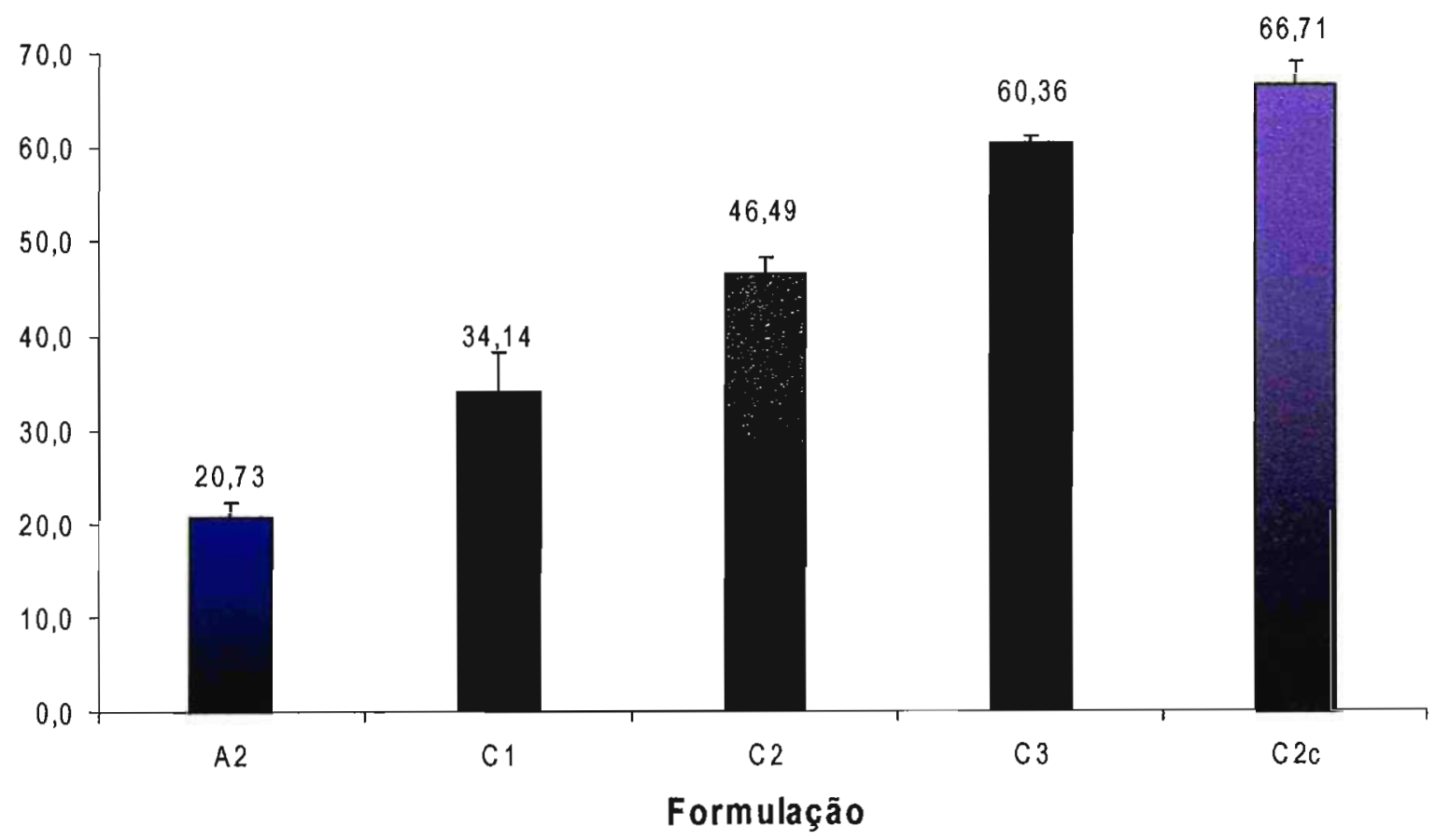

Figura 18. Sumário dos valores médios de eficiência de dissolução (ED\%) da furosemida a partir de comprimidos preparados com as formulações $A 2, C 1$, $\mathrm{C} 2, \mathrm{C} 3$ e $\mathrm{C} 2 \mathrm{c}$. 
Tabela 21. Influência da adição de HP- $\beta$-CD pela comparação dos valores de ED\% da furosemida por comprimidos preparados com as formulações $A 2, C 1$, $\mathrm{C} 2, \mathrm{C} 3$ e C2c.

\begin{tabular}{|c|c|c|c|c|}
\hline & A2 & C1 & Resultado & Valor-p \\
\hline \multirow[t]{2}{*}{$\mathrm{ED} \% \pm \mathrm{DP}$} & $20,73 \pm 1,59$ & $34,14 \pm 4,10$ & Diferentes & $<0,00001$ \\
\hline & A2 & $\mathrm{C} 2$ & & \\
\hline \multirow[t]{2}{*}{$E D \% \pm D P$} & $20,73 \pm 1,59$ & $46,49 \pm 1,83$ & Diferentes & $<0,00001$ \\
\hline & A2 & $\overline{c 3}$ & & \\
\hline \multirow[t]{2}{*}{$\mathrm{ED} \% \pm \mathrm{DP}$} & $20,73 \pm 1,59$ & $60,36 \pm 0,84$ & Diferentes & $<0,00001$ \\
\hline & C1 & $\overline{C 2}$ & & \\
\hline \multirow[t]{2}{*}{$\mathrm{ED} \% \pm \mathrm{DP}$} & $34,14 \pm 4,10$ & $46,49 \pm 1,83$ & Diferentes & $<0,00001$ \\
\hline & C1 & C3 & & \\
\hline \multirow[t]{2}{*}{$E D \% \pm D P$} & $34,14 \pm 4,10$ & $60,36 \pm 0,84$ & Diferentes & $<0,00001$ \\
\hline & $\mathrm{C1}$ & C2c & & \\
\hline \multirow[t]{2}{*}{$E D \% \pm D P$} & $34,14 \pm 4,10$ & $66,71 \pm 2,29$ & Diferentes & $<0,00001$ \\
\hline & $\mathrm{C2}$ & C3 & & \\
\hline \multirow[t]{2}{*}{$E D \% \pm D P$} & $46,49 \pm 1,83$ & $60,36 \pm 0,84$ & Diferentes & $<0,00001$ \\
\hline & $\mathrm{C2}$ & C2c & & \\
\hline \multirow[t]{2}{*}{$E D \% \pm D P$} & $46,49 \pm 1,83$ & $66,71 \pm 2,29$ & Diferentes & $<0,00001$ \\
\hline & C3 & C2c & & \\
\hline$E D \% \pm D P$ & $60,36 \pm 0,84$ & $66,71 \pm 2,29$ & Diferentes & $<0,00001$ \\
\hline
\end{tabular}


Tabela 22. Valores de área sob a curva (ASC) e eficiência de dissolução $(E D \%)$ calculados a partir dos perfis de dissolução da furosemida empregandose as formulações A2, D1, D2 e D3

\begin{tabular}{|c|c|c|c|c|}
\hline \multirow{2}{*}{$\Delta t(\min )$} & A2 & D1 & D2 & D3 \\
\hline & \multicolumn{4}{|c|}{ ASC Média $(n=6)$} \\
\hline $0-15$ & 30,11 & 51,03 & 52,10 & 109,21 \\
\hline $15-30$ & 77,14 & 128,47 & 130,61 & 239,02 \\
\hline $30-60$ & 237,50 & 365,49 & 388,09 & 603,74 \\
\hline $60-120$ & 699,77 & 1051,83 & 1188,62 & 1661,98 \\
\hline $120-180$ & 960,76 & 1462,59 & 1635,84 & 2140,06 \\
\hline $180-240$ & 1203,38 & 1821,23 & 1984,50 & 2532,47 \\
\hline $240-300$ & 1393,59 & 2118,66 & 2297,59 & 2912,18 \\
\hline $300-360$ & 1584,18 & 2350,58 & 2612,39 & 3179,39 \\
\hline $360-420$ & 1791,49 & 2565,66 & 2928,65 & 3367,34 \\
\hline $420-480$ & 1972,57 & 2763,21 & 3130,56 & 3606,68 \\
\hline \multirow[t]{3}{*}{$0-480$} & 9950,48 & 14678,75 & 16348,93 & 20352,07 \\
\hline & \multicolumn{4}{|c|}{$E D \% \pm D P(n=6)$} \\
\hline & $73 \pm 1,59$ & $0,58 \pm 1,93$ & $34,06 \pm 1,46$ & $42,40 \pm 1,49$ \\
\hline
\end{tabular}

Legenda: A2 = 25\% HPMC K4M; $10 \%$ Furos.; 0,5\% Est. Mg; 64,5\% CM

D1 $=25 \%$ HPMC K4M; $10 \%$ Furos.; 0,5\% Est. Mg; 44,5\% CM; 20\% lactose

D2 e D2c $=25 \%$ HPMC K4M; $10 \%$ Furos.; 0,5\% Est. Mg; 24,5\% CM; 40\% lactose

D3 $=25 \%$ HPMC K4M; 10\% Furos.; 0,5\% Est. Mg; 4,5\% CM; 60\% lactose 


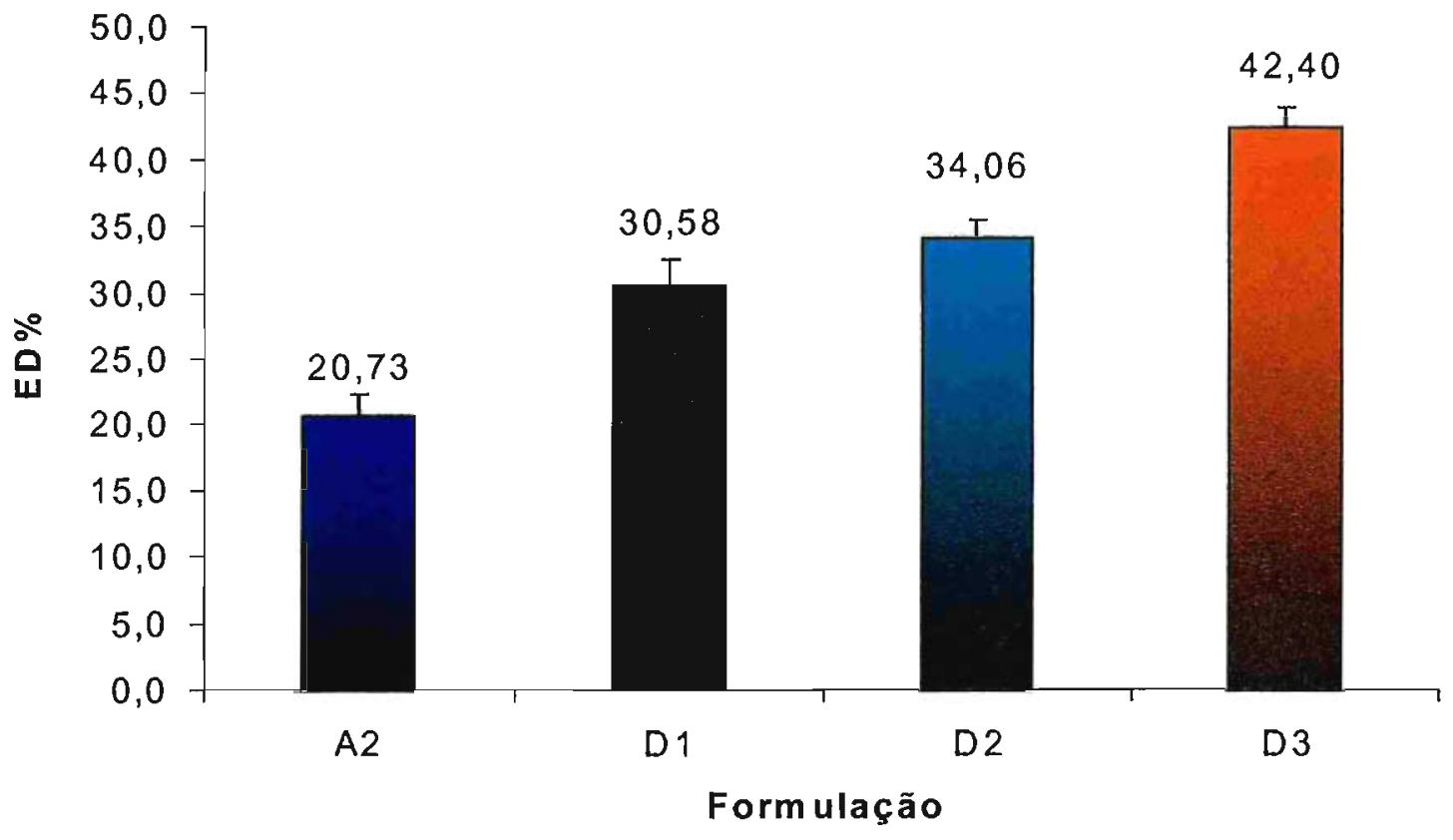

Figura 19. Sumário dos valores de eficiência de dissolução (ED\%) da furosemida a partir de comprimidos preparados com as formulações A2, D1, D2 e D3. 
Tabela 23. Influência da adição de lactose monohidratada, pela comparação dos valores de ED\% da furosemida por comprimidos preparados com as formulações A2, D1, D2 e D3

\begin{tabular}{|c|c|c|c|c|}
\hline & $\overline{A 2}$ & D1 & Resultado & Valor-p \\
\hline \multirow[t]{2}{*}{$E D \% \pm D P$} & $20,73 \pm 1,59$ & $30,58 \pm 1,94$ & Diferentes & $<0,00001$ \\
\hline & A2 & D2 & & \\
\hline \multirow[t]{2}{*}{$E D \% \pm D P$} & $20,73 \pm 1,59$ & $34,06 \pm 1,46$ & Diferentes & $<0,00001$ \\
\hline & A2 & D3 & & \\
\hline \multirow[t]{2}{*}{$E D \% \pm D P$} & $20,73 \pm 1,59$ & $42,40 \pm 1,49$ & Diferentes & $<0,00001$ \\
\hline & D1 & D2 & & \\
\hline \multirow[t]{2}{*}{$\mathrm{ED} \% \pm \mathrm{DP}$} & $30,58 \pm 1,93$ & $34,06 \pm 1,465$ & Diferentes & $<0,00001$ \\
\hline & D1 & D3 & & \\
\hline \multirow[t]{2}{*}{$\mathrm{ED} \% \pm \mathrm{DP}$} & $30,58 \pm 1,93$ & $42,40 \pm 1,48$ & Diferentes & $<0,00001$ \\
\hline & D2 & D3 & & \\
\hline $\mathrm{ED} \% \pm \mathrm{DP}$ & $34,06 \pm 1,46$ & $42,40 \pm 1,49$ & Diferentes & $<0,00001$ \\
\hline
\end{tabular}




\subsubsection{Determinação da cinética de dissolução da furosemida}

As Figuras de 20 a 29 apresentam a aplicação dos modelos matemáticos de linearização de ordem zero, primeira ordem e Higuchi aos perfis de dissolução da furosemida empregando-se as formulações $A 2, A 3, B 1$, B2, B3, B2c, C2, C3, C2C, D1, D2 e D3.

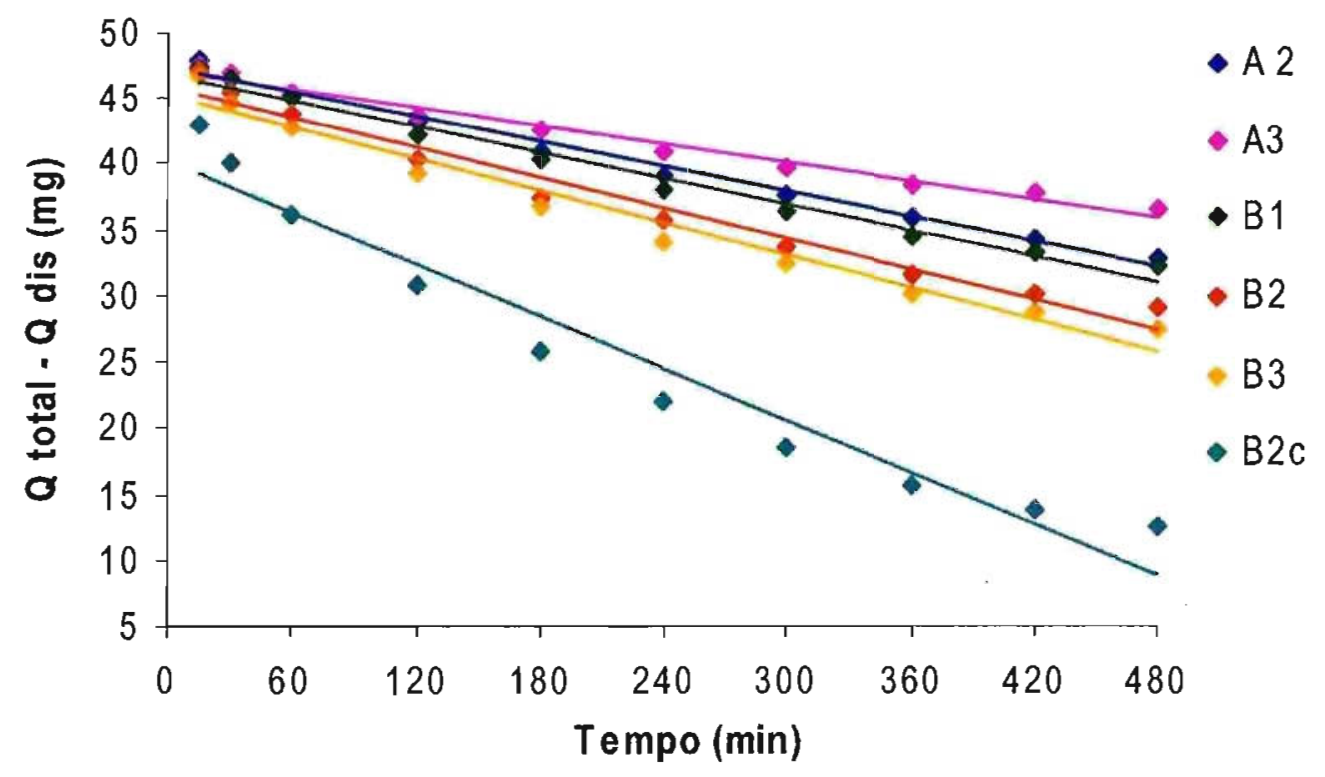

Figura 20. Curvas obtidas pela aplicação do modelo matemático de linearização de ordem zero aos perfis de dissolução da furosemida empregando-se as formulações A2, A3, B1, B2, B3 e B2C. 


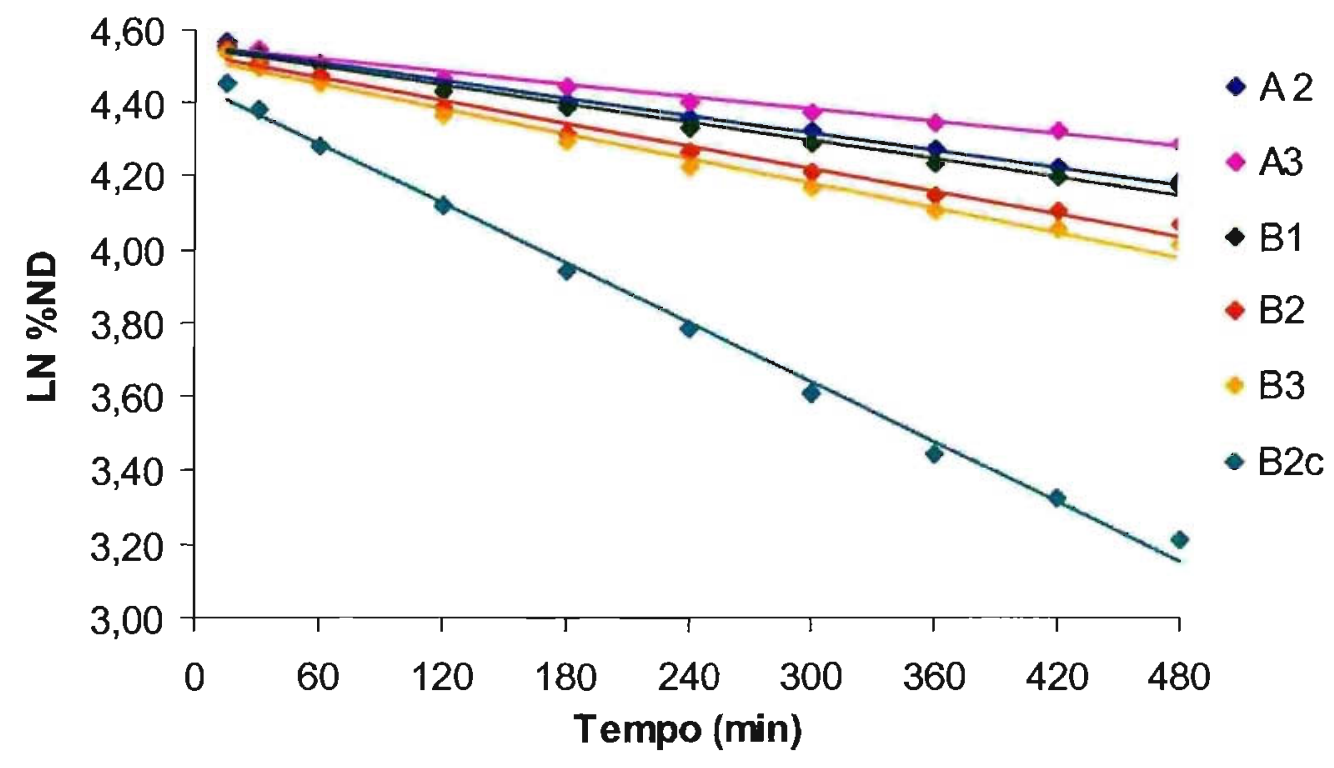

Figura 21. Curvas obtidas pela aplicação do modelo matemático de linearização de primeira ordem aos perfis de dissolução da furosemida empregando-se as formulações A2, A3, B1, B2, B3 e B2c.

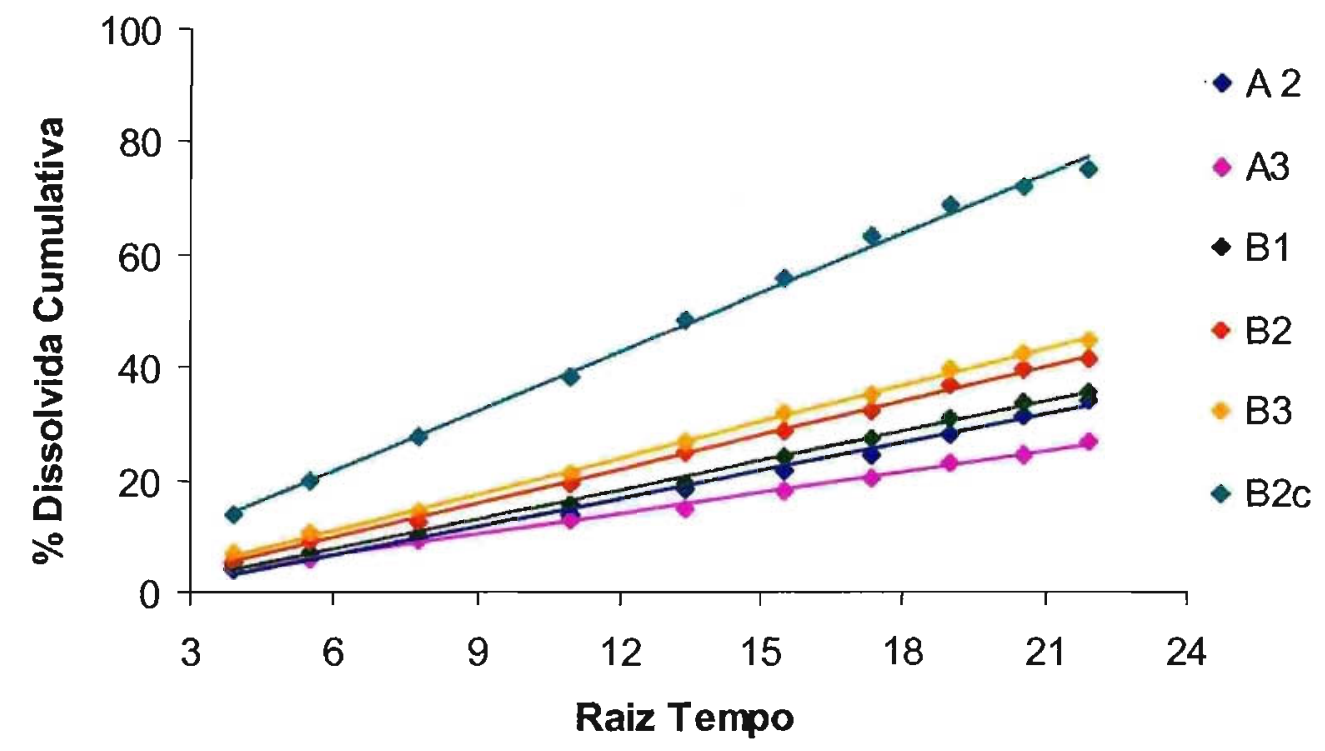

Figura 22. Curvas obtidas pela aplicação do modelo matemático de linearização de Higuchi aos perfis de dissolução da furosemida empregando-se as formulações A2, A3, B1, B2, B3 e B2c. 


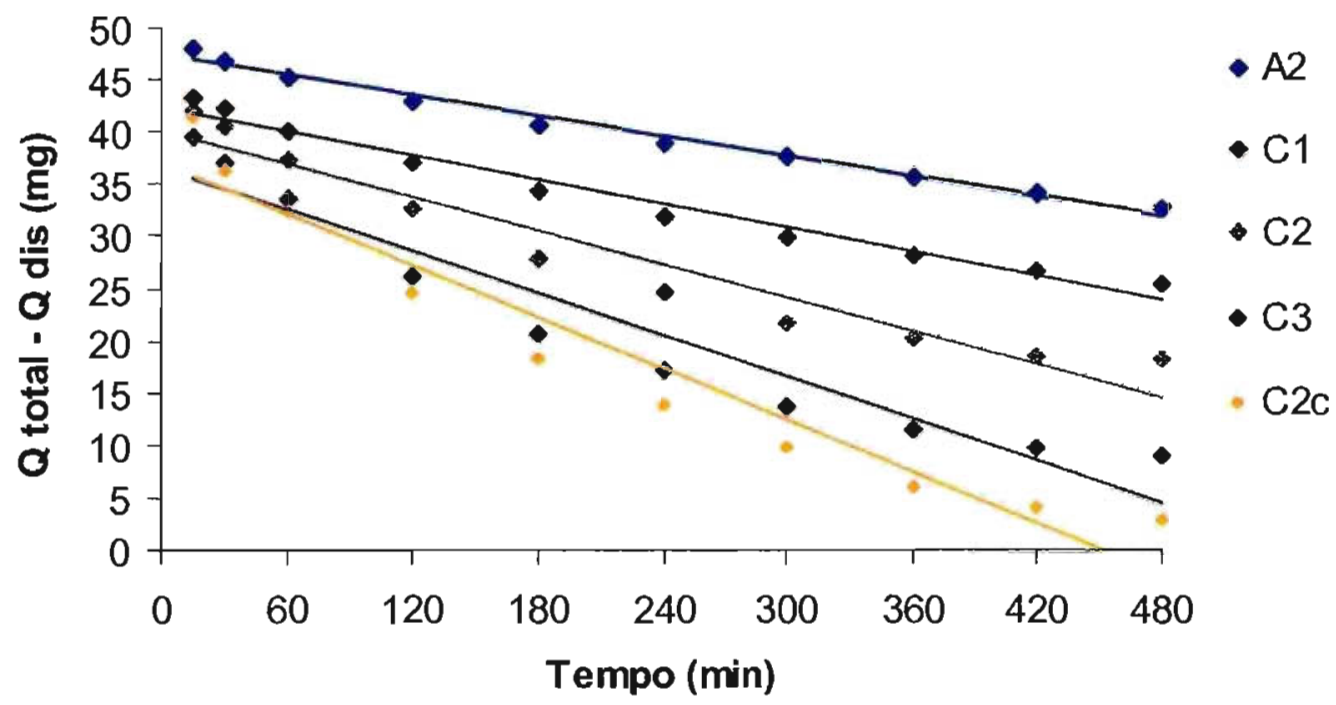

Figura 23. Curvas obtidas pela aplicação do modelo matemático de linearização de ordem zero aos perfis de dissolução da furosemida empregando-se as formulações A2, C1, C2 e C3.

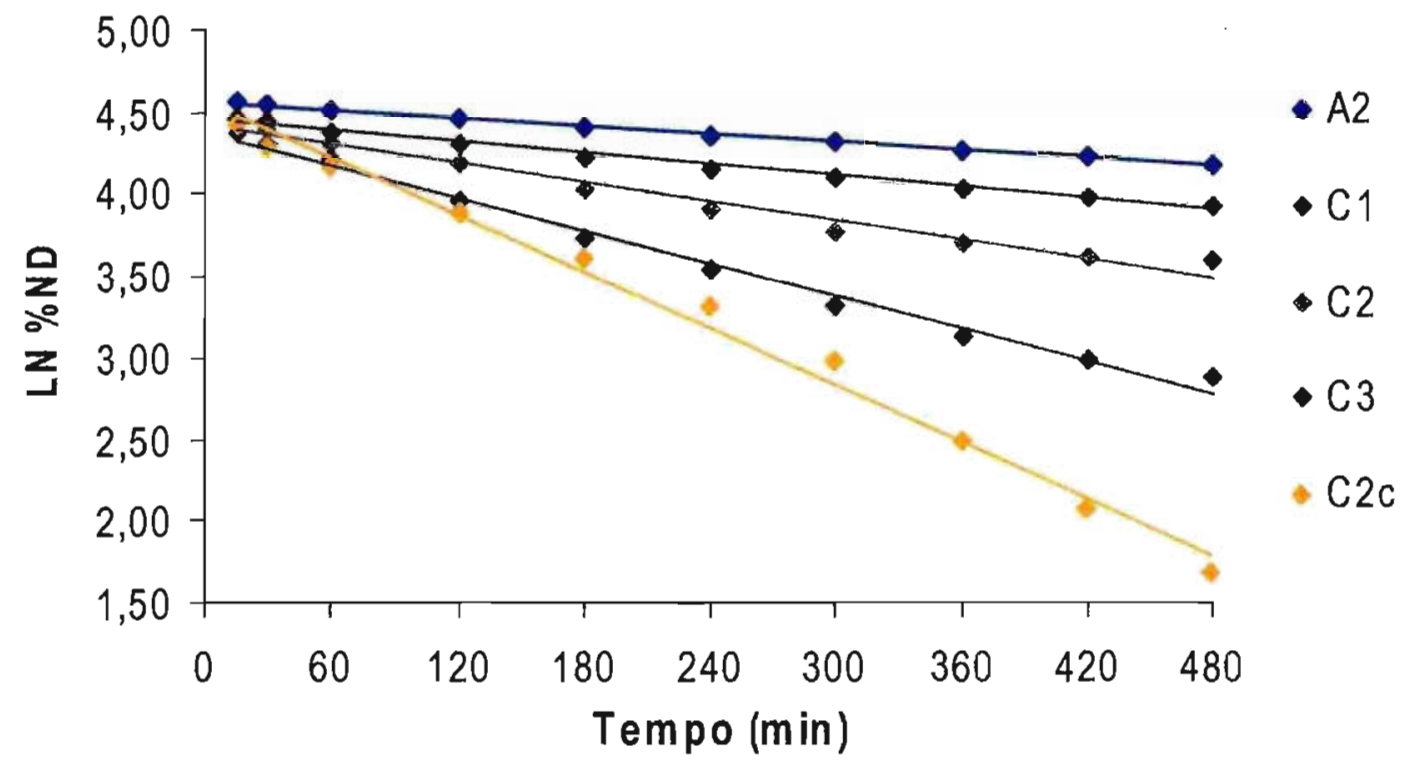

Figura 24. Curvas obtidas pela aplicação do modelo matemático de linearização de primeira ordem aos perfis de dissolução da furosemida empregando-se as formulações A2, C1, C2, C3 e C2c. 


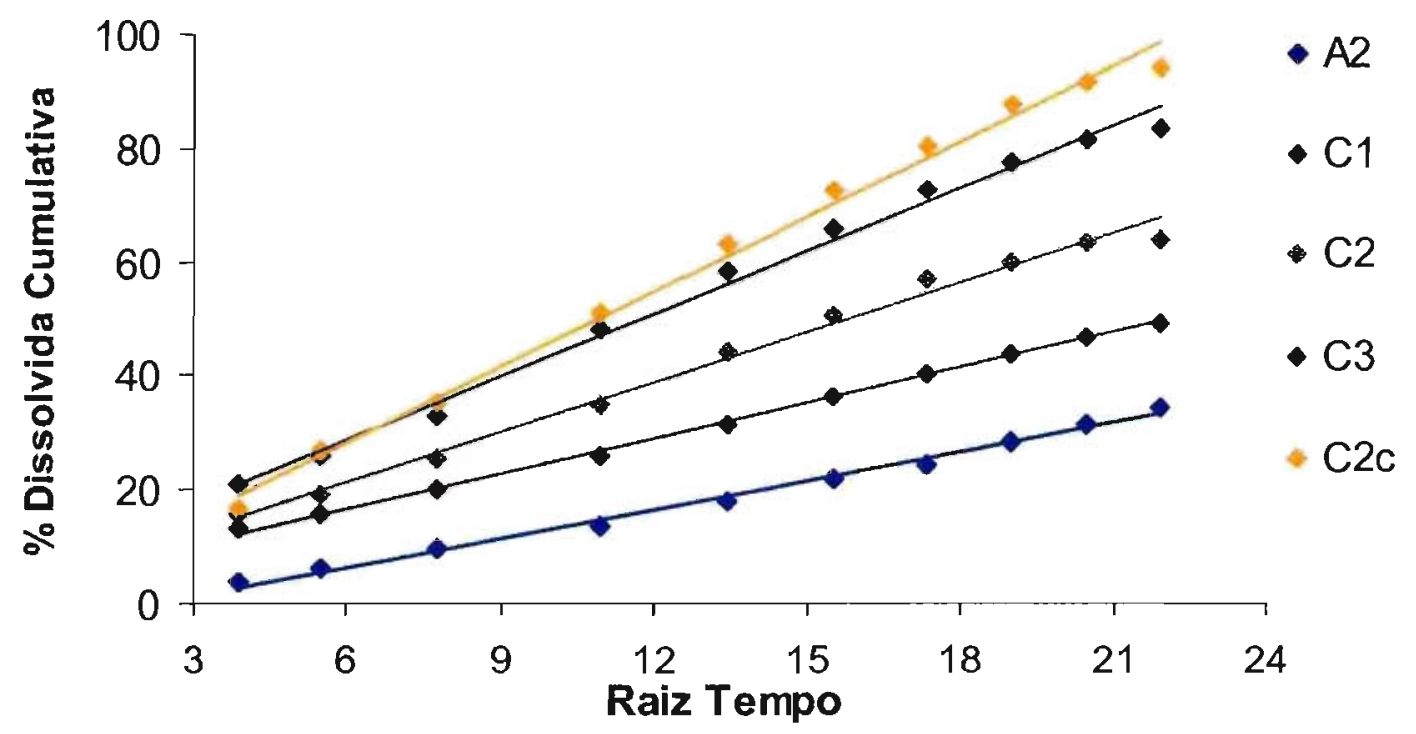

Figura 25. Curvas obtidas pela aplicação do modelo matemático de linearização de Higuchi aos perfis de dissolução da furosemida empregando-se as formulações A2, C1, C2, C3 e C2c.

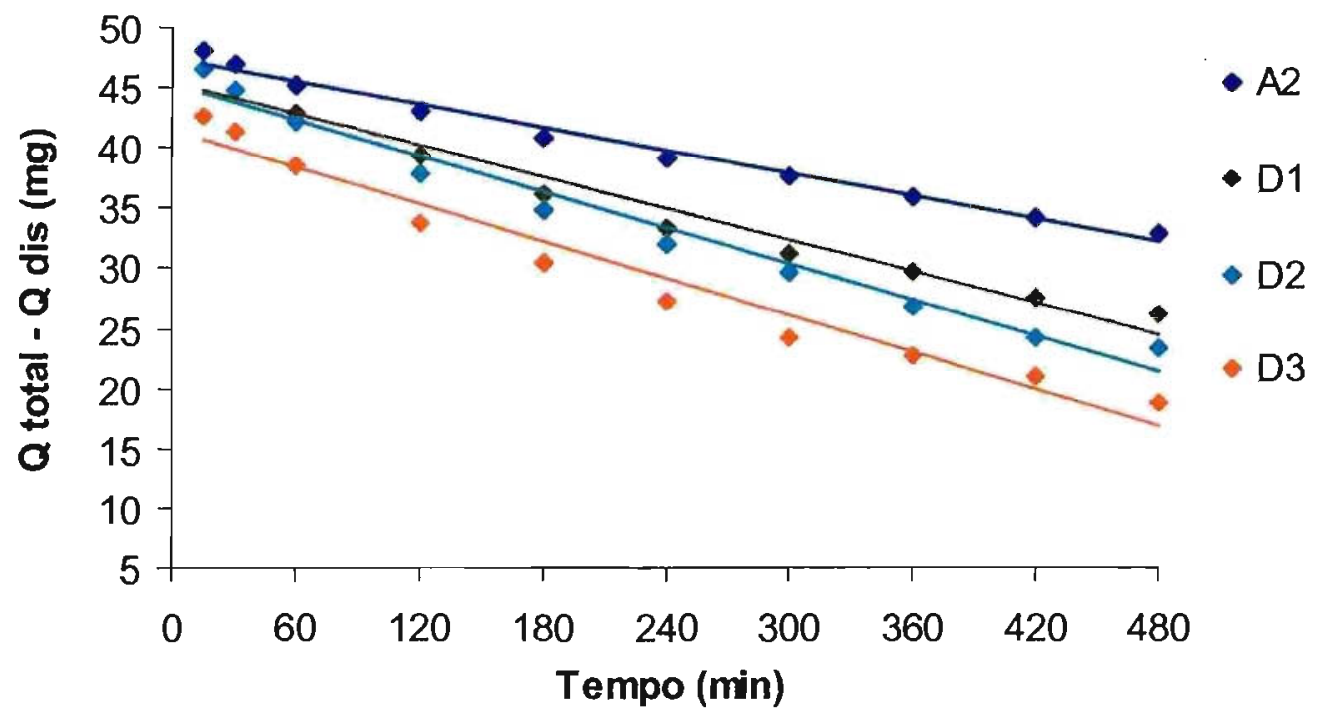

Figura 26. Curvas obtidas pela aplicação do modelo matemático de linearização de ordem zero aos perfis de dissolução da furosemida empregando-se as formulações A2, D1, D2 e D3. 


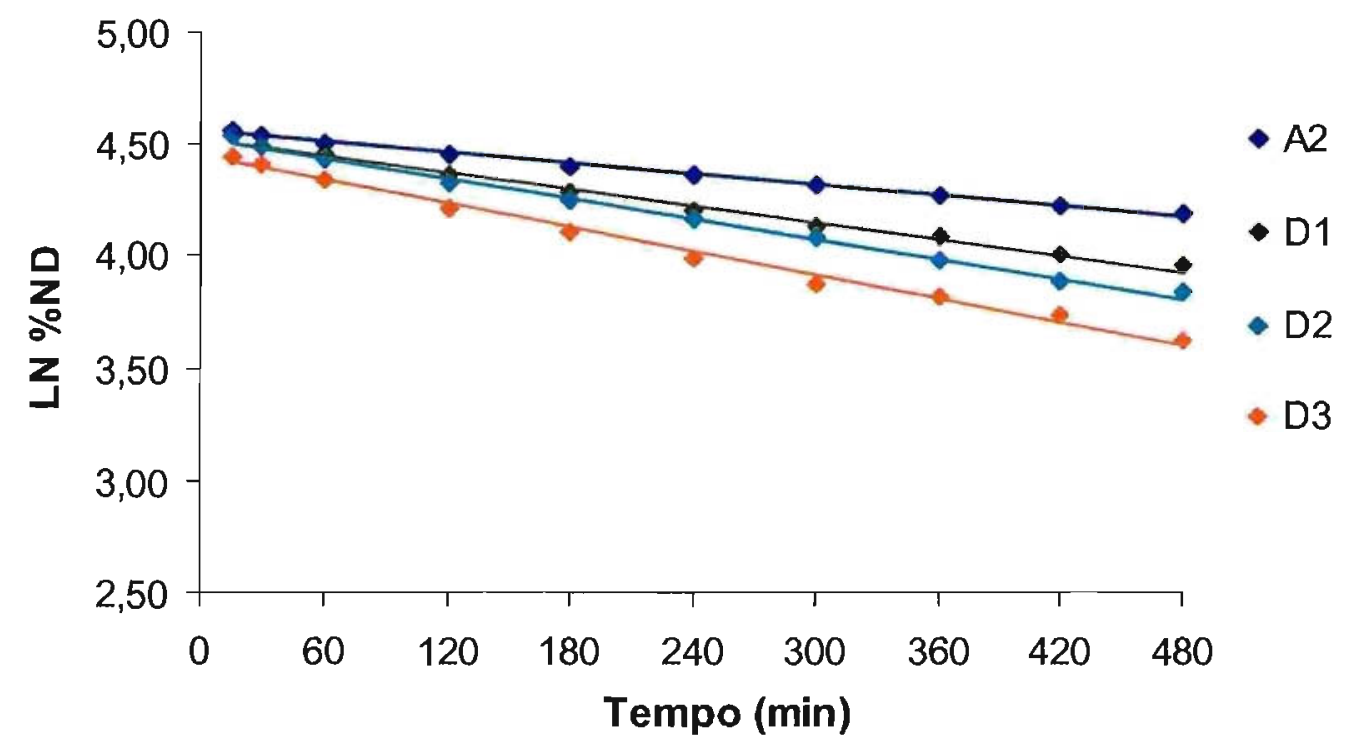

Figura 27. Curvas obtidas pela aplicação do modelo matemático de linearização de primeira ordem aos perfis de dissolução da furosemida empregando-se as formulações A2, D1, D2 e D3.

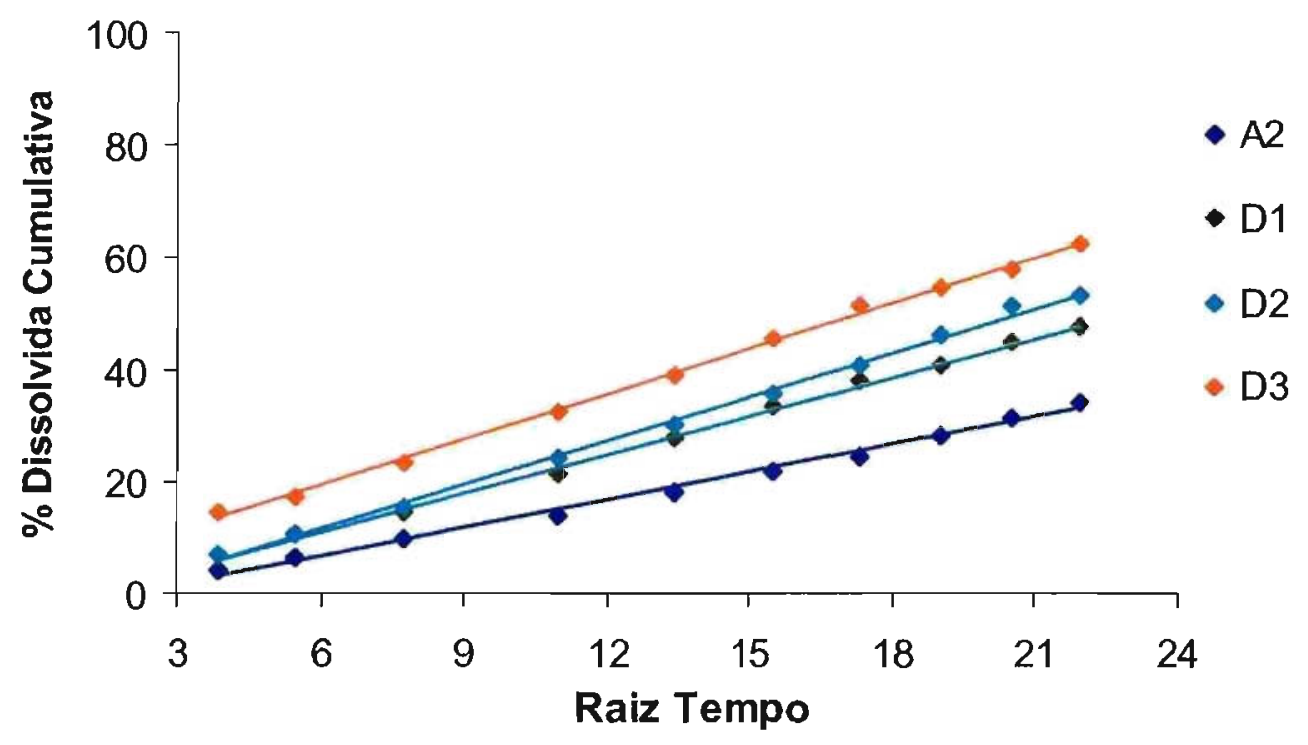

Figura 28. Curvas obtidas pela aplicação do modelo matemático de linearização de Higuchi aos perfis de dissolução da furosemida empregando-se as formulações A2, D1, D2 e D3. 
Tabela 24. Valores do coeficiente de correlação $\left(r^{2}\right)$ para os três modelos matemáticos utilizados na linearização das curvas de dissolução

\begin{tabular}{cccc}
\hline \multirow{2}{*}{ Formulação } & \multicolumn{3}{c}{ Coeficiente de Correlação $\left(\mathbf{r}^{2}\right)$} \\
\cline { 2 - 4 } A2 & Ordem Zero & Primeira Ordem & Higuchi \\
\hline A3 & 0,9868 & 0,9943 & $\mathbf{0 , 9 9 5 3}$ \\
B1 & 0,9868 & 0,9880 & $\mathbf{0 , 9 9 6 3}$ \\
B2 & 0,9793 & 0,9911 & $\mathbf{0 , 9 9 6 1}$ \\
B3 & 0,9682 & 0,9860 & $\mathbf{0 , 9 9 8 6}$ \\
B2C & 0,9691 & 0,9881 & $\mathbf{0 , 9 9 9 0}$ \\
C1 & 0,9526 & 0,9954 & $\mathbf{0 , 9 9 7 1}$ \\
C2 & 0,9715 & 0,9904 & $\mathbf{0 , 9 9 8 7}$ \\
C3 & 0,9397 & 0,9757 & $\mathbf{0 , 9 9 1 4}$ \\
C2C & 0,9303 & 0,9901 & $\mathbf{0 , 9 9 2 0}$ \\
D1 & 0,9374 & 0,9907 & $\mathbf{0 , 9 9 3 7}$ \\
D2 & 0,9728 & 0,9913 & $\mathbf{0 , 9 9 7 7}$ \\
D3 & 0,9751 & 0,9942 & $\mathbf{0 , 9 9 7 5}$ \\
\hline
\end{tabular}

Legenda: $\mathrm{A} 2=25 \%$ HPMC K4M; $10 \%$ Furos.; 0,5\% Est. Mg; 64,5\% CM

$\mathrm{A} 3=35 \%$ HPMC K4M; $10 \%$ Furos.; 0,5\% Est. Mg; 54,5\% CM

B1 $=25 \%$ HPMC K4M; $10 \%$ Furos.; 0,5\% Est. Mg; 44,5\% CM; $20 \% \beta-C D$

B2 e B2C $=25 \%$ HPMC K4M; $10 \%$ Furos.; 0,5\% Est. Mg; $24,5 \%$ CM; $40 \% \beta-C D$

$\mathrm{B3}=25 \%$ HPMC K4M; $10 \%$ Furos.; 0,5\% Est. Mg; 4,5\% CM; $60 \% \beta-C D$

$\mathrm{C} 1=25 \%$ HPMC K4M; $10 \%$ Furos.; 0,5\% Est. Mg; $44,5 \%$ CM; $20 \%$ HP- $\beta-C D$

$\mathrm{C} 2$ e $\mathrm{C} 2 \mathrm{c}=25 \%$ HPMC K4M; $10 \%$ Furos.; $0,5 \%$ Est. Mg; $24,5 \% \mathrm{CM} ; 40 \%$ HP- $\beta$-CD

$\mathrm{C} 3=25 \%$ HPMC K4M; $10 \%$ Furos.; $0,5 \%$ Est. Mg; $4,5 \%$ CM; $60 \%$ HP- $\beta-C D$

D1 $=25 \%$ HPMC K4M; $10 \%$ Furos.; $0,5 \%$ Est. Mg; 44,5\% CM; $20 \%$ lactose

D2 e D2c $=25 \%$ HPMC K4M; 10\% Furos.; 0,5\% Est. Mg; 24,5\% CM; 40\% lactose

D3 $=25 \%$ HPMC K4M; 10\% Furos.; 0,5\% Est. Mg; 4,5\% CM; $60 \%$ lactose 


\subsubsection{Determinação das constantes cinéticas}

A Tabela 29 sumariza os valores das constantes cinéticas, $k$ (constante da velocidade de dissolução), Q60, Q240 e Q480 (quantidade de fármaco dissolvido em 60, 240 e 480 minutos). Estes valores foram definidos matematicamente a partir da equação da reta de regressão que melhor definiu a cinética de dissolução. As quantidades foram avaliadas segundo os critérios de Prista et al. (1996) para uma forma farmacêutica de liberação prolongada, representados na Figura 4.

Tabela 25. Valores das constantes cinéticas determinadas a partir da equação definida pelo modelo matemático com maior índice de correlação

\begin{tabular}{ccccc}
\hline \multirow{2}{*}{ Formulação } & \multicolumn{4}{c}{ Constantes Cinéticas } \\
\cline { 2 - 5 } & $\mathbf{k}^{*}\left(\% / \mathbf{m i n}^{1 / 2}\right)$ & $\mathbf{Q 6 0}(\%)$ & $\mathbf{Q 2 4 0}(\%)$ & $\mathbf{Q 4 8 0}(\%)$ \\
\hline A2 & 1,664 & 9,410 & 21,697 & 34,086 \\
A3 & 1,224 & 9,079 & 18,132 & 26,928 \\
B1 & 1,738 & 9,933 & 23,873 & 35,386 \\
B3 & 2,032 & 12,362 & 28,611 & 41,589 \\
B2c & 2,137 & 14,345 & 31,755 & 44,851 \\
C1 & 3,493 & 27,656 & 55,889 & 74,885 \\
C2 & 2,046 & 20,068 & 36,385 & 49,213 \\
C3 & 2,887 & 25,484 & 50,690 & 63,930 \\
C2c & 3,665 & 32,701 & 66,694 & 81,770 \\
D1 & 4,395 & 35,298 & 72,348 & 94,018 \\
D2 & 2,309 & 14,192 & 33,127 & 47,595 \\
D3 & 2,635 & 15,405 & 35,838 & 53,062 \\
\hline${ }^{*} \mathrm{k}=$ coeficiente angular reta de regressão & 2,719 & 22,941 & 45,538 & 62,423 \\
\hline
\end{tabular}




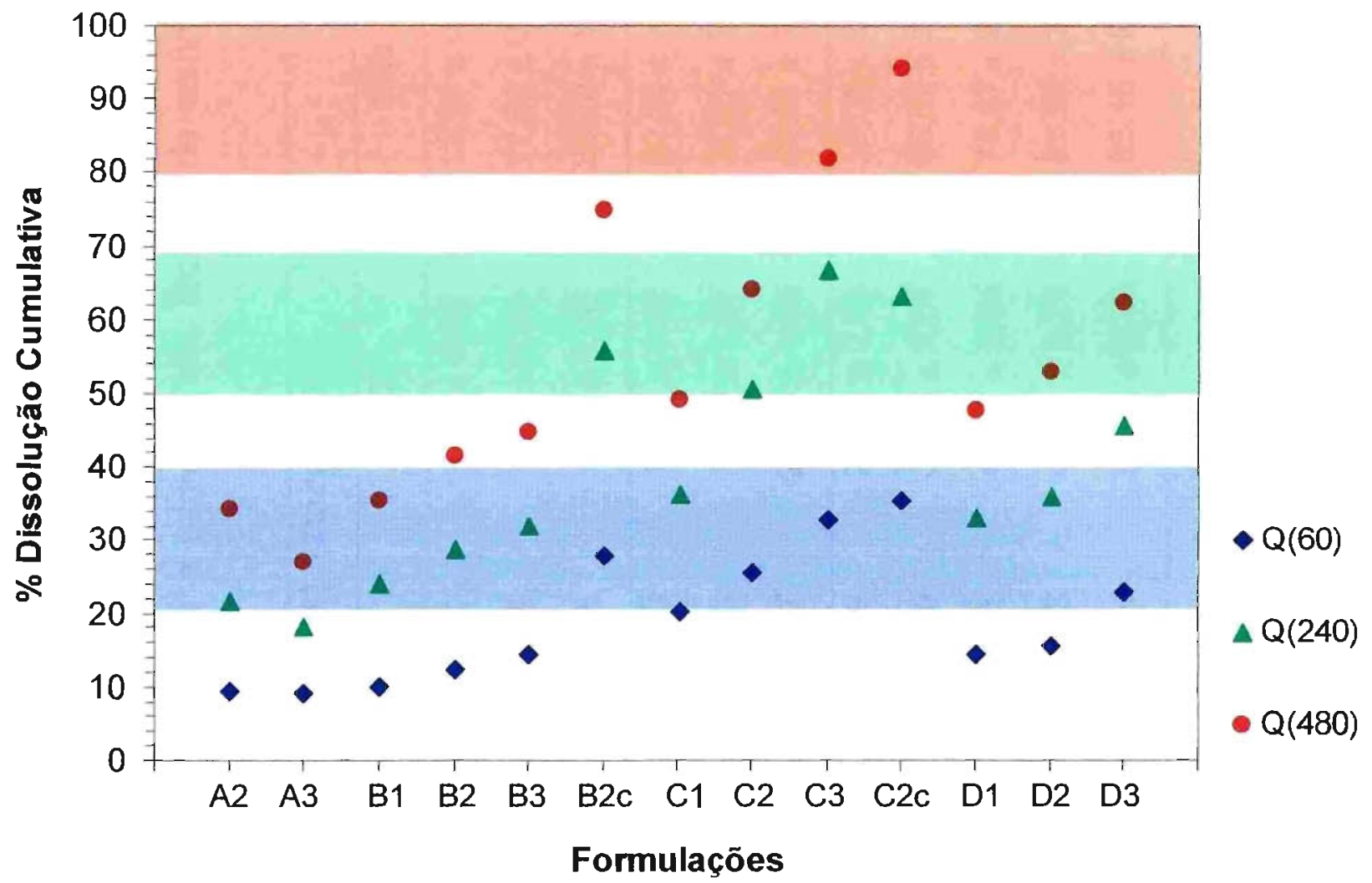

Figura 29. Quantidade de furosemida dissolvida até 60,240 e 480 minutos a partir do comprimidos preparados com as formulações A2-D3. Valores esperados segundo Prista et al. (1996): $20-40 \%$ em 60min; $50-70 \%$ em 240min; 80 - 100\% em 480min. 


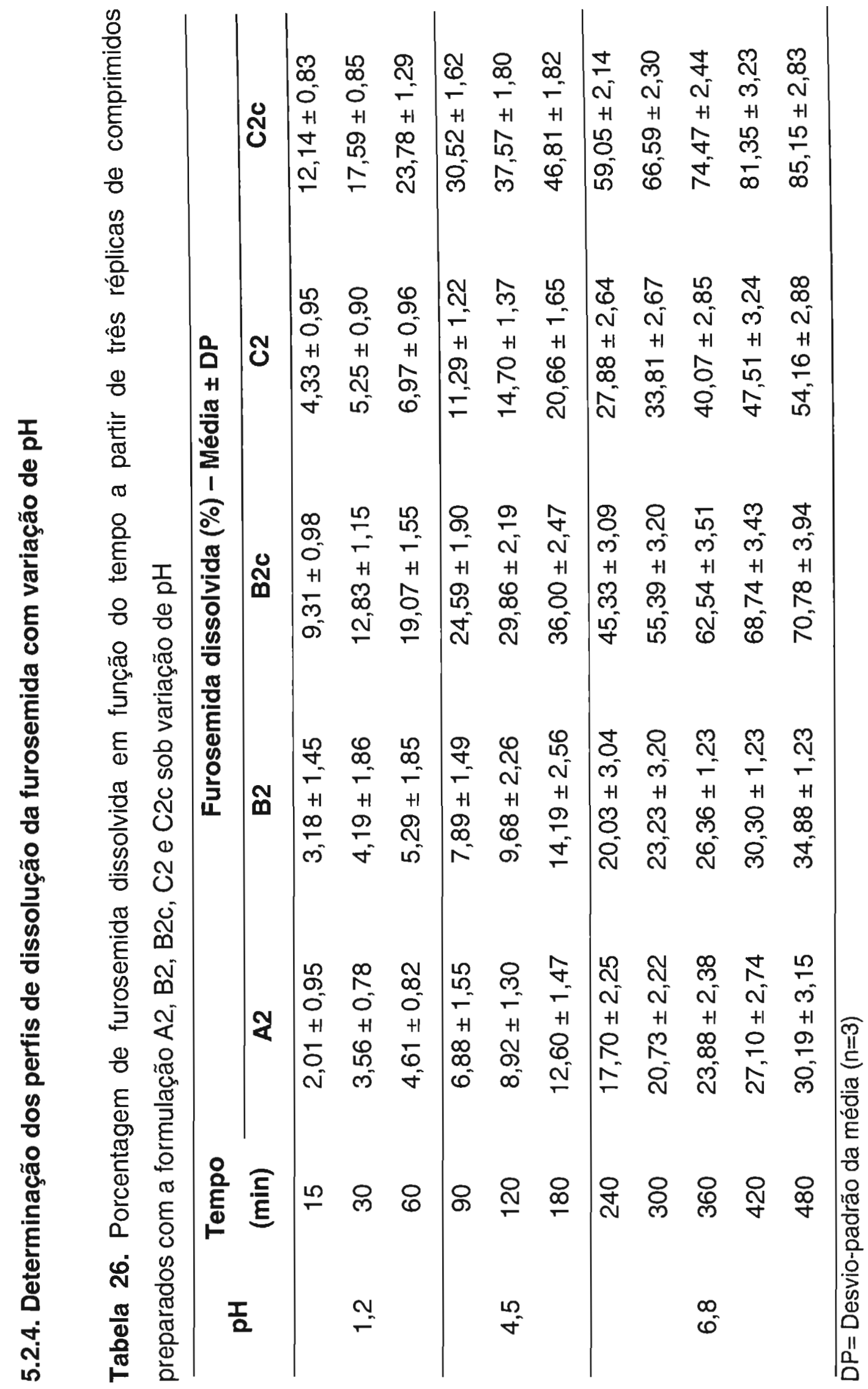




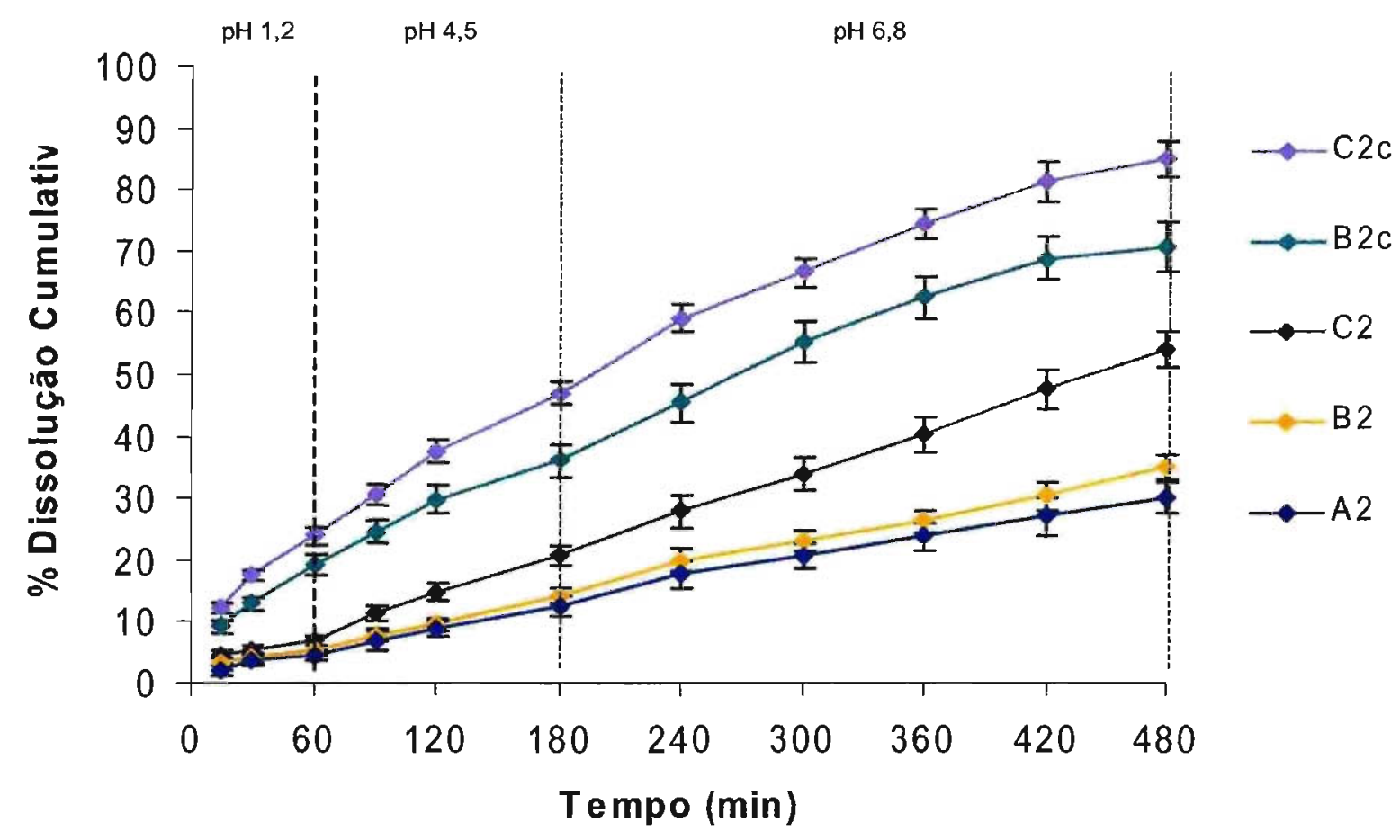

Figura 30. Perfil de dissolução da furosemida a partir de comprimidos preparados com a formulação $\mathrm{A} 2, \mathrm{~B} 2, \mathrm{~B} 2 \mathrm{c}, \mathrm{C} 2$ e $\mathrm{C} 2 \mathrm{c}$ em gradiente de $\mathrm{pH}$, sendo os primeiros $60 \mathrm{~min} \mathrm{em} \mathrm{pH} \mathrm{1,2;} \mathrm{os} 120$ min subsequentes em pH 4,5 e 300 min subsequentes em $\mathrm{pH} 6,8$. 
Tabela 27. Valores da média da área sob a curva (ASC) e eficiência de dissolução (ED\%) calculados a partir dos perfis de dissolução da furosemida nas formulações A2, B2, B2c, C2 e C2c sob variação de $\mathrm{pH}$

\begin{tabular}{|c|c|c|c|c|c|}
\hline \multirow{2}{*}{$\Delta t$ (min) } & A2 & B2 & B2C & C2 & C2C \\
\hline & \multicolumn{5}{|c|}{ ASC Média $(n=3)$} \\
\hline $0-15$ & 15,06 & 23,84 & 69,83 & 32,50 & 91,06 \\
\hline $15-30$ & 41,75 & 55,29 & 166,07 & 71,84 & 222,95 \\
\hline $30-60$ & 122,48 & 142,30 & 478,51 & 183,20 & 620,51 \\
\hline $60-90$ & 172,34 & 197,78 & 654,90 & 273,92 & 814,59 \\
\hline $90-120$ & 237,12 & 263,56 & 816,74 & 389,93 & 1021,40 \\
\hline $120-180$ & 645,87 & 716,02 & 1975,81 & 1060,83 & 2531,41 \\
\hline $180-240$ & 909,24 & 1026,65 & 2440,07 & 1456,09 & 3175,99 \\
\hline $240-300$ & 1152,92 & 1297,76 & 3021,82 & 1850,58 & 3769,46 \\
\hline $300-360$ & 1338,07 & 1487,66 & 3537,94 & 2216,42 & 4231,89 \\
\hline $360-420$ & 1529,15 & 1699,93 & 3938,22 & 2627,42 & 4674,61 \\
\hline $420-480$ & 1718,58 & 1955,37 & 4185,54 & 3050,09 & 4994,90 \\
\hline \multirow[t]{4}{*}{$0-480$} & 7882,58 & 8866,17 & 21285,45 & 13212,82 & 26148,76 \\
\hline & \multicolumn{5}{|c|}{ ED $\%$ - Média \pm DP $(n=3)$} \\
\hline & 16,42 & 18,47 & 44,34 & 27,53 & 54,48 \\
\hline & $\pm 1,903$ & $\pm 1,183$ & $\pm 2,190$ & $\pm 1,875$ & $\pm 1,674$ \\
\hline
\end{tabular}

Legenda: A2 = 25\% HPMC K4M; 10\% Furos.; 0,5\% Est. Mg; 64,5\% CM

$\mathrm{B} 2$ e B2C $=25 \%$ HPMC K4M; $10 \%$ Furos.; 0,5\% Est. Mg; $24,5 \%$ CM; $40 \%$ HP- $\beta-C D$ $\mathrm{C} 2$ e $\mathrm{C} 2 \mathrm{C}=25 \%$ HPMC K4M; $10 \%$ Furos.; $0,5 \%$ Est. Mg; $24,5 \% \mathrm{CM} ; 40 \%$ HP- $\beta-\mathrm{CD}$ 


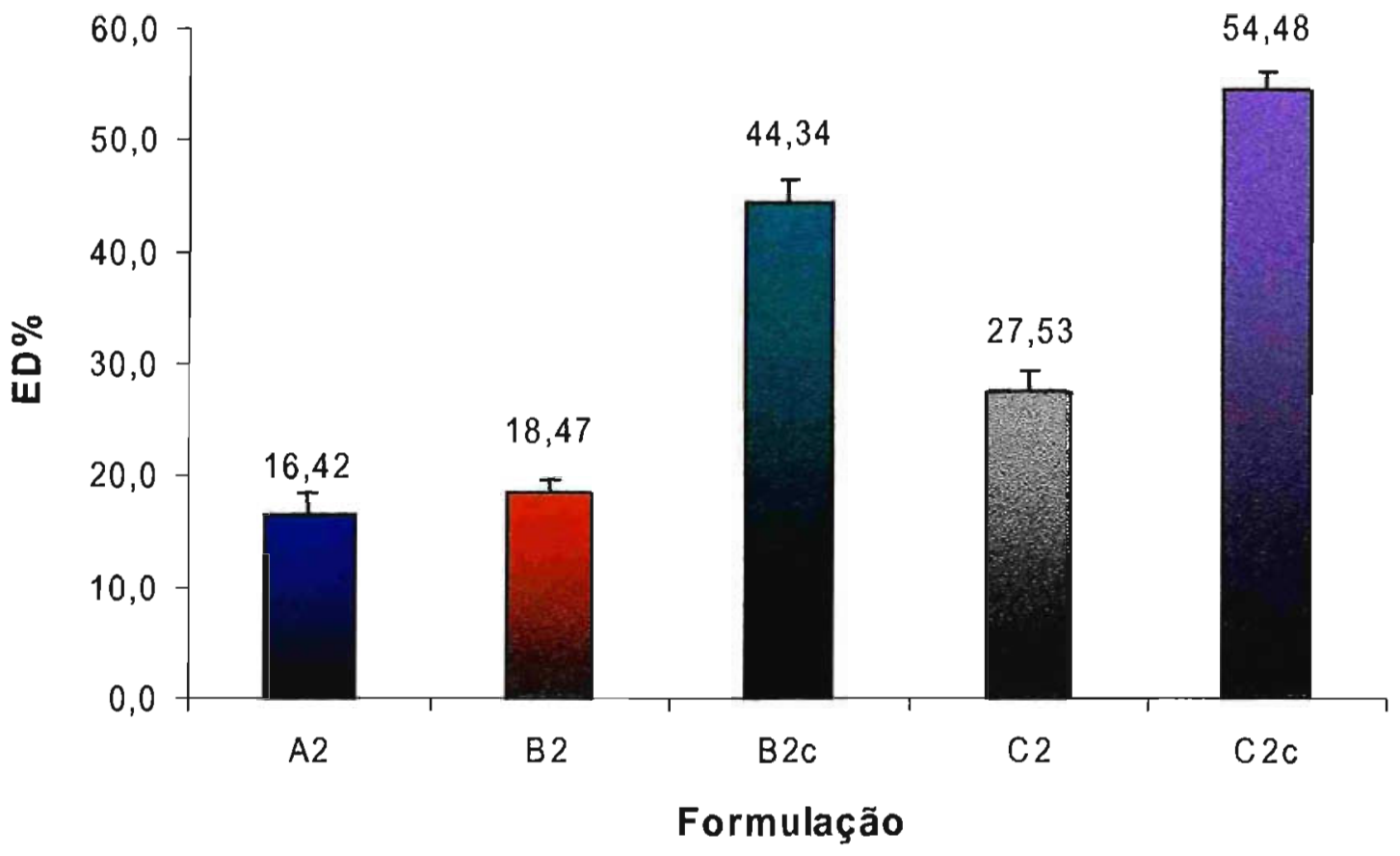

Figura 31. Sumário dos valores médios de eficiência de dissolução (ED\%) da furosemida, obtidos em ensaio de dissolução sob variação de $\mathrm{pH}$, a partir de comprimidos preparados com as formulações A2, B2, B2c, C2 e C2C. 
Tabela 28. Comparação dos valores de eficiência de dissolução (ED\%) da furosemida, obtidos em ensaio de dissolução com variação de $\mathrm{pH}$, a partir dos comprimidos preparados com as formulações A2, C1, C2, C2c e C3

\begin{tabular}{|c|c|c|c|c|}
\hline & A2 & B2 & Resultado & Valor-p \\
\hline \multirow[t]{2}{*}{$\mathrm{ED} \% \pm \mathrm{DP}$} & $16,42 \pm 1,90$ & $18,47 \pm 1,18$ & Semelhantes & 0,21195 \\
\hline & A2 & B2c & & \\
\hline \multirow{2}{*}{$\mathrm{ED} \% \pm \mathrm{DP}$} & $16,42 \pm 1,90$ & $44,34 \pm 2,19$ & Diferentes & 0,00012 \\
\hline & A2 & C2 & & \\
\hline \multirow[t]{2}{*}{$E D \% \pm D P$} & $16,42 \pm 1,90$ & $27,53 \pm 1,87$ & Diferentes & 0,00234 \\
\hline & A2 & $\mathrm{C} 2 \mathrm{c}$ & & \\
\hline \multirow[t]{2}{*}{$\mathrm{ED} \% \pm \mathrm{DP}$} & $16,42 \pm 1,90$ & $54,48 \pm 1,67$ & Diferentes & $<0,00001$ \\
\hline & B2 & B2c & & \\
\hline \multirow[t]{2}{*}{$\mathrm{ED} \% \pm \mathrm{DP}$} & $18,47 \pm 1,18$ & $44,34 \pm 2,19$ & Diferentes & 0,00012 \\
\hline & B2 & C2 & & \\
\hline \multirow[t]{2}{*}{$\mathrm{ED} \% \pm \mathrm{DP}$} & $18,47 \pm 1,18$ & $27,53 \pm 1,87$ & Diferentes & 0,00334 \\
\hline & B2 & C2c & & \\
\hline \multirow[t]{2}{*}{$\mathrm{ED} \% \pm \mathrm{DP}$} & $18,47 \pm 1,18$ & $54,48 \pm 1,67$ & Diferentes & $<0,00001$ \\
\hline & B2c & C2 & & \\
\hline \multirow[t]{2}{*}{$\mathrm{ED} \% \pm \mathrm{DP}$} & $44,34 \pm 2,19$ & $27,53 \pm 1,87$ & Diferentes & 0,00099 \\
\hline & B2c & C2c & & \\
\hline \multirow[t]{2}{*}{$E D \% \pm D P$} & $44,34 \pm 2,19$ & $54,48 \pm 1,67$ & Diferentes & 0,00653 \\
\hline & C2 & C2c & & \\
\hline$E D \% \pm D P$ & $27,53 \pm 1,87$ & $54,48 \pm 1,67$ & Diferentes & 0,00074 \\
\hline
\end{tabular}




\subsection{Ensaios físicos dos comprimidos}

A Tabela 29 sumariza os resultados dos ensaios de peso médio, dureza e friabilidade dos comprimidos preparados com as formulações $A 1, A 2, A 3, B 1$, $\mathrm{B} 2, \mathrm{~B} 3, \mathrm{~B} 2 \mathrm{c}, \mathrm{C1}, \mathrm{C} 2, \mathrm{C} 3, \mathrm{C} 2 \mathrm{c}, \mathrm{D} 1, \mathrm{D} 2 \mathrm{e} \mathrm{D} 3$.

Tabela 29. Ensaios físicos dos comprimidos preparados com as formulações $A 1, A 2, A 3, B 1, B 2, B 3, B 2 c, C 1, C 2, C 3, C 2 c, D 1, D 2$ e D3

\begin{tabular}{|c|c|c|c|}
\hline Formulações & $\begin{array}{c}\text { Peso médio (mg) } \\
\pm \mathrm{DP}^{\star}\end{array}$ & $\begin{array}{c}\text { Dureza (Kgf) } \\
\pm D^{\star \star}\end{array}$ & Friabilidade $\%$ \\
\hline A1 & $502,21 \pm 0,56$ & $8,0 \pm 0,77$ & 0,49 \\
\hline $\mathrm{A} 2$ & $501,25 \pm 0,47$ & $9,0 \pm 0,55$ & 0,67 \\
\hline $\mathrm{A} 3$ & $501,02 \pm 0,61$ & $7,5 \pm 0,65$ & 0,73 \\
\hline B1 & $500,24 \pm 0,77$ & $8,5 \pm 0,56$ & 0,87 \\
\hline B2 & $500,89 \pm 0,54$ & $8,5 \pm 0,74$ & 0,45 \\
\hline B3 & $500,65 \pm 0,36$ & $8,5 \pm 0,56$ & 1,42 \\
\hline $\mathrm{B} 2 \mathrm{C}$ & $501,26 \pm 0,20$ & $9,0 \pm 0,44$ & 1,21 \\
\hline $\mathrm{C} 1$ & $501,04 \pm 0,71$ & $7,0 \pm 0,37$ & 0,84 \\
\hline $\mathrm{C} 2$ & $500,34 \pm 0,45$ & $9,0 \pm 0,42$ & 0,64 \\
\hline C3 & $500,51 \pm 0,24$ & $8,5 \pm 0,44$ & 0,73 \\
\hline $\mathrm{C} 2 \mathrm{c}$ & $501,44 \pm 0,32$ & $8,5 \pm 0,60$ & 0,94 \\
\hline D1 & $499,65 \pm 0,21$ & $8,5 \pm 0,56$ & 0,90 \\
\hline D2 & $499,84 \pm 0,17$ & $11,5 \pm 0,15$ & 0,32 \\
\hline D3 & $500,34 \pm 0,26$ & $10,5 \pm 0,25$ & 0,51 \\
\hline Critério & $500 \mathrm{mg} \pm 1 \%$ & $>5,0$ & $<1,5$ \\
\hline
\end{tabular}




\subsection{Validação dos ensaios de quantificação da furosemida}

\subsubsection{Espectro de absorção da furosemida}

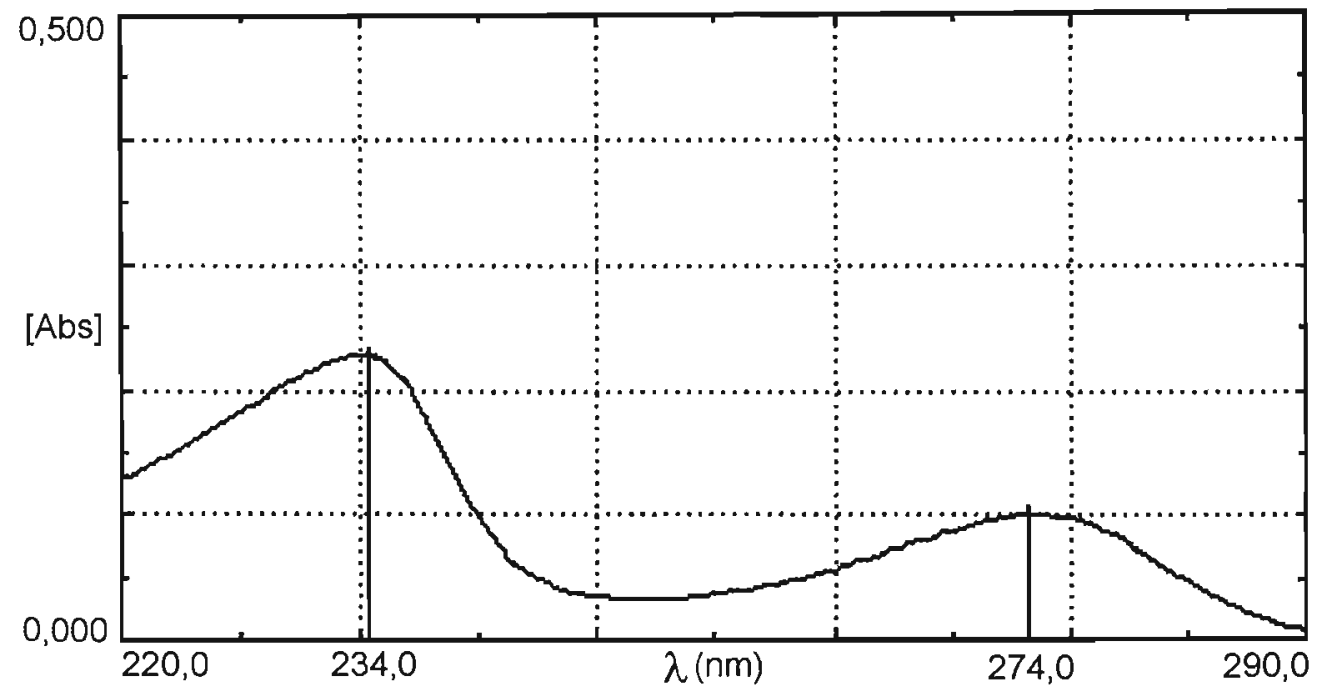

Figura 32. Espectro de absorção na região do ultravioleta de solução de furosemida a $2 \mu \mathrm{g} / \mathrm{mL}$ em HCl 0,1 $\mathrm{N} \mathrm{pH} \mathrm{1,2.}$

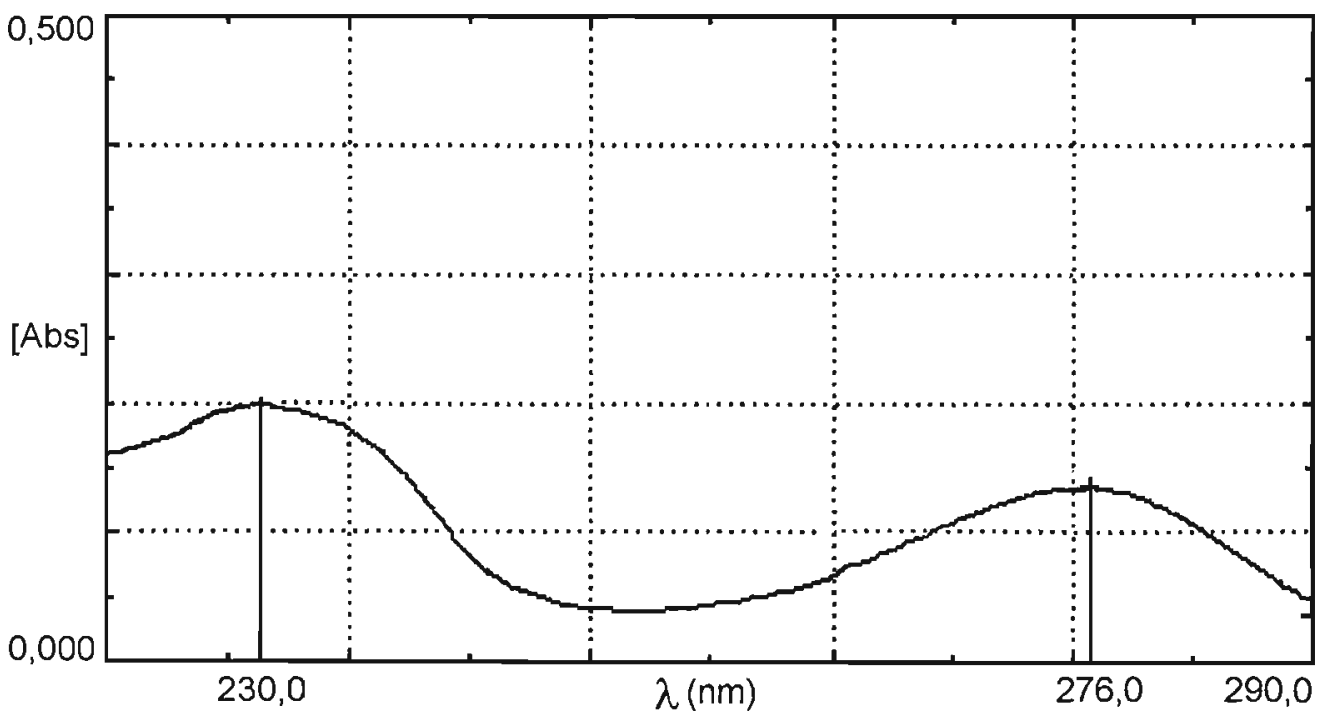

Figura 33. Espectro de absorção na região do ultravioleta de solução de furosemida a $2 \mu \mathrm{g} / \mathrm{mL}$ em tampão fosfato $0,1 \mathrm{M} \mathrm{pH} \mathrm{4,5}$. 


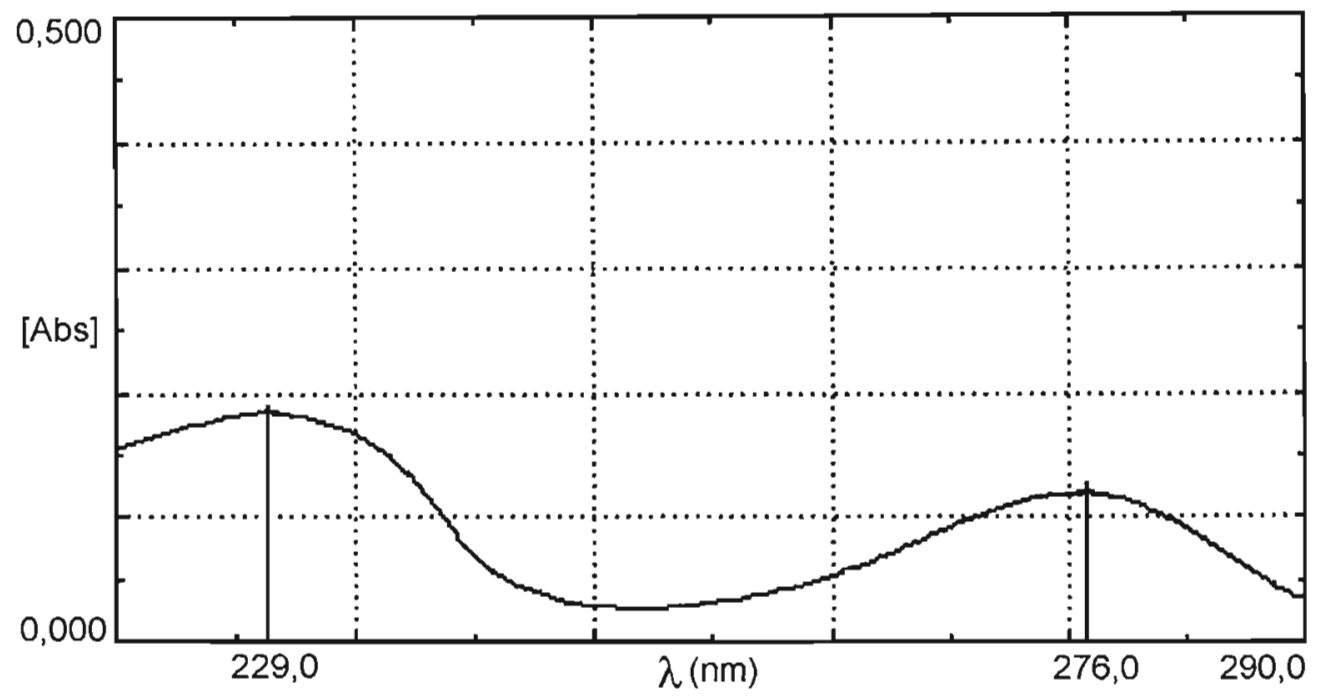

Figura 34. Espectro de absorção na região do ultravioleta de solução de furosemida a $2 \mu \mathrm{g} / \mathrm{mL}$ em tampão fosfato $0,05 \mathrm{M} \mathrm{pH} 6,8$.

\subsubsection{Linearidade}

A linearidade do método analítico por espectrofotometria no UV, nos deferentes meios utilizados, está representada nas Tabelas 30, 31, 32, 33, 34 e 35 e nas Figuras 35, 36 e 37. 
Tabela 30. Resultados referentes à curva de calibração da furosemida em meio $\mathrm{HCl} 0,1 \mathrm{~N} \mathrm{pH} \mathrm{1,2}$

\begin{tabular}{cccc}
\hline $\begin{array}{c}\text { Concentração } \\
(\mu \mathbf{g} / \mathbf{m L})\end{array}$ & $\begin{array}{c}\text { Absorbância } \\
\text { Média (274 } \mathbf{~ n m})\end{array}$ & DP & CV\% \\
\hline 0,5 & 0,0251 & 0,0080 & 31,873 \\
1,0 & 0,0473 & 0,0070 & 14,799 \\
2,0 & 0,0997 & 0,0046 & 4,609 \\
4,0 & 0,2006 & 0,0052 & 2,577 \\
8,0 & 0,4018 & 0,0139 & 3,471 \\
12,0 & 0,6243 & 0,0237 & 3,790 \\
16,0 & 0,8318 & 0,0214 & 2,575 \\
20,0 & 1,0612 & 0,0515 & 4,855 \\
24,0 & 1,2155 & 0,0580 & 4,775 \\
\hline
\end{tabular}

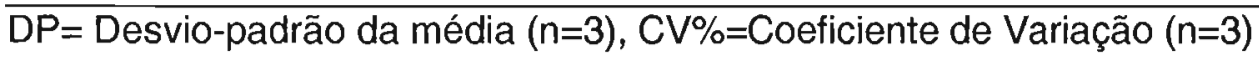

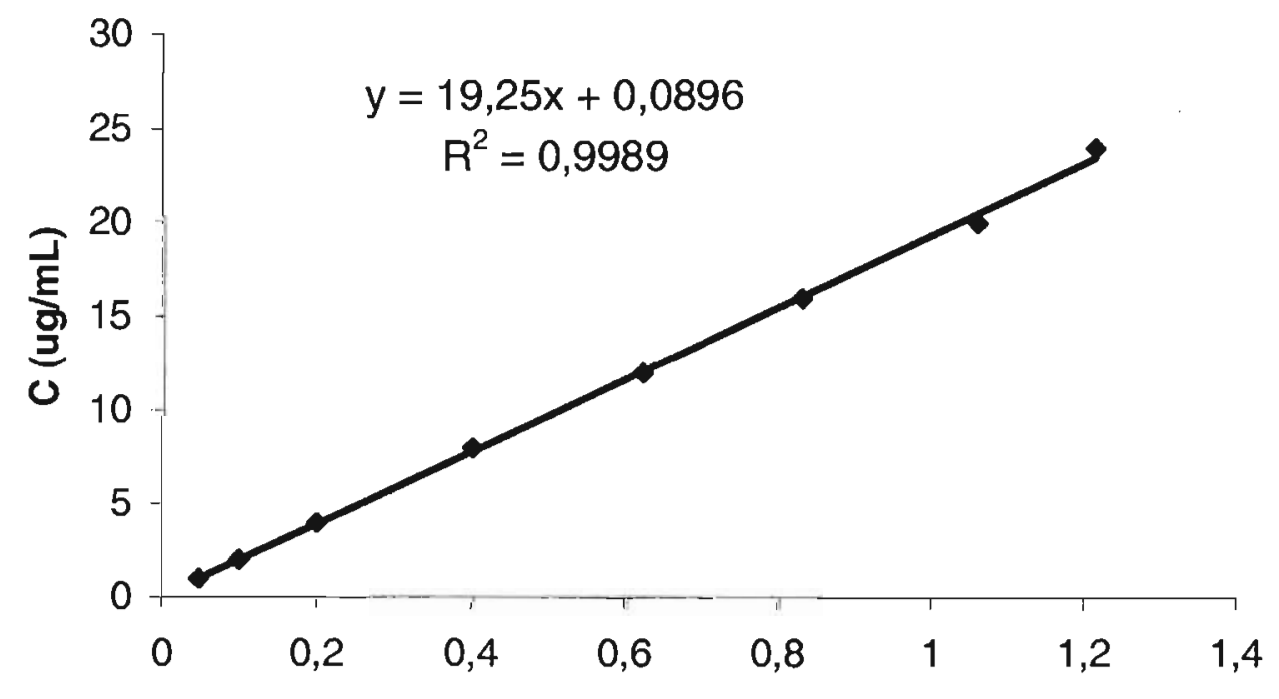

Abs (274nm)

Figura 35. Curva de calibração de furosemida obtida por espectrofotometria a $274 \mathrm{~nm}$ a partir de diluições volumétricas da solução-padrão em $\mathrm{HCl} 0,1 \mathrm{~N} \mathrm{pH}$ 1,2 . 
Tabela 31. Parâmetros relacionados à curva de calibração de furosemida obtida por espectrofotometria a $274 \mathrm{~nm}$ a partir de diluições volumétricas da solução-padrão em HCl 0,1 N pH 1,2

\begin{tabular}{cc}
\hline Parâmetros & Valores Obtidos \\
\hline Coeficiente angular $(\mathrm{a})$ & 19,250 \\
Coeficiente linear $(\mathrm{b})$ & 0,0896 \\
Coeficiente de correlação $\left(\mathrm{r}^{2}\right)$ & 0,9989 \\
Limite de quantificação $(\mu \mathrm{g} / \mathrm{mL})$ & 1,0 \\
\hline
\end{tabular}

Tabela 32. Resultados referentes à curva de calibração da furosemida em meio tampão fosfato $0,05 \mathrm{M} \mathrm{pH} \mathrm{4,5}$

\begin{tabular}{cccc}
\hline $\begin{array}{c}\text { Concentração } \\
(\mu \mathrm{g} / \mathbf{m L})\end{array}$ & $\begin{array}{c}\text { Absorbância } \\
\text { Média (276 nm) }\end{array}$ & DP & CV\% \\
\hline 0,5 & 0,0292 & 0,0091 & 21,2151 \\
1,0 & 0,0533 & 0,0051 & 9,5548 \\
2,0 & 0,1207 & 0,0057 & 4,7392 \\
4,0 & 0,2359 & 0,0108 & 4,5929 \\
8,0 & 0,5082 & 0,0142 & 2,7974 \\
12,0 & 0,7104 & 0,0255 & 3,5883 \\
16,0 & 0,9571 & 0,0243 & 2,5430 \\
20,0 & 1,1940 & 0,0145 & 1,2144 \\
24,0 & 1,4276 & 0,0248 & 1,7402 \\
\hline
\end{tabular}

$\mathrm{DP}=$ Desvio-padrão da média $(\mathrm{n}=3), \mathrm{CV} \%=$ Coeficiente de Variação $(n=3)$ 


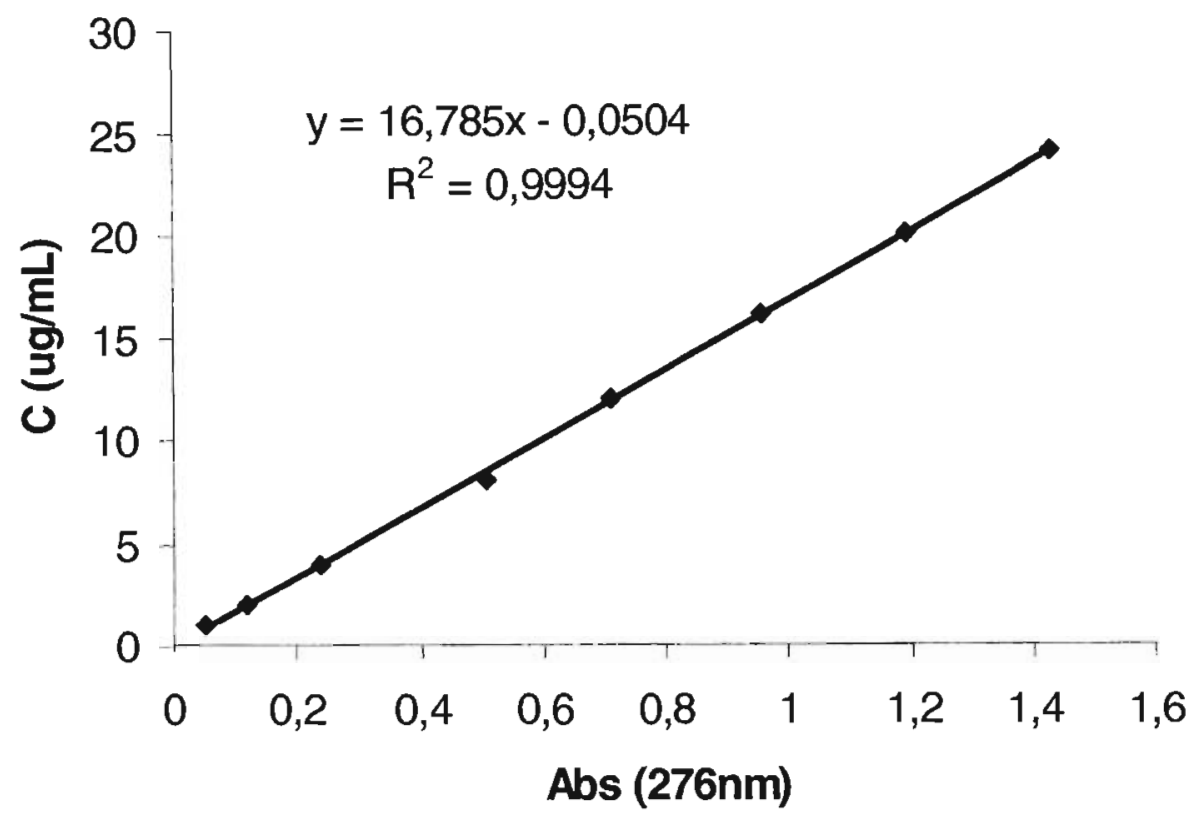

Figura 36. Curva de calibração de furosemida obtida por espectrofotometria a $276 \mathrm{~nm}$ a partir de diluições volumétricas da solução-padrão em tampão fosfato $0,05 \mathrm{M} \mathrm{pH} 4,5$.

Tabela 33. Parâmetros relacionados à curva de calibração de furosemida obtida por espectrofotometria a $276 \mathrm{~nm}$ a partir de diluições volumétricas da solução-padrão em tampão fosfato $0,05 \mathrm{M} \mathrm{pH} \mathrm{4,5}$

\begin{tabular}{cc}
\hline Parâmetros & Valores Obtidos \\
\hline Coeficiente angular $(a)$ & 16,785 \\
Coeficiente linear $(b)$ & 0,0504 \\
Coeficiente de correlação $\left(r^{2}\right)$ & 0,9994 \\
Limite de quantificação $(\mu \mathrm{g} / \mathrm{mL})$ & 1,0 \\
\hline
\end{tabular}


Tabela 34. Resultados referentes à curva de calibração da furosemida em meio tampão fosfato $0,05 \mathrm{M} \mathrm{pH} \mathrm{6,8}$

\begin{tabular}{cccc}
\hline $\begin{array}{c}\text { Concentração } \\
(\mu \mathrm{g} / \mathrm{mL})\end{array}$ & $\begin{array}{c}\text { Absorbância } \\
\text { Média (276 } \mathrm{nm})\end{array}$ & DP & CV\% \\
\hline 0,5 & 0,0341 & 0,0121 & 35,4839 \\
1,0 & 0,0540 & 0,0070 & 12,9630 \\
2,0 & 0,1087 & 0,0034 & 3,0810 \\
4,0 & 0,2253 & 0,0089 & 3,9283 \\
8,0 & 0,4909 & 0,0168 & 3,4301 \\
12,0 & 0,6976 & 0,0198 & 2,8393 \\
16,0 & 0,9398 & 0,0195 & 2,0764 \\
20,0 & 1,1768 & 0,0209 & 1,7774 \\
24,0 & 1,4170 & 0,0309 & 2,1810 \\
\hline
\end{tabular}

$\overline{\mathrm{DP}}=$ Desvio-padrão da média $(\mathrm{n}=3), \mathrm{CV} \%=$ Coeficiente de Variação $(\mathrm{n}=3)$

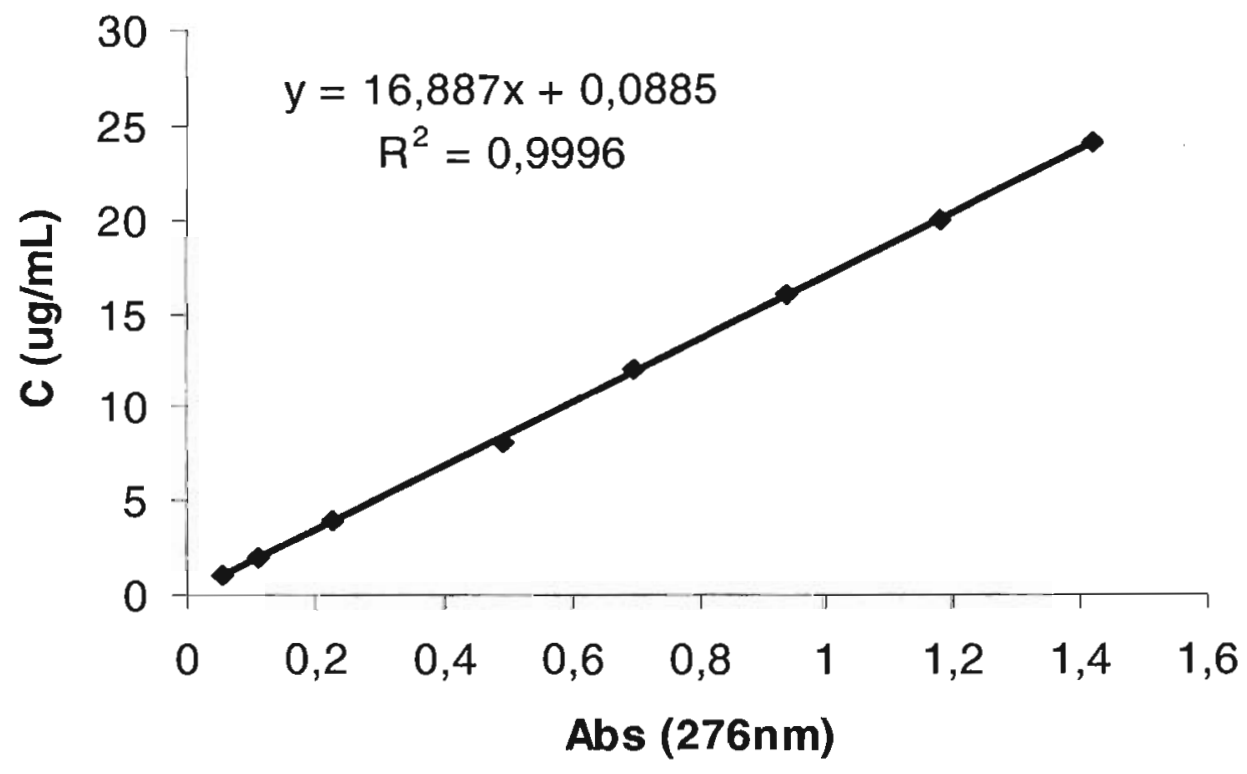

Figura 37. Curva de calibração de furosemida obtida por espectrofotometria a $276 \mathrm{~nm}$ a partir de diluições volumétricas da solução-padrão em tampão fosfato $0,05 \mathrm{M} \mathrm{pH} 6,8$. 
Tabela 35. Parâmetros relacionados à curva de calibração de furosemida obtida por espectrofotometria a $276 \mathrm{~nm}$ a partir de diluições volumétricas da solução-padrão em tampão fosfato $0,05 \mathrm{M} \mathrm{pH} \mathrm{6,8}$

\begin{tabular}{cc}
\hline Parâmetros & Valores Obtidos \\
\hline Coeficiente angular $(\mathrm{a})$ & 16,886 \\
Coeficiente linear $(\mathrm{b})$ & 0,0885 \\
Coeficiente de correlação $\left(\mathrm{r}^{2}\right)$ & 0,9996 \\
Limite de quantificação $(\mu \mathrm{g} / \mathrm{mL})$ & 1,0 \\
\hline
\end{tabular}

\subsubsection{Precisão}

Os resultados referentes a precisão intra e inter-ensaios do método espectrofotométrico no UV estão apresentados nas Tabelas 35, 36 e 37.

Tabela 36. Precisão do método espectrofotométrico a $274 \mathrm{~nm}$ em meio $\mathrm{HCl} 0,1$ $\mathrm{NpH} \mathrm{1,2}$

\begin{tabular}{ccc}
\hline $\begin{array}{c}\text { Concentração } \\
(\mu \mathbf{g} / \mathbf{m L})\end{array}$ & $\begin{array}{c}\text { Precisão intra-ensaio } \\
(\mathbf{C V} \%)\end{array}$ & $\begin{array}{c}\text { Precisão inter-ensaio } \\
(\mathrm{CV} \%)\end{array}$ \\
\hline 2,0 & 4,854 & 4,611 \\
12,0 & 4,214 & 4,021 \\
24,0 & 4,612 & 4,954 \\
\hline
\end{tabular}

Tabela 37. Precisão do método espectrofotométrico a $276 \mathrm{~nm}$ em meio tampão fosfato $0,05 \mathrm{M} \mathrm{pH} 4,5$

\begin{tabular}{ccc}
\hline $\begin{array}{c}\text { Concentração } \\
(\mu \mathrm{g} / \mathrm{mL})\end{array}$ & $\begin{array}{c}\text { Precisão intra-ensaio } \\
(\mathbf{C V} \%)\end{array}$ & $\begin{array}{c}\text { Precisão inter-ensaio } \\
(\mathbf{C V} \%)\end{array}$ \\
\hline 2,0 & 4,739 & 4,512 \\
12,0 & 3,588 & 4,019 \\
24,0 & 1,740 & 2,804 \\
\hline CV\% = Coeficiente de variação $(\mathrm{n}=6)$ &
\end{tabular}


Tabela 38. Precisão do método espectrofotométrico a $276 \mathrm{~nm}$ em meio tampão fosfato $0,05 \mathrm{M} \mathrm{pH} \mathrm{6,8}$

\begin{tabular}{ccc}
\hline $\begin{array}{c}\text { Concentração } \\
(\mu \mathrm{g} / \mathrm{mL})\end{array}$ & $\begin{array}{c}\text { Precisão intra-ensaio } \\
(\mathrm{CV} \%)\end{array}$ & $\begin{array}{c}\text { Precisão inter-ensaio } \\
(\mathbf{C V} \%)\end{array}$ \\
\hline 2,0 & 4,521 & 4,069 \\
12,0 & 3,954 & 4,215 \\
24,0 & 3,214 & 3,984 \\
\hline
\end{tabular}

$\overline{\mathrm{CV}} \%=$ Coeficiente de variação $(n=6)$

\subsubsection{Especificidade}

A especificidade do método espectrofotométrico no UV está apresentada nas Figuras 37 e 38.

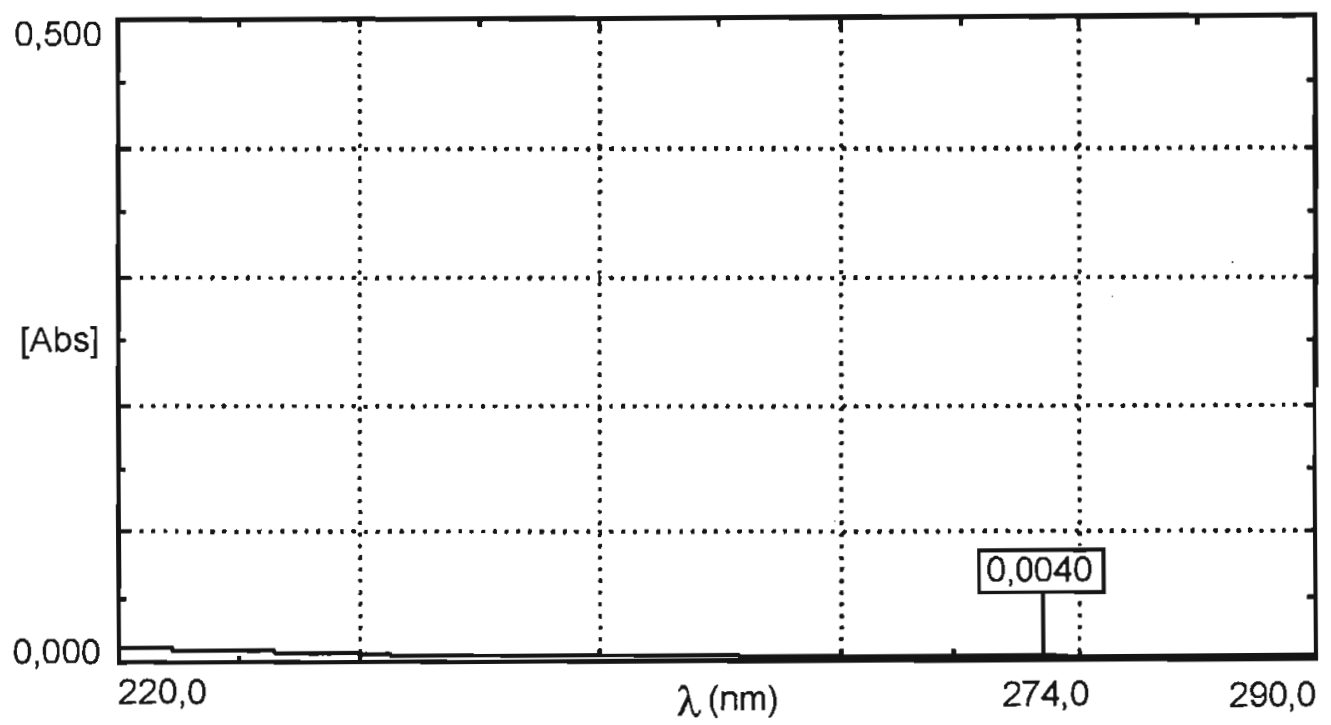

Figura 38. Especificidade do método analítico em meio $\mathrm{HCl} 0,1 \mathrm{M} \mathrm{pH} 1,2$. 


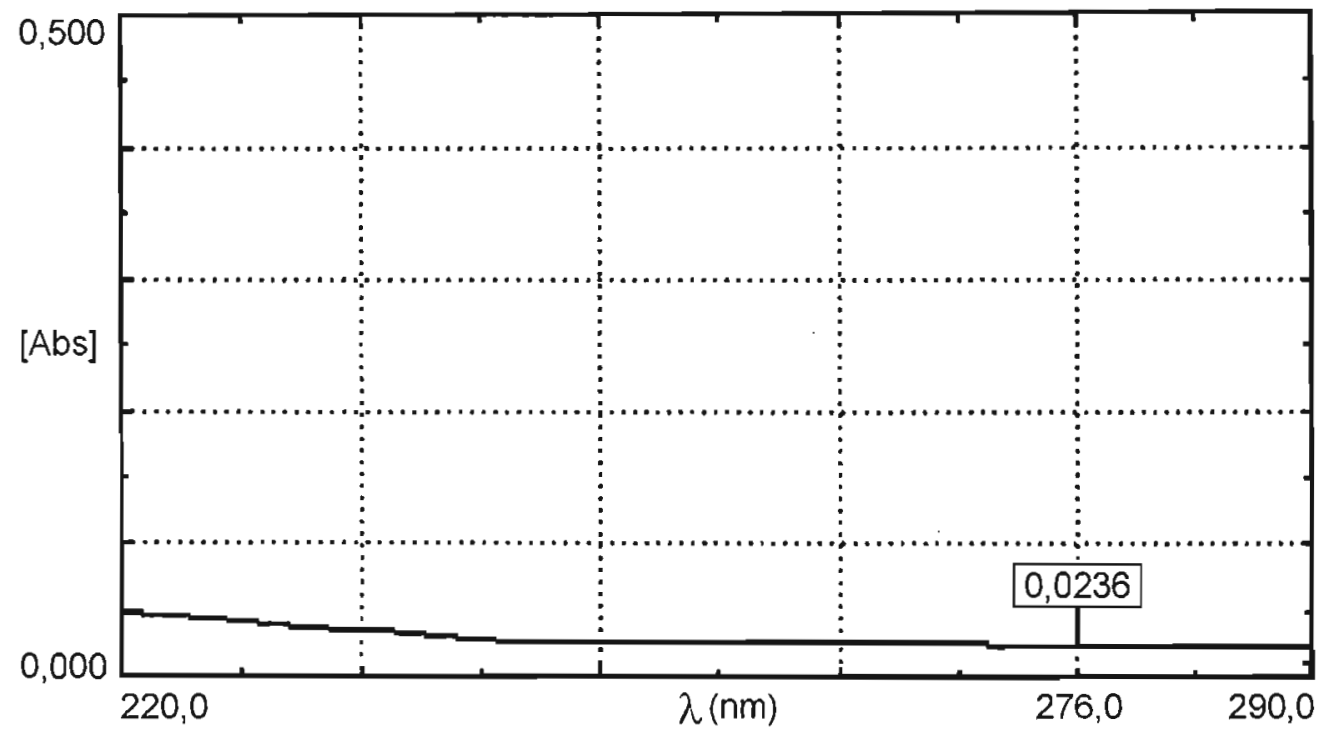

Figura 39. Especificidade do método analítico em tampão fosfato $0,05 \mathrm{M} \mathrm{pH}$ 4,5 .

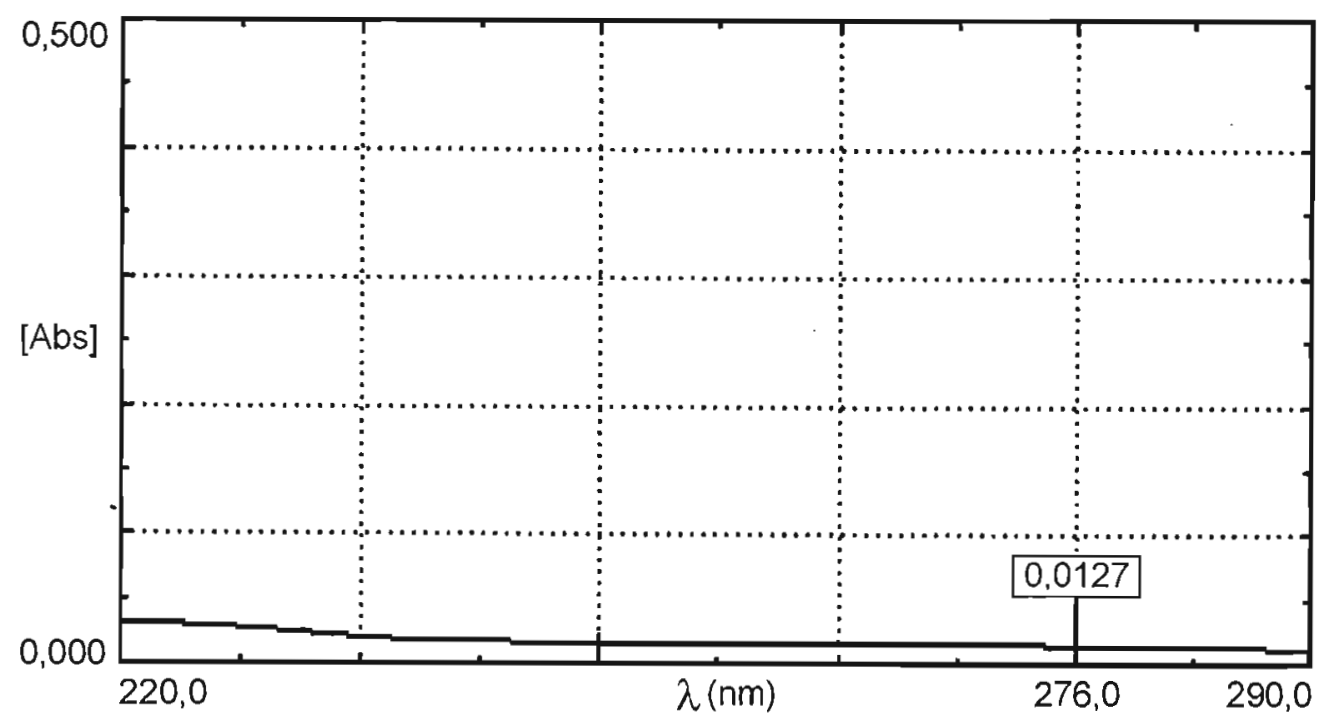

Figura 40. Especificidade do método analítico em tampão fosfato $0,05 \mathrm{M} \mathrm{pH}$ 6,8 . 
6. DISCUSSÃO 
Nas últimas décadas as formas farmacêuticas de liberação prolongada vêm ganhando progressiva aceitação e utilização na terapêutica. Os benefícios incluem: maior tempo de ação farmacológica; redução do número de administrações diárias; menor risco de acúmulo e/ou intoxicação pelo fármaco; maior complacência ao tratamento por parte do paciente e maior economia no longo prazo (Prista et al., 1996; Lordi, 2001; Collett \& Moreton, 2005).

As formas de liberação prolongada podem ser especialmente vantajosas na terapia anti-hipertensiva por proverem melhor controle farmacológico no pós-despertar, um período crítico ao hipertenso do ponto de vista clínico, caracterizado por abrupto aumento da pressão arterial e geralmente associado a manifestações clínicas graves (Ortega et al., 2000).

Os diuréticos de alça, como a furosemida, são considerados fármacos de segunda opção no controle da hipertensão, especialmente pelo seu efeito muito intenso e de curta duração. No entanto, apresentam considerável vantagem frente aos tiazídicos por terem relação dose-reposta mais linear e de maior amplitude, além de não comprometerem a filtração glomerular a longo prazo (Reubi, 1966, Hylander et al., 1987).

A incorporação da furosemida a uma forma de liberação prolongada é uma estratégia terapêutica racional por se preservar as vantagens de um diurético de alça, porém, com efeito menos pronunciado e mais duradouro, gerando menor desconforto ao paciente crônico (Ebihara et al., 1983). Possibilita-se, também, redução do número de administrações diárias, facilitando a adesão do paciente ao tratamento, o qual geralmente acompanha o hipertenso por longo período.

A reduzida solubilidade da furosemida, especialmente em meios ácidos, pode se tratar de um contraposto frente ao devido desempenho de liberação por formas farmacêuticas que possam contê-la (Smal et al., 1996). 
A formação de complexos de inclusão com ciclodextrinas é um recurso altamente eficaz no aumento da solubilidade de diversos fármacos (Loftsson \& Brewster, 1997). Estes oligossacarídeos podem possibilitar, inclusive, melhorias nas propriedades de liberação de fármacos a partir de formas farmacêuticas, funcionando, neste caso, como promotores de liberação (Bibby et al., 2000).

Dentre os recursos tecnológicos disponíveis para se controlar a liberação de fármacos administrados oralmente, destacam-se os sistemas matriciais hidrofílicos. As matrizes hidrofílicas, empregadas como suporte para formas de liberação prolongada, apresentam vantagens não só quanto à simplicidade e baixo custo de preparação, mas principalmente em relação à sua versatilidade no controle da velocidade e extensão de liberação. Elegendose adequadamente o tipo e concentração do material suporte, e fazendo uso de outros adjuvantes farmacêuticos, é possivel modular a liberação de uma gama de fármacos de maneira independente às heterogêneas condições do trato gastrintestinal (Veiga, 1988; Salsa et al., 1997; Collett \& Moreton, 2005).

Dentro do exposto anteriormente, objetivou-se, com este trabalho, investigar a influência da complexação da furosemida, ou sua simples mistura, com $\beta$-ciclodextrina ( $\beta-C D$ ) ou hidroxipropil- $\beta$-ciclodextrina (HP- $\beta-C D)$, no perfil de liberação in vitro do fármaco por comprimidos matriciais hidrofílicos à base de HPMC, desenvolvido com o intuito de modular a liberação do fármaco por um período de 8 horas.

Com base nas observações de outros autores (Kreaz et al., 1998; Ozdemir \& Ordu, 1998; Ammar et al., 1999; Spamer et al., 2002; Vlachou \& Papaioannou, 2003), decidiu-se por investigar duas técnicas de complexação da furosemida com as ciclodextrinas as quais, deste ponto em diante, e de modo a facilitar a explanação, serão denominadas como técnicas de malaxagem e liofilização. 
De modo a confirmar a formação dos complexos pelas técnicas utilizadas, os produtos obtidos foram caracterizados por calorimetria diferencial exploratória (DSC) e espectrofotometria na região do infravermelho (IV), cujos resultados foram comparados sempre frente àqueles com as misturas físicas entre o fármaco e as ciclodextrinas bem como com os compostos isolados.

A curva de DSC da furosemida (Figuras 4 e 5) revela um pequeno pico endotérmico em $206^{\circ} \mathrm{C}$, relativo à sua fusão, um acentuado pico exotérmico em aproximadamente $220^{\circ} \mathrm{C}$, o qual é associado à degradação do fármaco (Kreaz et al., 1998), e um pico endotérmico em aproximadamente $268^{\circ} \mathrm{C}$, referente à fusão do produto de degradação.

Tanto a curva de DSC da $\beta-C D$ quanto da HP- $\beta-C D$ revelam um fenômeno endotérmico entre 60 e $120^{\circ} \mathrm{C}$, referente à evaporação da água (não visualizável nas figuras em função da escala). Em aproximadamente $218^{\circ} \mathrm{C}$, a $\beta-C D$ apresenta um pico endotérmico característico da fusão das unidades glicosídicas (Figura 4) (Kreaz et al., 1998).

Com relação às curvas termoanalíticas das misturas físicas (Figura $4 \mathrm{e}$ 5), observa-se a sobreposição dos eventos exo e endotérmicos característicos das substâncias isoladas. A diminuição do pico exotérmico característico da furosemida acontece em função da diluição do fármaco pelas ciclodextrinas.

Os produtos obtidos por malaxagem (furosemida/ $\beta-C D$ e furosemida/ HP- $\beta$-CD) apresentam perfis termoanalíticos semelhantes àqueles observados com as misturas físicas. A ausência de eventos geralmente associados à complexação, como o deslocamento ou desaparecimento de picos endo e exotérmicos (Loukas et al., 1997), característicos dos fármacos, descartam a possibilidade de complexação pela técnica da malaxagem, nas condições empregadas. 
Para o produto obtido pela técnica de liofilização utilizando-se $\beta-C D$ (Figura 4), observa-se um deslocamento do pico exotérmico do fármaco para aproximadamente $242^{\circ} \mathrm{C}$ (reprodutível para $\mathrm{n}=3$ ), resultando em um composto com características únicas, diferentemente ao comportamento termoanalítico das duas substâncias isoladas ou sua mistura física, o que pode indicar a formação de complexo de inclusão (Loukas et al., 1997).

Quanto ao produto obtido por liofilização furosemida/HP- $\beta$-CD, o evento exotérmico característico do fármaco praticamente desaparece (reprodutível para $n=3$ ), como observado na Figura 5 . Tal comportamento térmico indica a complexação entre furosemida e HP- $\beta-C D$. A caracterização dos complexos de furosemida com as ciclodextrinas foi complementada por espectrofotometria na região do infravermelho (IV), cujos espectros estão apresentados nas Figuras 6 e 7.

Observando-se os espectros de absorção no IV e os grupos funcionais da furosemida (Figura 1), pode-se concluir que o material utilizado corresponde realmente ao composto, caracterizado por picos em 1.562 e $1.593 \mathrm{~cm}^{-1}$, referentes ao estiramento $\mathrm{N}-\mathrm{H}$ do grupo $-\mathrm{SO}_{2} \mathrm{NH}_{2}$, em $1.671 \mathrm{~cm}^{-1}$, relativo ao estiramento da carbonila $(C=O)$ do grupo carboxílico, e em $3.200-3.400 \mathrm{~cm}^{-1}$, referentes às bandas de estiramento $\mathrm{O}-\mathrm{H}$ e $\mathrm{C}-\mathrm{H}$ aromático (Figuras 6 e 7) (Sweetman, 2006).

Nos espectros de absorção de $\beta-C D$ e HP- $\beta-C D$ isoladas (Figuras 6 e 7), observam-se uma larga banda entre $3.060 \mathrm{e} 3.700 \mathrm{~cm}^{-1}$, referente à freqüência de estiramento $\mathrm{O}-\mathrm{H}$ dos grupos hidroxila, uma banda entre 2.800 e $3.000 \mathrm{~cm}^{-1}$, relativa ao estiramento $\mathrm{C}-\mathrm{H}$ alifático, uma banda em aproximadamente 1.600 $\mathrm{cm}^{-1}$, referente ao estiramento $\mathrm{C}-\mathrm{O}$ das ligações éster, e bandas entre $900 \mathrm{e}$ $1.200 \mathrm{~cm}^{-1}$, referentes à freqüência de estiramento $\mathrm{C}-\mathrm{C}$ alifático (Özkan et al., 2000). 
Observando-se os espectros de absorção na região do IV das misturas físicas entre furosemida e as ciclodextrinas (Figuras 6 e 7), conclui-se que os mesmos correspondem a simples sobreposição dos espectros dos compostos isolados, não indicando qualquer tipo de interação.

Nos espectros dos produtos obtidos por malaxagem não se detectam diferenças expressivas quando comparados àqueles das misturas físicas. Tais resultados complementam as observações termoanalíticas, sugerindo que os complexos não são obtidos por tal técnica, nas condições empregadas.

Resultados contrários foram obtidos por Spamer et al. (2002), que comprovaram a formação de complexos entre furosemida e HP- $\beta-C D$ ou sulfobutiléter-7- $\beta-C D$ pela técnica de malaxagem em condições muito semelhantes às empregadas neste trabalho.

Nos produtos obtidos por liofilização, a banda referente ao estiramento $\mathrm{C}=\mathrm{O}$ da furosemida (em $1.670 \mathrm{~cm}^{-1}$ ) é evidentemente reduzida, indicando uma mudança no ambiente da carbonila do fármaco como conseqüência de uma possível interação com as ciclodextrinas. Adicionalmente, os picos em $1.562 \mathrm{e}$ $1.593 \mathrm{~cm}^{-1}$, característicos do fármaco, continuam nos produtos de liofilização, porém, com menor intensidade quando comparadas às respectivas misturas físicas.

Os resultados de DSC e IV, analisados conjuntamente, sugerem que a formação de complexos de furosemida com $\beta-C D$ ou HP- $\beta-C D$ possa ocorrer quando soluções de ambos os compostos são submetidas à homogeneização seguida de secagem por liofilização, confirmando as observações de outros autores quanto à aplicabilidade de tal técnica para obtenção de complexos de inclusão da furosemida (Kreaz et al., 1998; Ozdemir \& Ordu, 1998; Ammar et al., 1999; Spamer et al., 2002; Vlachou \& Papaioannou, 2003). No entanto, por 
meio das técnicas analíticas empregadas, torna-se dificultoso estimar a real eficiência e rendimento do processo de complexação.

Nos resultados de dissolução da furosemida pura ou do fármaco processado com $\beta-C D$ ou HP- $\beta-C D$, apresentados nas Tabelas $8,9,10,11,12$ e 13 e Figuras 8, 9, 10, 11, 12 e 13, observam-se que os produtos obtidos por malaxagem e liofilização exibem velocidade de dissolução expressivamente superiores ao fármaco puro nos meios $\mathrm{HCl}$ pH 1,2, tampão fosfato $\mathrm{pH} 4,5 \mathrm{e}$ tampão fosfato $\mathrm{pH} \mathrm{6,8}$, resultados estes compatíveis com as observações de outros autores (Kreaz et al., 1998; Ammar et al., 1999; Vlachou et al., 2003). Já as misturas físicas com ambas ciclodextrinas não trouxeram alteração pronunciada na dissolução da furosemida.

Outras técnicas também já se mostraram úteis no aumento da solubilidade aparente da furosemida. Shin et al. (1998) preparam dispersões sólidas de furosemida e crospovidona, excipiente de alta solubilidade, por meio das técnicas de co-precipitação e co-moagem e observaram expressivo aumento da velocidade de dissolução da furosemida em $\mathrm{pH} 1,2$, meio no qual o fármaco é notoriamente pouco solúvel. Tal performance foi atribuída ao aumento da hidrofilicidade das partículas do fármaco pela crospovidona.

Apesar de não se observar formação de complexos, como discutido acima, os produtos obtidos por malaxagem aumentaram significativamente a velocidade e extensão de dissolução da furosemida, podendo sugerir que algum tipo de interação, diferente da inclusão molecular, possa ocorrer e favorecer a dissolução do fármaco, ou simplesmente modificar a hidrofilicidade de suas partículas, atuando como uma dispersão sólida.

Os produtos preparados com HP- $\beta-C D$ foram mais eficientes na melhoria do perfil de dissolução da furosemida, comparado àqueles obtidos com $\beta$-CD. Nos meios de $\mathrm{pH} 4,5$ e $\mathrm{pH} 6,8$, o produto de liofilização 
furosemida/HP- $\beta$-CD propiciou dissolução quase total do fármaco dentro de 15 min, chegando a 94,15 e 99,75\%, respectivamente. Em meio $\mathrm{HCl}$ 0,1 N pH 1,2, após $60 \mathrm{~min}$, a quantidade de furosemida dissolvida a partir do mesmo produto $(82,36 \%)$ foi aproximadamente 3,5 vezes maior que o fármaco puro $(23,20 \%)$.

Tais resultados também evidenciam a formação de complexos entre a furosemida e as ciclodextrinas pela técnica de liofilização e sugerem que a complexação é suficiente para propiciar uma dissolução $\mathrm{pH}$-independente do fármaco, visto o expressivo aumento da eficiência de dissolução nos diferentes $\mathrm{pH}$. Mesma propriedade foi observada por Ammar et al. (1999), por meio da inclusão molecular da furosemida, em razão molar $1: 1$, com dimetil- $\beta$ ciclodextrina e $\gamma$-ciclodextrina.

O fato da furosemida testada isoladamente nos ensaios supracitados ter sido submetida ao processo de liofilização reforça a hipótese de que as ciclodextrinas tenham sido os únicos fatores de contribuição para o aumento da velocidade e extensão de dissolução do fármaco nos meios empregados.

O ensaio de dissolução representa uma etapa fundamental no desenvolvimento e controle de formas farmacêuticas sólidas destinadas à administração oral, por permitir a quantificação do fármaco liberado em função do tempo em condições que possam mimetizar o ambiente gastrintestinal, provendo considerável previsibilidade do seu comportamento in vivo (Kano, 2003). Não obstante, determinar o perfil de dissolução do fármaco torna-se imprescindível, já que o mesmo somente será passivel de absorção, ou em outras palavras, se tornará biodisponível, uma vez dissolvido nos fluidos orgânicos (Serra, 1998).

De modo a evidenciar a influência da presença de ciclodextrinas, tanto complexadas quanto em mistura física com a furosemida, no perfil de liberação do fármaco a partir dos comprimidos matriciais, estabeleceu-se o maior número 
possível de constantes nas formulações, como o tipo e concentração do material suporte (agente formador da matriz), diluente e agente lubrificante, conforme apresentado na Tabela 4.

O Methocel ${ }^{\circledR}$ (HPMC), presente nas formulações estudadas (Tabela 4), é o polímero mais freqüentemente utilizado como agente formador de matriz. Age, inicialmente, hidratando-se em contato com o meio circundante e formando rapidamente uma camada superficial de gel, capaz de reter a imediata liberação do fármaco. À medida que o polímero se hidrata esta camada geleificada expande-se progressivamente para 0 interior do comprimido, consolidando a estrutura matricial e provendo um ambiente propício à dissolução e difusão do fármaco. A velocidade de liberação do fármaco é controlada pela difusão através da camada de gel ou erosão da estrutura matricial, sendo que a viscosidade da barreira formada e a velocidade de hidratação do polímero têm grande influência nestes processos (Veiga, 1988; Salsa et al., 1997; Collett \& Moreton, 2005).

Considerando-se a baixa solubilidade da furosemida, dados da literatura e informações do fabricante (Colorcon, 2000), optou-se pelo emprego do Methoce ${ }^{\circledR}$ K4M Premium CR, o qual proporciona rápida formação de gel e coalescência polimérica, características estas adequadas para obtenção de sistemas matriciais. Apresenta, também, tamanho e formato de partícula que conferem boa fluidez e compressibilidade dos pós, sendo aplicável para processos de compressão direta. Adicionalmente, o produto de escolha exibe baixa viscosidade $(4.000 \mathrm{cP})$ quando comparado a outros produtos da mesma linha (Tabela 3), o que é mais indicado quando se trabalha com fármacos de baixa solubilidade (Colorcon, 2000).

As formulações da série $\mathrm{A}$ foram preparadas como estudo preliminar de formulação, de maneira a selecionar a melhor concentração do agente formador de matriz (HPMC) a ser estabelecido para as outras formulações. $O$ 
critério para escolha da melhor concentração foi a constatação do desempenho essencial de uma forma farmacêutica de liberação prolongada, ou seja, estender a liberação do fármaco pelo tempo estipulado. Considerando as indicações do fabricante e dados da literatura (Colorcon, 2000), avaliou-se 0 acréscimo de 15, 25 e 35\% (p/p) de HPMC, presentes nas formulações A1, A2 e $A 3$, respectivamente.

Os comprimidos preparados com a formulação A1 (15\% HPMC) tiveram completa erosão nos primeiros 30 minutos de ensaio de dissolução, não atendendo, portanto, aos requisitos mínimos. Em virtude disso, o perfil de dissolução e demais constatações sobre esta formulação não foram apresentados, já que os ensaios foram descontinuados.

Os comprimidos preparados com as formulações A2 e A3, cujos perfis de liberação estão representados na Figura 14, tiveram comportamentos semelhantes, no entanto a formulação $A 3$ apresentou velocidade e extensão de liberação significativamente menor comparada à A2 (Figura 14 e Tabela 14). Tais resultados são coerentes com dados da literatura e pode-se justificá-los pelo aumento do caminho difusional do fármaco (maior tortuosidade) e maior viscosidade da barreira, conseqüentes da maior concentração do material geleificante, o que leva a uma diminuição da quantidade liberada ( $\mathrm{Xu}$ \& Sunada, 1995).

Deste modo, adotou-se $25 \%$ como a concentração de HPMC para as demais formulações e convencionou-se a formulação A2 como formulação básica para efeitos de comparação e avaliação da influência das ciclodextrinas.

O conceito de eficiência de dissolução, introduzido por Khan \& Rhodes (1975), tornou-se uma importante ferramenta na ciência biofarmacêutica, funcionando como um parâmetro de comparação simples, direto e robusto entre perlis de dissolução. Este parâmetro é vantajoso quando se deseja 
comparar a influência das variáveis de formulação ou processo sobre a dissolução de uma forma farmacêutica, proporcionando comparações mais realistas, uma vez que se considera o perfil como um todo, ao contrário dos valores de meia-vida de dissolução $\left(t_{50}\right)$, que representam apenas um valor pontual do perfil (O'hara et al., 1998).

Pelas representações gráficas comparativas (Figuras 14 e 17) e resultados de ANOVA (Tabela 19), conclui-se que a adição de $20 \%(p / p)$ de $\beta-C D$, como mistura física (formulação $B 1$ ), não teve influência significativa $(p>0,05)$ na eficiência de dissolução da furosemida, comparado à formulação básica (A2). Já a adição de $40 \%$ e $60 \%$ (p/p) de $\beta-C D$, como mistura física, formulações B2 e B3, respectivamente, trouxeram aumento significativo na extensão de liberação do fármaco em meio tampão fosfato $\mathrm{pH} \mathrm{6,8.} \mathrm{No} \mathrm{entanto,}$ nenhuma das formulações contendo $\beta-C D$, como mistura física, atenderam aos critérios sugeridos por Prista et al. (1996) para desempenho de uma forma de liberação prolongada de 8 horas (Tabela 6), como pode ser constatado na Figura 29.

Os critérios propostas por Prista et al. (1996) tratam-se de especificações generalistas e não oficiais para se avaliar a performance de formas farmacêuticas de liberação prolongada. Não são suficientes para o desenvolvimento preciso e definitivo de uma forma de liberação prolongada por não considerarem as reais necessidade terapêuticas. No entanto, podem ser uma ferramenta útil para fases precoces ou conceituais de desenvolvimento galênico, por nortearem limites de liberação em diferentes períodos de tempo.

Conforme observado nas Figuras 15 e 18 e Tabelas 15, 20 e 21, a presença de 20,40 e $60 \%$ (p/p) de HP- $\beta-C D$, como mistura física, nas formulações $\mathrm{C} 1, \mathrm{C} 2$ e $\mathrm{C} 3$, respectivamente, gerou aumento significativo $(p<0,05)$ na velocidade e extensão de liberação da furosemida, em meio

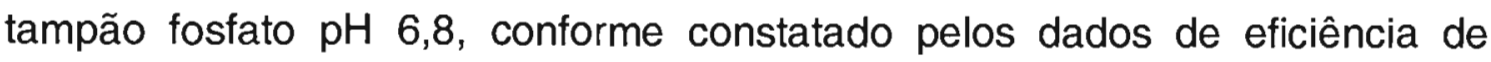


dissolução (ED\%) e constante de velocidade de dissolução $\left(k_{d}\right)$ do fármaco em comparação à formulação básica. Com relação ao critério de aceitação de Prista et al. (1996) (Tabela 6), a formulação C3 atendeu às especificações na totalidade, tendo liberado aproximadamente $32,7 \%, 66,7 \%, 81,8 \%$ em 60,240 e 480 minutos, respectivamente (Figura 30; Tabela 24).

Equivalentemente, Ikeda et al. (2001) observaram que o aumento crescente da porcentagem de HP- $\beta$-CD em comprimidos matriciais foi capaz de ampliar, em proporção, a velocidade de liberação do fármaco a partir de comprimidos matriciais à base de etilcelulose.

Tais resultados sugerem a contribuição individual ou conjunta das seguintes hipóteses: 1 . a presença de HP- $\beta-C D$, composto de alta solubilidade (200 mg/100 mL de água), poderia aumentar a capacidade de hidratação da matriz favorecendo a liberação do fármaco; 2. uma vez dissolvida, a HP- $\beta-C D$ daria lugar a poros, enfraquecendo a estrutura matricial, contribuindo com a penetração do meio no comprimido e difusão do fármaco e 3. a HP-ß-CD poderia complexar-se com a furosemida no microambiente matricial, aumentando sua solubilidade e facilitando sua dissolução e difusão, sendo que tal propriedade já foi sugerida por diversos autores (Bibby et al., 2000; Sangalli et al. 2001; Rao et al., 2002; Ribeiro et al., 2005).

A presença de lactose monohidratada nos comprimidos foi avaliada como modelo discriminatório da hipótese 3 acima citada, uma vez que tal carboidrato possui solubilidade comparável à HP- $\beta-C D$, porém, não possui a capacidade de complexação com o fármaco.

A presença de 20, 40 e $60 \%(p / p)$ de lactose, formulações D1, D2 e D3, respectivamente, trouxe aumento significativo na velocidade e extensão de liberação da furosemida comparada à formulação básica (Figuras 16 e 19 e Tabelas 16, 22 e 23), no entanto, tais formulações não foram tão eficientes 
quanto as formulações contendo HP- $\beta-C D(C 1, C 2$ e $C 3)$, o que reforça a veracidade da hipótese 3 supracitada.

Estes resultados são comparáveis às observações de Rao et al. (2002), que constataram que a presença de sulfobutiléter-7- $\beta$-cicldextrina como mistura física, em razão molar de 1:1, foi superior à influência da lactose, sacarose e do cloreto de potássio, no perfil de liberação da prednisolona.

As formulações B2C e C2c foram preparadas de modo a conter complexos de inclusão de furosemida, em razão molar $1: 1, \operatorname{com} \beta-C D$ ou HP- $\beta$ $C D$, obtidos pela técnica da liofilização. $A$ contribuição das ciclodextrinas no peso total dos comprimidos obtidos com estas formulações foi de aproximadamente $40 \%(p / p)$ (Tabela 4$)$.

Pelas Tabelas 14 e 15, observa-se que comprimidos contendo complexos furosemida/HP- $\beta$-CD (formulação B2c) exibiram ED\% do fármaco, em meio tampão fosfato $\mathrm{pH} 6,8$, expressivamente maior quando comparados àqueles com a formulação básica (A2) e formulações contendo misturas físicas (B1, B2 e B3). No entanto, os comprimidos preparados com a formulação B2C não atenderam aos critérios sugeridos por Prista et al. (1996), como pode ser constatado na Figura 29 , tendo liberado, aproximadamente, $75 \%$ do total de fármaco após 480 min de ensaio.

Os comprimidos contendo complexos furosemida/HP- $\beta-C D$ (formulação C2c), cujos resultados dos ensaios de dissolução em meio tampão fosfato $\mathrm{pH}$ 6,8 estão apresentados nas Figuras 15 e 18 e Tabelas 15, 20 e 21, exibiram o melhor desempenho de liberação entre todas as formulações testadas. Após $480 \mathrm{~min}$, a furosemida foi liberada quase em sua totalidade $(94,02 \%)$, apresentando $E D \%$ da furosemida significativamente maior quando comparada à formulação básica (A2) e formulações contendo misturas físicas (C1, C2 e 
C3). Quanto ao critério de aceitação de Prista et al. (1996) (Tabela 6), a formulação C2c atendeu às especificações em sua totalidade (Figura 29).

O estudo da cinética de dissolução da furosemida a partir das formulações propostas foi realizado pela aplicação de modelos matemáticos de linearização de ordem zero, primeira ordem e Higuchi. Tais modelos matemáticos puderam, também, sugerir o mecanismo de liberação envolvido (Pather et al., 1998).

A cinética de ordem zero é atingida quando existe uma relação linear entre a quantidade de fármaco não dissolvida e o intervalo de tempo. Entende-se, portanto, que a proporção entre a massa total do comprimido e a quantidade de fármaco remanescente não sofra variação no período estipulado. Em um comprimido matricial, tal situação só é possível se a depleção de fármaco ocorrer concomitantemente à dissolução ou desintegração da matriz, sugerindo que a erosão do comprimido matricial seja o mecanismo de liberação predominante (Pather et al., 1998).

Já os modelos cinéticos de primeira ordem e Higuchi indicam que a quantidade de fármaco remanescente não é constante em função do tempo. Entende-se, portanto, que a proporção entre a massa do comprimido e a massa de fármaco não dissolvida varie em um determinado intervalo. Para um sistema matricial, tal situação só é possível se a depleção do fármaco ocorrer a uma velocidade maior que a desintegração ou dissolução da matriz, sugerindo que a difusão do fármaco seja o mecanismo predominante (Pather et al., 1998).

O estudo da cinética de dissolução das formulações testadas, apresentados nas Figuras de 20 a 29 e Tabela 24, demonstrou maior adequação dos perfis de dissolução aos modelos de primeira ordem e Higuchi, uma vez que os valores do coeficiente de correlação da reta de regressão se situaram muito próximo à unidade. Dentro do contexto acima exposto, os 
resultados sugerem que a difusão do fármaco é o mecanismo de liberação predominante nos comprimidos avaliados, quando empregado tampão fosfato $0,05 \mathrm{M} \mathrm{pH} 6,8$ como meio dissolução.

Os resultados dos ensaios de dissolução das formulações A2, B2, B2c, C2 e C2c com variação de $\mathrm{pH}$ estão apresentados nas Figuras 30 e 31 e Tabelas 26 e 27. Observa-se que a dissolução da furosemida a partir das formulações B2c e C2c exibe velocidade visualmente constante nos diferentes $\mathrm{pH}$ testados, sugerindo que a complexação da furosemida com as ciclodextrinas possa favorecer uma liberação $\mathrm{pH}$-independente do fármaco pelos comprimidos matriciais. O mesmo não é observado com comprimidos contendo as ciclodextrinas em simples misturas físicas (formulações B2 e C2). Tais resultados são coerentes com o comportamento de dissolução da furosemida, em diferentes $\mathrm{pH}$, pelos complexos ou misturas físicas com as ciclodextrinas, ou seja, quando não incorporadas às matrizes, conforme apresentado nas Figuras 8-13.

Com as observações acima, pode-se inferir que a complexação do fármaco com as ciclodextrinas contribui para o desenvolvimento de formas de liberação prolongada de furosemida mais eficientes, considerando-se a melhor conformidade do processo de liberação com as condições fisiológicas de $\mathrm{pH}$ do trato gastrintestinal, sugerindo melhor biodisponibilidade do fármaco. Pode tratar-se, inclusive, de útil alternativa para desenvolvimento de comprimidos de liberação prolongada contendo outros fármacos de baixa solubilidade.

Os resultados dos ensaios físicos com os comprimidos (Tabela 25) demonstram que o método de compressão direta, quando aplicado às formulações testadas, foi suficiente para se obter comprimidos com dureza, peso médio e friabilidade dentro das exigências estabelecidas. A variação inexpressiva do peso dos comprimidos revela boa fluidez das misturas de pós utilizadas, gerando preenchimento homogêneo da matriz da máquina de 
compressão. Esta observação, no entanto, não se aplica às formulações B2c e C2c, preparadas com os de produtos obtidos por liofilização com as ciclodextrinas, os quais apresentam baixas fluidez e densidade, gerando a necessidade do preenchimento manual da matriz da máquina de compressão para obtenção dos comprimidos.

O método de quantificação da furosemida por espectrofotometria no UV demonstrou linearidade na faixa de 1 a $24 \mu \mathrm{g} / \mathrm{mL}$ quando utilizados $\mathrm{HCl} 0,1 \mathrm{~N}$ $\mathrm{pH} 1,2$, tampão fosfato $0,05 \mathrm{M} \mathrm{pH} 4,5$ e tampão fosfato $0,05 \mathrm{M} \mathrm{pH} \mathrm{6,8} \mathrm{como}$ diluentes, atendendo ao critério mínimo estabelecido $\left(R^{2} \geq 0,99\right)$ (Figuras $39 \mathrm{e}$ 40; Tabelas 26, 27, 28 e 29). Considerou-se o limite de quantificação em 1 $\mu \mathrm{g} / \mathrm{mL}$, o qual apresentou precisão dentro do limite estabelecido ( $C V<20 \%)$. Os coeficientes de variação (CV\%) obtidos foram inferiores ao critério mínimo estabelecido (5\%), comprovando-se a precisão intra e inter-ensaio do método espectrofotométrico para quantificação da furosemida (Tabelas 30 e 31). A absorção desprezível dos demais compostos empregados, nos comprimentos de onda de $274 \mathrm{~nm}$ e $276 \mathrm{~nm}$, comprova a especificidade do método em meio $\mathrm{HCl} 0,1 \mathrm{~N} \mathrm{pH} \mathrm{1,2,} \mathrm{tampão} \mathrm{fosfato} 0,05 \mathrm{M} \mathrm{pH} 4,5$ e tampão fosfato $0,05 \mathrm{M} \mathrm{pH}$ 6,8, respectivamente (Figuras 41 e 42). 
7. CONCLUSÃO 
Baseado nas informações anteriormente apresentadas, pode-se concluir que:

- Os ensaios termoanalíticos, ensaios de espectrofotometria no IV e ensaios de dissolução sugerem que a furosemida forme complexos de inclusão com $\beta-C D$ e HP- $\beta$-CD pela técnica da liofilização.

- A complexação da furosemida com $\beta-C D$ ou HP- $\beta-C D$ aumentou significativamente a velocidade de dissolução do fármaco, sendo capaz, inclusive, de propiciar uma dissolução $\mathrm{pH}$-independente do mesmo.

- A presença de ciclodextrinas, como misturas físicas ou complexadas ao fármaco, nos comprimidos matriciais, trouxe aumento significativo na velocidade e extensão de liberação da furosemida quando comparadas à formulação básica, sendo que as formulações contendo HP- $\beta$-CD apresentaram desempenho superior àquelas $\operatorname{com} \beta-C D$.

- Comprimidos matriciais hidrofílicos à base de HPMC K4M, contendo $\mathrm{HP}-\beta-\mathrm{CD}$, tanto em mistura física quanto complexada à furosemida, mostraram-se formas farmacêuticas viáveis para se prolongar a liberação de furosemida dentro de um período de oito horas.

- Os resultados dos ensaios dissolução com variação de $\mathrm{pH}$ sugerem que incorporação de complexos de furosemida com $\beta-C D$ ou HP- $\beta-C D$ aos comprimidos matriciais possa prover perfis de liberação $\mathrm{pH}$ independentes

- A técnica de compressão direta mostrou-se eficiente para obtenção de comprimidos matriciais com dureza, friabilidade e peso médio adequados. 


\section{REFERÊNCIAS BIBLIOGRÁFICAS}

De acordo com a NBR6023/2000, preconizada pela Associação Brasileira de Normas Técnicas (ABNT).

Títulos dos periódicos abreviados de acordo com Chemical Abstracts Service Source Index (CASSI). 
1. AOAC - Association of Official Analytical Chemists. Official methods of analysis of the Association of Analytical Chemists. 16 ed. Washington, 1995. v.1, pt1., p.18.

2. AMMAR, H.O.; GHORAB M.; EL-NAHHAS, S.A.; EMARA, L.H.; MAKRAM, T.S. Inclusion complexation of furosemide in cyclodextrins - Part 1: Effect of cyclodextrins on the physicochemical characteristics of furosemida, Pharmazie, v.54, n.2, p.142-144, 1999.

3. ANSEL H.C., POPOVICH N.G., ALLEN L.V. Farmacotécnica: formas farmacêuticas e sistemas de liberação de fármacos. São Paulo: Premier, 2000. cap 5, p.175- 250.

4. BAVEJA, S.K.; RAO, R.K.V. Sustained release tablet formulation of centperazine. Int. J. Pharm., v.31, p.169-174, 1986.

5. BIBBY, D.C.; DAVIES, N. M.; TUCKER I. G. Mechanisms by which cyclodextrins modify drug release from polymeric drug delivery systems, Int. J. Pharm. 197, p. 1-11, 2000.

6. BOLES, L.L.P.; SCHOENWALD, R.D. Furosemide (frusemide) pharmacokinetic/pharmacodynamic review. Part I. Clin. Pharmacokinet., v.18, p.381-408, 1990.

7. BRASIL. Agência Nacional de Vigilância Sanitária. RE n. 899, de 29 de maio de 2003. Guia para validação de métodos analíticos e bioanalíticos. Diário Oficial da União, Brasília, 02 de junho de 2003.

8. BURI, P. Formulation, caracteristiques et intérêt des formes galeniques orales á liberation prolongée de type matrice. Boll. Chim. Farm., Milão, v.123, p. 453-465, 1984. 
9. CARCAMO E.C. Cinetica de Disolucion de Medicamentos. Secretaria General de la Organizacion de los Estudos Americanos, Washington, 102 p., 1981.

10. CENTER FOR FOOD AND NUTRITION POLICY (CFNP). Technical Advisory Panel Review - Furosemide Livestock. Virginia Tech;Alexandria. 2002.

11. CHIEN, Y.W. Novel drug delivery systems. 2.ed. New York:Marcel Dekker, 1992. cap.3, p. 139-196.

12. COLLETT, J.; MORETON, C. Formas farmacêuticas perorais de liberação modificada. In: AULTON, M.E., ed. Delineamento de Formas Farmacêuticas. 2.ed. Porto Alegre: Artmed, 2005, cap.20, p.298-313.

13. COLOMBO, P.; BETTINI, R.; MASSIMO, G.; CATELLANI, P.L.; SANTI, P.; PEPPAS, N.A. Drug diffusion front movements is important in drug release control from swellable matrix tablets. J. Pharm. Sci., v.84, p.991-997, 1995.

14. COLORCON. Using methocel cellulose ethers for controlled release of drugs in hydrophilic matrix systems. Catálogo de produto:EUA, 2000.

15. COSTA, P.; LOBO, J.M.S. Avaliação das características de libertação de fármacos a partir de formas sólida. Ver. Port. Farm., Lisboa, v.45, n.1, p. $41-51,2000$.

16. DAVIS, S.S. The effect of food on the gastrintestinal transit of pellets and osmotic device (Osmet) Int. J. Pharm. v.21, p.331-340, 1984. 
17. DICIONÁRIO DE ESPECIALIDADES FARMACÊUTICAS: DEF 2005/2006. 34 ed. Rio de Janeiro: Ed. De Publicações Científicas; 2005.

18. DUCHÉNE, D.; WOUESSIDJEWE D. Pharmaceutical uses of cyclodextrins and derivatives. Drug Dev. Ind. Pharm., v.16, p.2487-2499, 1990.

19. EBIHARA, A.; TAWARA K.; OKA T. Pharmacodynamic and pharmacokinetic study of a slow release formulation of furosemida in man. Artz. Forsch., v.33, n.1, p.163-166, 1983.

20. FARIA, A. N. Tratamento de diabetes e hipertensão no obeso. Arq bras. endocrinol. Metab, São Paulo, v.46, n.2, 2002.

21. FARMACOPÉIA BRASILEIRA. 4.ed. São Paulo: Atheneu, 1988.

22. FERRAZ, H.G.; PINHO, J.J.R.G.; UEHARA A.C.; REIS, M.T.L.; SIGUENAGA, A.M. Estudo comparativo do perfil de dissolução de comprimidos de cloreto de potássio comercializados no Brasil. Braz. J. Pharm. Sci., v.35, n.1, p.95-99, 1999.

23. FIP - FEDERATION INTERNATIONAL PHARMACEUTIQUE. FIP guidelines for dissolution testing of solid oral products (final drafts, 1995). Drug Inf. J. v.30, p.1071- 1084, 1996.

24. FORD, J.L.; RUBinstein, M.H.; McAUL, F.; HOGAN, J.E. Propanol hydrochloride and aminophylline release from matrix tablets containing hydroxypropylmethylcellulose. Int. J. Pharm.,v.24, p. 339-350, 1985.

25. FUNDAÇÃO PARA O REMÉdIO POPULAR (FURP). Memento terapêutico. 2.ed. São Paulo:Imprensa Oficial, 1998. 
26. GABR, K.E. Effect of organic acids on the release patterns of weakly basic drugs from inert sustained release matrix tablets. Eur. J. Pharm. Biopharm., v.38, n.6, p.199-202, 1992.

27. GIUNCHEDI, P.; MAGGI, L.; LA MANNA, A.; CONTE, U. Modification of the dissolution behaviour of a water-insoluble drug, naftazone, for zeroorder release matrix preparation. J Pharm. Pharmacol., v.46, p.476-480, 1994.

28. HAMMARLUND, M.U.; BENET, L.Z. Furosemide pharmacokinetics and pharmacodynamics in health and disease - an update. $J$. Pharmacokineti. Biopharm., v. 17, n.1, p.1-46, 1988

29. HIGUCHI, T. Mechanism of sustained-action medication: theoretical analysis of rate of release of solid drugs dispersed in solid matrices. $J$. Pharm Sci., New York, v.52, p. 1145-1149, 1963.

30. HIRAYAMA, F.E.; UEKAMA K. Cyclodextrina-based controlled drug release system, Adv. Drug Del. Rev, v.36, p.125-141, 1998.

31. HITE, M., TURNER, S.; FEDERICI, C. Part 1: Oral delivery of poorly soluble drugs. Pharmaceutical Manufacturing and Packing Sourcer, Summer. 3ed. Samedan Ltd., pp38-40, 2003

32. HORTER, D.; DRESSMAN J.B. Influence of physicochemical properties on dissolution of drugs in the gastrintestinal tract. Adv. drug deliv. rev., v.46, p.75-87, 2001.

33. HUANG, L.L.; SCHWARTZ, J.B. Studies on drug release from carbomer tablet matrix., Drug Dev. Ind. Pharm., New York, v.21, n.13, p14871501, 1995. 
34. HYLANDER, B.; DANIELSON, M.; ELIASSON, K. Comparison of hydrochlorothiazide and slow-release furosemide as adjuvant therapy to beta-blockers in the treatment of moderate hypertension. Act. Med. Scand., v.22, n.2, p.137-142, 1987

35. IKEDA, Y.; MOTOUNE, S.; MARUMOTO, A.; SONODA. Y.; HIRAYAMA, F.; ARIMA, H.; UEKAMA K. Effect of 2-Hydroxypropyl- $\beta$-cyclodextrin on release rate of metoprolol from ternary metoprolol/2-hydroxypropyl- $\beta$ cyclodextrin/ethylcellulose tablets. J. Inclusion Phen. and Macrocyclic Chem., v.44, p.141-144, 2002.

36. ISHIKAWA, T.; WATANABE, Y.; TAKAYAMA, K.; ENDO, $\mathrm{H}_{\text {.; }}$ MATSUMOTO, M. Effect of HPMC on the release profiles and biovailability of a poorly water-soluble drug from tablets prepares using Macrogol and HPMC. Int. J. Pharm., Amsderdam, v.202, p.173-178, 2000.

37. JACKSON, E.K. Diuréticos. In: HARDMAN, J.G.; LIMBIRD, L.E.; MOUNOFF, P.B.; RUDDON, R.W.; GILMAN, A.G., eds. Goodman \& Gilman, As bases farmacológicas da terapêutica. 9.ed. Rio de Janeiro: Editora Guanabara Koogan S.A., 1996, cap 29, p.501-522.

38. JUG, M.; BECIREVIC-LACAN, M. Influence of hydroxypropyl- $\beta$-cyclodextrin complexation on piroxicam release from buccoadhesive tablets. Eur. $J$. of Pharm. Sci., v.21, p.251-260, 2004

39. KANO, E.K. Avaliação biofarmacêutica de formulações contendo cefadroxil: estudos "invitro" e "in vitro" (bioequivalência). Dissertação de Mestrado. Faculdade de Ciências Farmacêuticas da Universidade de São Paulo, São Paulo, 233p., 2003 
40. KHAN, K.A.; RHODES, C.T. The concept of dissolution efficiency. J. Pharm. Pharmacol., v.27, p. 48-49, 1975.

41. KOESTER, L.S.; XAVIER, C.R.; MAYORGA, P.; VALQUIRIA, L.; BASSANI, V.L. Influence of $\beta$-cyclodextrin complexation on carbamazepine release from hydroxypropylmethylcellulose matrix tablets. Eur J. Pharm. Biopharm., v.55, p.85-91, 2003.

42. KOROLKOVAS, A. Inclusão molecular em ciclodextrinas: propriedades e aplicações terapêuticas. Enlace Farmalab, v.2, n.2, p.6-15, 1991.

43. KRANZ, H.; WAGNER, T. Effects of formulation and process variables on the release of a weakly basic drug from single unit extended release formulations. Eur J. Pharm. Biopharm., v.XX, p.1-7, 2005.

44. KREAZ, R.M.A.; NOVÁK, C.; ERÖS, I.; KATA, M. Thermoanalytical studies on complexes of furosemida with beta-cyclodextrin derivates. J. Therm. Anal. Calor., 55, 125-122, 1999.

45. KREAZ, R.M.A.; DOMBI, G.Y.; KATA, M. The Influence of $\beta$-Cyclodextrins on the Solubility of Furosemide, J. Inclusion Phen. and Macrocyclic Chem., 31, p.189-196, 1998.

46. LAFUENTE, C.S.; FAUCCI, M. T.; AREVALO, M.F.; FUENTES, J.I.; RABASCO, A.M.; MURA, P. Development of sustained release matrix tablets of didanosine containing methacrylic and ethylcellulose polymers. Int. J. Pharm., v.234, p.213-221, 2002.

47. LIEBERMAN, H.A.; LACHMAN, L.; SCHARTZ, J.B. Pharmaceutical dosage forms: tablets. 3.ed. New York: Marcel Dekker, 1990. 
48. LOFTSSON, T.; BREWSTER, M.E. Pharmaceutical Applications of Cyclodextrins. 1. Drug Solubilization and Stabilization. J. Pharm. Sci., v.85, n. 10, p. 1017-1025, 1996.

49. LOFTSSON, T.; BREWSTER, M.E. Cyclodextrins as pharmaceutical excipients. Pharm. Tech. Eur., v.9, p. 26-34, 1997.

50. LORDI, N.G. Formas farmacêuticas de liberação prolongada. In: LACHMAN L.; LIBERMAN H.A; KANIG J.L., eds. Teoria e Prática na Indústria Farmacêutica. 3.ed. Lisboa:Fundação Calouste Gulbekian, 2001. cap 14, p.737-781.

51. LOUKAS, Y.L.; VRAKA, V.; GREGORIADES, G. Novel non-acidic formulations of halopiridol complexed with b-cyclodextrin derivatives. J. Pharm. Biomed. Anal., v.16, p.263-268, 1997.

52. LOUKAS, Y.L.; VRAKA, V.; GREGORIADIS, G. Drugs, in cyclodextrinas, in lipossomes: a novel aprproach to the chemical stability of sensitive drugs to hydrolysis. Int. J. Pharm., v.162, p.137-142, 1998.

53. MACMAHON, S.; RODGERS, A. The effects of blood pressure reduction in older patients: an overview of the randomized control trials in elderly hypertension. Clin. Exp. Hypertens, 15, p.967-978, 1993.

54. MARQUES, M.R.C.; BROWN, W. Desenvolvimento e validação de métodos de dissolução para formas farmacêuticas sólidas orais. Ver. Analytica, v.1, n.1, 2002.

55. MEHTA, K.A.; KISLALIOGLU, M.S.; PHUAPRADIT, W.; MALICK, A.W.; $\mathrm{SHAH}, \mathrm{N} . \mathrm{H}$. Release performance of a poorly soluble drug from a novel, 
Eudragit ${ }^{\circledR}$-based multi-unit erosion matrix. Int. J. Pharm. V.213, p.7-12, 2001.

56. MION, J.D.; MACHADO, C.A.; GOMES, M.A.M.; NOBRE, F.; KOHLMANN, J.O.; AMODEO, C.; PRAXEDES, J.N.; PASCOAL, I.; MAGALHÃES, L.C.; MION FOSS, N.T. Hipertensão Arterial - Abordagem Geral. Sociedade Brasileira de Cardiologia e Sociedade Brasileira de Nefrologia. In: Associação Médica Brasileira e Conselho Federal de Medicina. Projeto Diretrizes . v. II, São Paulo, Brasília, 2005.

57. MULLER, J.E. Circadian variation in cardiovascular events. Am. J. Hypertens., v.12, p.35-42, 1999

58. OATES, J.A. Fármacos anti-hipertensivos e terapia farmacológica da hipertensão. In: HARDMAN, J.G.; LIMBIRD, L.E.; MOLINOFF, P.B.; RUDDON, R.W.; GILMAN, A.G., eds. Goodman \& Gilman, As bases farmacológicas da terapêutica. 9.ed. Rio de Janeiro: Editora Guanabara Koogan S.A., 1996, cap 29, p.501-522.

59. O'HARA, T; DUNNE, A.; BUTLER, J.; DEVANE, J. A review of methods used to compare dissolution profile data. Pharm. Sci. Technol. Today 1 , p.214-223, 1998.

60. ORGANIZAÇÃO PAN-AMERICANA DA SAÚDE (OPAS/OMS), 42ำ Conselho Diretor, 52ำ Sessão do Comitê Regional, Documento CD42/11: "Doenças cardiovasculares, especialmente hipertensão", Washington, D.C., 2000.

61. ORTEGA, K.C.; SANTELLO, J.L.; NOBRE, F. et al. Verapamil COER-24 180/240 mg na hipertensão arterial leve a moderada em dose única 
diária avaliado pela monitorização ambulatorial da pressão arterial. Arq. Bras. Cardiol., v.74, n.3, p.283-290, 2000.

62. OZDEMIR, N.; ORDU, S. Improvement of dissolution properties of furosemide by complexation with beta-cyclodextrin. Drug. Dev. Ind. Pharm., v.24, n.1, p.19-25, 1998.

63. ÖZKAN, Y.; ATAY, T.; DIKMEN, N.; ISMER, A.; ABOUL-ENEIN, H.Y. Improvment of water solubility and in vitro dissolution rate of gliclazide by complexation with $\beta$-cyclodextrin. Pharm. Acta Helv.,74, p. 365-370, 2000.

64. PATHER, S.I.; RUSSELL, I.; SYCE, J.A.; NEAU, S.H. Sustained release theophylline tablets by direct compression Part 1: formulation and in vitro testing. Int. J. Pharm., v.164, p.1-10, 1998.

65. PHARMACOPOEIA OF THE UNITED STATES OF AMERICA (USP), United States Pharmacopeial Convention, Rockville, 28 Ed., 2006.

66. PRISTA, L.N.; ALVES, A.C.; MORGADO, R. Técnica farmacêutica e farmácia galênica. 4.ed.. Lisboa:Fundação Calouste Gulbenkian, 1996. v. 3, cap. 14, p.2025-2054.

67. RAO, V.M.; HASLAM, J.L.; STELLA, V.J. Controlled and complete release of a model poorly water-soluble drug, prednisolone, from hydroxypropyl methylcellulose matrix tablets using (SBE)7M-b-cyclodextrin as a solubilizing agent. J. Pharm. Sci., v.90, p.807-816, 2001.

68. REYNOLDS, T.; GERHRKE, S.H; HUSSAIN, A.S.; SHENOUDA, L.S. Polymer erosion and drug release characterization of 
hydroxypropylmethylcellulose matrices. J. Pharm Sci., New York, v.87, n.9, p.1115-1123, 1998.

69. REUBI, F. C. Clinical use of furosemida. Ann. N.Y. Acad. Sci., v.139, p.433-442, 1966.

70. REMINGTON: the science and practice of pharmacy. 20. ed. Baltimore: Lippincott Williams and Wilkins, 2000, p. 902-920.

71. RIBEIRO, L.; FERREIRA, D.C.; VEIGA F.J.B. In vitro controlled release of vinpocetine-cyclodextrin-tartaric acid multicomponent complexes from HPMC swellable tablets J. Control. Release, v.103, p.325-339, 2005.

72. ROSOFF, M. Controlled release of drugs: polymers and aggregate systems. 1.ed. v.1. New York:VCH Publishers, 1989.

73. SALSA, T.; VEIGA, F.; PINA, M.E. Oral controlled-release dosage forms. I. Celulose ether polymers in hydrophilic matrices. Dru. Dev. Pharm. Ind. V.23, n.9, p.929-938, 1997.

74. SAMY E.M., SAFWAT S.M. In vitro release of anti-inflammatory drugs with $\beta$-cyclodextrin from hydrophilic gel bases. STP Pharma. Sci. v.4, p.458465, 1994.

75. SANGALLI, M.E.; ZEMA, L.; MARONI, A.; FOPPOLI, A.; GIORDANO, F.; GAZZANIGA, A. Influence of betacyclodextrin on the release of poorly soluble drugs from inert and hydrophilic heterogeneous polymeric matrices. Biomaterials, v. 22, p.2647-2651, 2001.

76. SERRA, C.H.R. Avaliação biofarmacotécnica de comprimidos contendo furosemida: cinética de dissolução e bioequivalência. 
Tese de Doutoramento, Faculdade de Ciências Farmacêuticas da Universidade de São Paulo, São Paulo,. 206 p., 1998.

77. SHIN, S.C.; OH, I.J.; LEE, Y.B.; CHOI, H.K.; CHOI, J.S. Enhanced dissolution of furosemide by coprecipitating or cogrinding with crospovidone Int. J. Pharm. v.175, n.1, p.17-24, 1998.

78. SMAL, J.; MARVOLA, M.; LILJEQUIST, C.; HAPPONEN, I. Prolongedrelease hydroxypropylmethylcellulose matrix tablets of furosemida for administration to dogs. J. Vet. Pharmacol. Therap., v.19, p.482-487, 1996.

79. SPAMER, E.; MÜLLER D.G., WESSELS P.L., VENTER J.P. Characterization of the complexes of furosemide with 2-hydroxypropyl-bcyclodextrin and sulfobutyl ether-7-b-cyclodextrin. Eur. J. Pharm. Sciences, v.16, p. 247-253, 2002.

80. SZEJTLI, J. Cyclodextrin Technology. 1.ed. Dordrecht : Kluwer Academic Publishers, 1988.

81. SZEJTLI, J.; OSA, T. Chemistry physical and biological properties of cyclodextrins. 1.ed. Oxford: Pergamon, p.5-40, 1996.

82. SWEETMAN, S. Martindale: The complete drug reference. Pharmaceutical Press, London (electronic version), 2006.

83. TIMMINS, P.; DELARGY, A.M.; HOOWARD, J.R. Optimization and characterization of a pH-independent extended-release hydrophilic matrix tablet, Pharm. Dev. Technol., 2 (1), p.25-31, 1997.

84. THE MERCK INDEX. 12.ed., Merck \& Co., Inc., 1996. 
85. UEKEMA, K.; HIRAYAMA, F.; IRIE, T. Cyclodextrin Drug Carrier Systems. Chem., p. 2045-2076, 1998.

86. VEIGA, F.J.B. Medicamentos orais de libertação controlada. Comprimidos matriciais hidrófilos. Bol. Fac. Farm. Coimbra, Coimbra, v.12, n.2, p.1787, 1988.

87. VELASCO, M.V; FORD, J.L.; ROWE, P.; RAJABI-SIAHBOOMI, A.R. Influence of drug:hydroxypropylmethycellulose ratio, drug and polymer particle size and compression force on the release of diclofenac sodium from HPMC tablets. J. Control. Release, v.57, p.75-85, 1999.

88. VERHOEVEN, J.; PESCHIER, L.J.C.; DANHOF, M.; JUNGINGER, H. E. A. Controlled-release tablet of furosemide: design, in vitro evaluation, pharmacological and pharmacodynamic evaluation. J. Pharm., v.45, p.65-77, 1988.

89. VILARNOVO, B.P.; TENREIRO, C.M.; SANTOS, J.F.R.; DOVAL, J.V.; CONCHEIRO, A.; LORENZO, C.A.; JUAN, J.; LABANDEIRA, J.J.T. Modulating drug release with cyclodextrins in hydroxypropyl methylcellulose gels and tablets. J. Control. Release, v.94, p.351-363, 2004.

90. VLACHOU, M.; PAPAIOANNOU, G. Preparation and characterization of the inclusion complex of furosemide with hydroxypropyl- $\beta$-cyclodextrin. J. Biomat. Applications, v.17, p. 197-206, 2003.

91. WANG, Z.; HORIKAWA, T.; HIRAYAMA F., UEKAMA K. Design and in vitro evaluation of modified release oral dosage form of nifedipine by hybridization of hydroxypropyl- $\beta$-cyclodextrin and hydroxypropylmethyl cellulose. J. Pharm. Pharmacol., v.45, p.942-946, 1993. 
92. XU, G.; SUNADA, H. Influence of formulation change on drug release kinectics from hydroxypropylmethylcellulose matrix tablets. Chem. Pharm. Bull., Tokyo, v.3, n.3, p.483-487, 1995.

93. ZINGONE, G.; RUBESSA, F. Preformulation study of the inclusion complex warfarin-cyclodextrin. Int. J. Pharm., v.291, p. 3-10, 2005. 
9. ANEXOS 


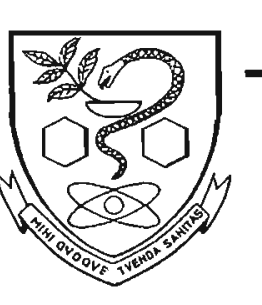

UNIVERSIDADE DE SÃO PAULO

Faculdade de Ciéncias Farmacêuticas

Secretaria de Pós-Graduação

\section{Informações para os Membros de Bancas Julgadoras de Mestrado/Doutorado}

1. O candidato fará uma apresentação oral do seu trabalho, com duração máxima de trinta minutos.

2. Os membros da banca farão a argüição oral. Cada examinador disporá, no máximo, de trinta minutos para argüir o candidato, exclusivamente sobre o tema do trabalho apresentado, e o candidato disporá de trinta minutos para sua resposta.

2.1 Com a devida anuência das partes (examinador e candidato), é facultada a argüição na forma de diálogo em até sessenta minutos por examinador.

3. A sessão de defesa será aberta ao público.

4. Terminada a argüição por todos os membros da banca, a mesma se reunirá reservadamente e expressará na ata (relatório de defesa) a aprovação ou reprovação do candidato, baseando-se no trabalho escrito e na argüição.

4.1 Caso algum membro da banca reprove o candidato, a Comissão Julgadora deverá emitir um parecer a ser escrito em campo exclusivamente indicado na ata.

4.2 Será considerado aprovado o aluno que obtiver aprovação por unanimidade ou pela maioria da banca.

5. Dúvidas poderão ser esclarecidas junto à Secretaria de PósGraduação: pgfarma@usp.br, (11) 30913621.

São Paulo, 18 de março de 2005.

Profa. Dra. Bernadette D. G. M. Franco

Presidente da CPG/FCF/USP 